of

\title{
A Comprehensive Landscape for Fibril Association Behaviors Encoded Synergistically by Saccharides and Peptides
}

Rongying Liu ${ }^{\mathrm{a}}$, Ran Zhang ${ }^{\mathrm{b}}$, Long $\mathrm{Li}^{\mathrm{a}}$, Zdravko Kochovski ${ }^{\mathrm{c}}$, Lintong Yao ${ }^{\mathrm{a}}$, Mu-Ping $\mathrm{Nieh}^{\mathrm{d}}$, Yan $\mathrm{Lu}^{\mathrm{c}, \mathrm{e}}$, Tongfei Shi ${ }^{\mathrm{b}}$, Guosong Chen ${ }^{\mathrm{a}, \mathrm{f}_{*}}$

${ }^{\mathrm{a}}$ The State Key Laboratory of Molecular Engineering of Polymers and Department of Macromolecular Science, Fudan University, Shanghai 200433, China

${ }^{\mathrm{b}}$ State Key Laboratory of Polymer Physics and Chemistry, Changchun Institute of Applied Chemistry, Chinese Academy of Sciences, Changchun 130022, PR China

${ }^{\mathrm{c}}$ Department for Electrochemical Energy Storage, Helmholtz-Zentrum Berlin für Materialien und Energie, 14109 Berlin, Germany

${ }^{\mathrm{d}}$ Polymer Program, Institute of Materials Science and Department of Chemical and Biomolecular Engineering, University of Connecticut, Storrs, Connecticut 06269, United States ${ }^{\mathrm{e}}$ Institute of Chemistry, University of Potsdam, 14476 Potsdam, Germany

${ }^{\mathrm{f}}$ Multiscale Research Institute of Complex Systems, Fudan University, Shanghai 200433, China 


\section{Table of Contents}

$\begin{array}{ll}\text { 1. General information } & \text { S3 }\end{array}$

2. Pre-screen of glyco-peptide models by molecular simulation S6

$\begin{array}{ll}\text { 3. Glyco-peptide Synthesis } & \text { S12 }\end{array}$

$\begin{array}{ll}\text { 4. The fibril association behaviors of SL-3F } & \text { S14 }\end{array}$

$\begin{array}{ll}\text { 5. The fibril association behaviors of SL-4F } & \text { S29 }\end{array}$

$\begin{array}{ll}\text { 6. The fibril association behaviors of SL-2F } & \text { S32 }\end{array}$

7. The fibril association behaviors of SL-FYF and SL-FUF $\quad$ S35

8. The correlation between fibril association with hydrogelation $\quad$ S36

9. The correlation between fibril association with anticancer activities $\quad$ S37

$\begin{array}{ll}\text { 10. Synthesis and Characterization } & \text { S43 }\end{array}$

11. ${ }^{1} \mathrm{H}$ and ${ }^{13} \mathrm{C}$ NMR $\quad$ S52

12. References $\quad$ S63 


\section{General Information}

\section{Materials.}

Chemicals were purchased from TCI and GL Biochem (Shanghai) and used as received. $(2,3)$ Sialyllactose $\mathbf{( S L}$ ) was purchased from sigma-aldrich. Sialidase S was purchased from Neobioscience. Phosphate-buffered saline (PBS) and RPMI 1640 medium were purchased from Gibco Invitrogen Corp. Fetal bovine serum (FBS) was purchased from Biological Industries. CCK-8 kit and BSA were purchased from Solarbio Life Science company. $75 \mu \mathrm{m}$ nylon cell strainer and $5 \mu \mathrm{m}$-sized Transwell plates were purchased from Corning. B16F10-luc-GFP, D-luciferin and potassium salt were purchased from Shanghai Sciencelight Biology Science\&Technology Co. Ltd. BV-2 and HepG2 cell line were purchased form ATCC. C57BL/6 mice were purchased from Shanghai SLAC Laboratory Animal Company.

\section{Characterizations.}

${ }^{1} \mathbf{H},{ }^{13} \mathbf{C}$ and ${ }^{19} \mathbf{F}$ NMR spectra was taken by AVANCE III HD $400 \mathrm{MHz}$ of Bruker BioSpin International. Chemical shift values of compounds were referenced using the tetramethylsilane (TMS) with peak at $0 \mathrm{ppm}$.

Matrix Assisted Laser Desorption Ionization-Time of Flight (Maldi-TOF) Mass Spectrum was taken by a AB SCIEX 5800 instrument.

Circular dichroism (CD) spectra were taken by a JASCO-815 instrument with a 1 mm cuvette.

Ultraviolet-vis (UV-vis) absorption spectra were recorded by Shimadzu UV-2550 spectrophotometer.

Atomic Force Microscope (AFM) was operated in air on a Bruker Multimode VIII SPM equipped with a $\mathbf{J}$ scanner. Experiments were performed in peakforce QNM mode with SNL-10 tip $(k=0.350 \mathrm{~N} / \mathrm{m})$. Sample $(3 \mu \mathrm{L})$ was firstly dropped on freshly cleaved mica, and after standing for 2 mins, used a pipette $(10 \mu \mathrm{L})$ to suck up the visible liquid. The sample stayed for drying in air for $24 \mathrm{~h}$ for AFM test.

Dynamic Light Scattering was performed by 3D modulated laser light scattering from LS instruments.

Zeta-Potential was performed by Malvern Zeta-sizer Nano ZS90.

Synchrotron small angle X-ray scattering (SAXS) experiment was performed at the BL19U beamline station of Shanghai Synchrotron Radiation Facility (SSRF). The wavelength was $0.124 \mathrm{~nm}$. Distance of sample-to-detector was $1.89 \mathrm{~m}$. The exposure time was $600 \mathrm{~s}$.

Transmission electron microscopy (TEM) was performed using an FEI Tecnai G2 
operated at $200 \mathrm{kV}$, a JEOL JEM-2010 operated at $80 \mathrm{kV}$ and a JEOL JEM-2100 operated at $200 \mathrm{kV}$. Negatively stained samples were prepared by applying a $3 \mu 1$ drop of sample solution to carbon-coated copper TEM grids and the excessive solution was blotted away with filter paper. Samples were subsequently stained with $1 \mathrm{wt} \%$ uranyl acetate and the grids air dried. Tomographic data from negative stained samples were collected on a JEOL JEM-2100 equipped with a $4 \mathrm{k} \times 4 \mathrm{k}$ CMOS digital camera (TVIPS TemCam-F416). Tilt series were collected to $\pm 60^{\circ}$ with a $2^{\circ}$ angular increment and a total dose of roughly $300 \mathrm{e}^{-} / \AA^{2}$. Samples for Cryo-EM were prepared by applying $4 \mu \mathrm{L}$ drop of sample solution to holey carbon grids (Quantifoil R2/1) and plunge-frozen into liquid ethane with an FEI vitrobot Mark IV set at $4^{\circ} \mathrm{C}$ and $95 \%$ humidity. Vitrified grids were either transferred directly to the microscope cryoholder or stored in liquid nitrogen. All grids were glow-discharged before use. All Cryo-EM images were acquired on a JEOL JEM-2100 equipped with a $4 \mathrm{k} \times 4 \mathrm{k}$ CMOS digital camera (TVIPS TemCam-F416).

\section{Methods}

\section{Cell Line and Animal Model.}

B16F10 tumor cells were cultured in complete RPMI 1640 culture medium (Gibco) supplemented with $10 \%$ fetal bovine serum (Gibco), $100 \mathrm{IU} / \mathrm{mL}$ of penicillin (Gibco), and $100 \mu \mathrm{g} / \mathrm{mL}$ of streptomycin (Gibco). Cells were maintained under fully humidified atmosphere at $37{ }^{\circ} \mathrm{C}$ and $5 \% \mathrm{CO}_{2}$ conditions. All animals were maintained in specific pathogen-free condition. Animal experiments were performed according to the Guidelines of Fudan University for the Care and Use of Laboratory Animals. B16F10 tumor xenograft mice were established by abdominal cavity inoculation with $5 \times 10^{6} \mathrm{~B} 16 \mathrm{~F} 10$ tumor cells.

\section{Cell Viability Assay.}

Cell viability assay was performed by using Cell Counting Kit-8 (CCK-8) to detect dehydrogenase activity under both time- and dose-dependent experiments. Briefly, B16F10 cells were treated with different concentration of various glyco-peptide models (from $0 \mu \mathrm{g} / \mathrm{mL}$ to $250 \mu \mathrm{g} / \mathrm{mL}$ ) for a fixed incubation time of $24 \mathrm{~h}$ or containing $250 \mu \mathrm{g} / \mathrm{mL}$ of glyco-peptide models for a range of incubation time from 24 to $72 \mathrm{~h}$. CCK8 reagent was added into cell culture and incubated for $2 \mathrm{~h}$. The absorbance was measured at $450 \mathrm{~nm}$ using a microplate reader (BioTek ELx800). 


\section{Transwell Assay.}

The transwell chamber was infiltrated with PBS and placed into a 24-well culture plate. At the same time, B16F10 cells in logarithmic growth phase were adjusted with $0.5 \%$ BSA serum-free RPMI 1640 culture medium. $100 \mu \mathrm{L}\left(1 \times 10^{5}\right)$ cells with 0.25 $\mathrm{mg} / \mathrm{mL}$ various glyco-peptide were seeded into the transwell upper chamber with three replicates in each group. In the lower chamber, $700 \mu \mathrm{L}$ serum-free RPMI 1640 culture medium $(0.5 \%$ BSA). Taking $700 \mu \mathrm{L}$ of RPMI 1640 culture medium of $10 \%$ fetal bovine serum as the positive control and $700 \mu \mathrm{L}$ serum-free RPMI 1640 culture medium containing $0.5 \% \mathrm{SBA}$ as the negative control. Cells were incubated at $37{ }^{\circ} \mathrm{C}$ and $5 \% \mathrm{CO}_{2}$ condition for $12 \mathrm{~h}$. Cells were washed with pre-chilled PBS at $4{ }^{\circ} \mathrm{C}$ for several times and fixed with $4 \%$ paraformaldehyde for $10 \mathrm{~min}$ and stained Giemsa for $15 \mathrm{~min}$. The number of migrating cells was recorded under microscope and analyzed by Prism 6.

\section{In Vivo Therapeutic Experiments.}

In vivo tumor metastasis was evaluated in B16F10-Luc-GFP-bearing C57BL/6 mice as follows. Eighteen 6-week-old female C57BL/6 mice were inoculated subcutaneously with $200 \mu \mathrm{L}$ of a B16F10-Luc-GFP cell suspension $\left(5 \times 10^{6}\right.$ cells $\left./ \mathrm{mL}\right)$ and divided into three groups (six mice per group). After two days inoculation, $50 \mu \mathrm{L}$ of the fibrils of SL-FYF and SL-3F were intravenously injected into the mice; a control group received only PBS. Distribution of the B16F10-Luc-GFP cells in the mice was observed 3 days after injection. Animal experiments were performed according to the Guidelines of Fudan University for the Care and Use of Laboratory Animals. 


\section{Pre-screen of glyco-peptide models by molecular simulation}

\section{Simulation details}

The all-atom model for the resulting glyco-peptide models including SL-2F, SL-3F, SL-4F, SL-FYF and SL-FUF were constructed corresponding to the configurations in Scheme S6. Gromacs 5.13/2016.6 package $^{[1]}$ was employed for all the MD simulations. The $\mathrm{COOH}$ group on sialyllactose was all deprotonated and the partial charge of $\mathrm{COO}^{-}$was set at -0.66 , while charge compensation was maintained by adding sodium ions (atom charge at +0.66 ) in equal number. The CHARMM36 $6^{[2,3]}$ force field was used for the molecules and TIP3P model ${ }^{[4]}$ for explicit water molecules. Particle Mesh Ewald method ${ }^{[5]}$ was used to calculate the electrostatic interactions of the system with a grid spacing of $1.75 \AA$, while short-ranged electrostatic and Van der Waals interactions were truncated at $1.2 \mathrm{~nm}$. The reference temperature was maintained at $298 \mathrm{~K}$ by the stochastic integrator with a relaxation time at 2 ps. The pressure was maintained at 1.0 bar by the Berendsen algorithm with a relaxation time of 1 ps. The system composed of the SL- $\boldsymbol{n} \mathbf{F}$ molecules, water and sodium ions was pre-equilibrated in the NVT ensemble for $500 \mathrm{ps}$ and another $500 \mathrm{ps}$ in the NPT ensemble with position restraints on SL-nF before any production NPT simulations. An integration time-step at $1 \mathrm{fs}$ was used for all above simulations. The simulation box size of single-stranded, double-strand and quadra-stranded fibers was designed as $(6.2 \mathrm{~nm} \times 6.2 \mathrm{~nm} \times 7.8 \mathrm{~nm}),(7 \mathrm{~nm} \times 7 \mathrm{~nm} \times 7.8 \mathrm{~nm})$ and $(8.5 \mathrm{~nm} \times 15$ $\mathrm{nm} \times 9 \mathrm{~nm}$ ). Water molecules were added to the simulation box by using the Gromacs gmx solvate command and sodium ions by Gromacs gmx genion. A geometrical criterion was used to determine if hydrogen bonds exist, which included a reference donor-accepter distance limit of $3.5 \AA$ and a cutoff value of $30^{\circ}$ for hydrogen-donor-acceptor angle. The results of solvent accessible surface area (SASA) of each phenylalanine residue and sugar component were obtained by using the gmx sasa code in Gromacs package with default parameters.

Two types of initial configurations, random positions and template structures, were considered for simulation in this work. For the first tpye, randomly distributed SL-3F molecules were placed in a cubic box $(6 \mathrm{~nm} \times 6 \mathrm{~nm} \times 6 \mathrm{~nm})$ with 3 D periodic conditions. However, during the production run at a timescale of $300 \mathrm{~ns}$, the free style assembly of SL-3F failed to present any ordered fiber structures. Apparantly the simulations of SL-3F were trapped in numbers of metastable states due to the complexity of the all-atom model with explicit solvents (Figure S7).

For the second type, template initial configurations were employed in the exploration of stable fibrous structures. In detail, two fundamental types of strand formation were proposed depending on the assembly of oligophenylalanines which 
were the antiparallel packing and parallel packing of the phenylalanine blocks. The spacing was $0.5 \mathrm{~nm}$ between neighboring SL-nF molecules which largely facilitated inter-oligophenylalanine hydrogen bonding and hydrophobic stacking of phenylalanine sidechains. However during early tests, the antiparallel packing structure was found unstable (Scheme 1b), while the parallel packing structure was still intact after $50 \mathrm{~ns}$ examination. This is probably because the alternative locations of the sugar blocks on two sides of the antiparallel phenylalanine sheet fail to provide enough sugar interactions which could be important in stabilizing the packing structure. On the other hand, the sugar blocks packing on the same side of the parallel phenylalanine sheet were granted with higher possibilities of mutural interactions (Scheme 1c). In this sense, the single-stranded fibrous structure were proposed by placing two such parallel phenylalanine sheets together as shown in Figure 3d. With odd number of phenylalanine residues on the molecules (such as SL-3F, SL-FYF and SL-FUF), two of the phenyl rings from molecules of each sheets constructed the hydrophobic strand center responsible for strand-forming, and one phenyl ring of each molecule decorating the outer strand acting as strand-associating components. With even number of phenylalanine residues (such as SL-2F and SL-4F) the numbers of phenyl rings were assigned the same for strand-forming and strand-associating roles. The double-strand and multi-strand fibers were constructed by placing single-stranded fibrous structures together where the strand-associating phenylalanines were located closely as shown in Figure 3e. 


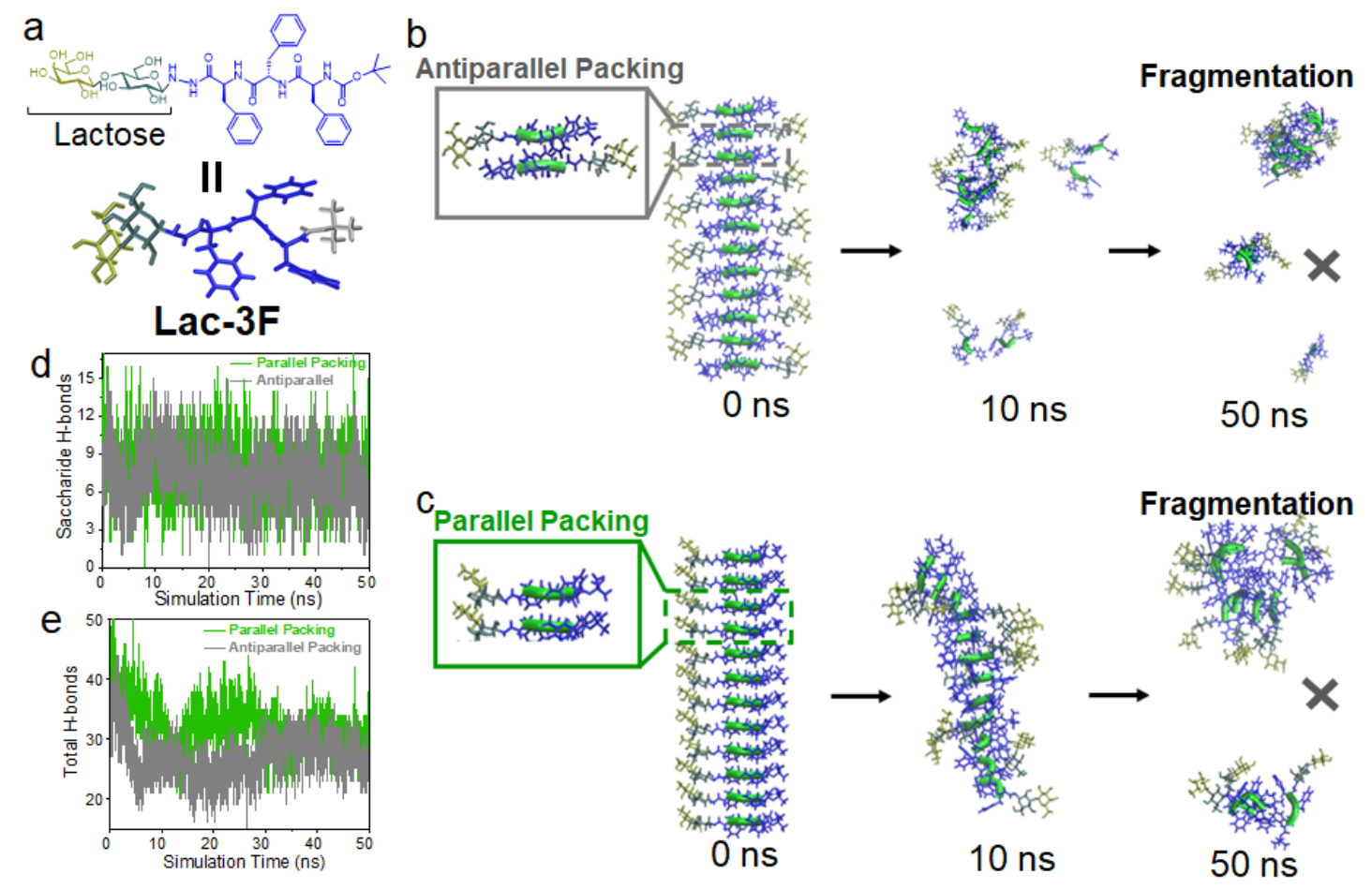

Scheme S1 a) the model of Lac-3F, all-atom molecular dynamics simulation results for b) antiparallel packing mode and c) parallel packing mode, quantified comparison of hydrogen bonds formed by d) saccharide part (saccharide H-bonds) and e) two components (saccharide part and peptide moiety) (total H-bonds) in parallel packing mode and antiparallel packing mode (12 $\mathrm{x}$ Lac-3F). 


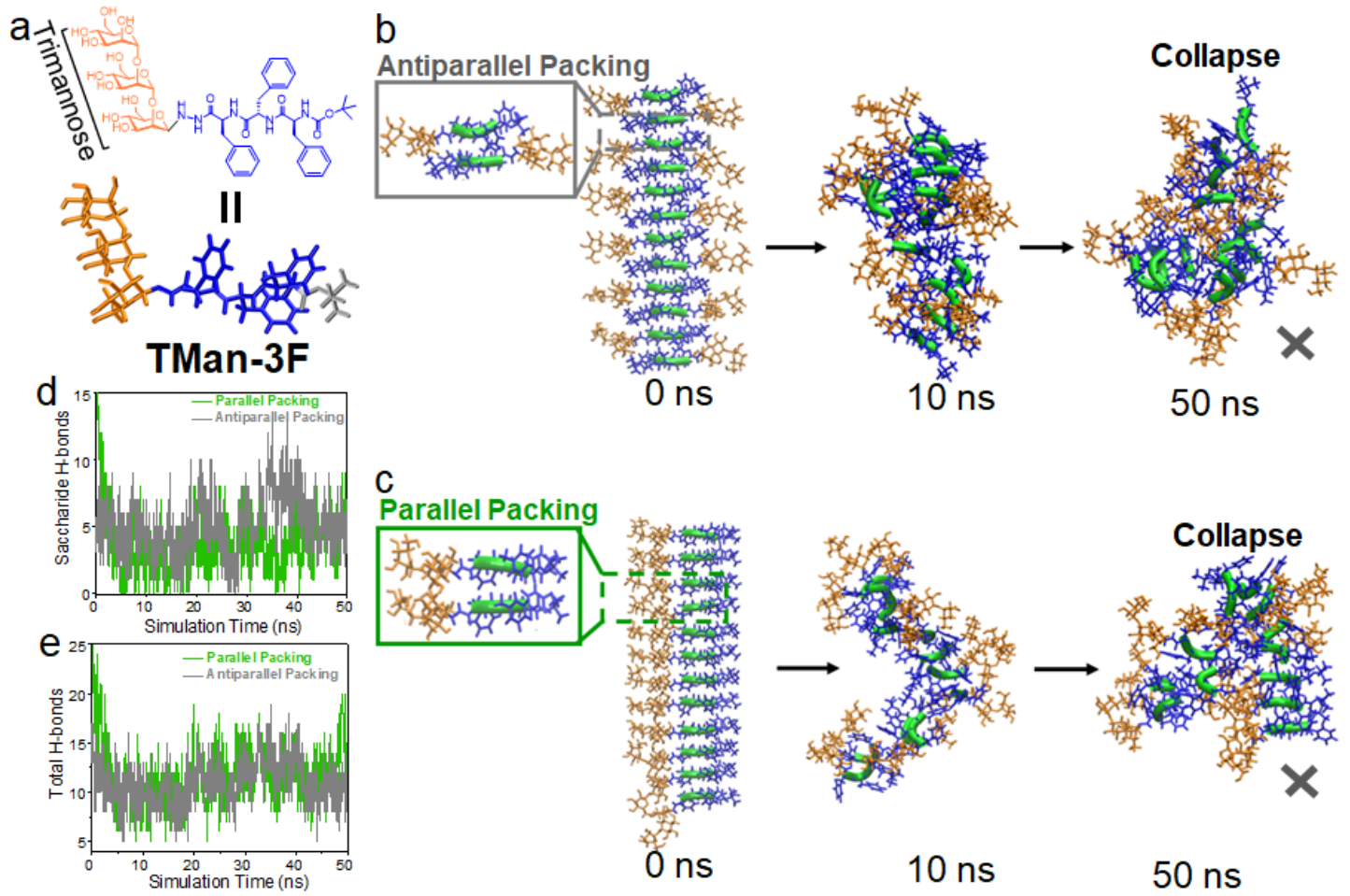

Scheme S2 a) the model of TMan-3F, all-atom molecular dynamics simulation results for b) antiparallel packing mode and c) parallel packing mode, quantified comparison of hydrogen bonds formed by d) saccharide part (saccharide H-bonds) and e) two components (saccharide part and peptide moiety) (total H-bonds) in parallel packing mode and antiparallel packing mode (12 $\mathrm{x}$ TMan-3F). 
a

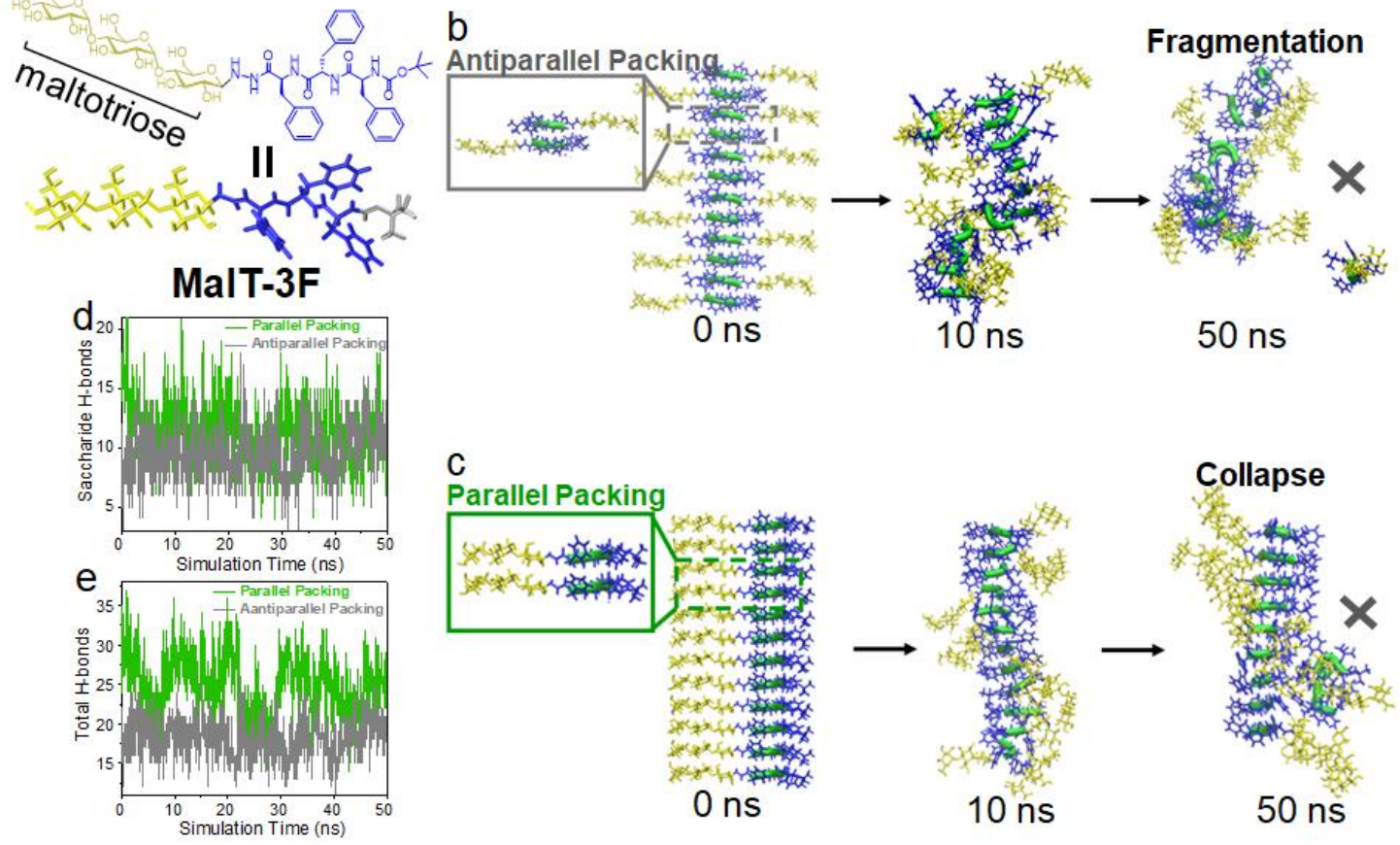

Scheme S3 a) the model of MalT-3F, all-atom molecular dynamics simulation results for b) antiparallel packing mode and c) parallel packing mode, quantified comparison of hydrogen bonds formed by d) saccharide part (saccharide H-bonds) and e) two components (saccharide part and peptide moiety) (total H-bonds) in parallel packing mode and antiparallel packing mode (12 x MalT-3F). 


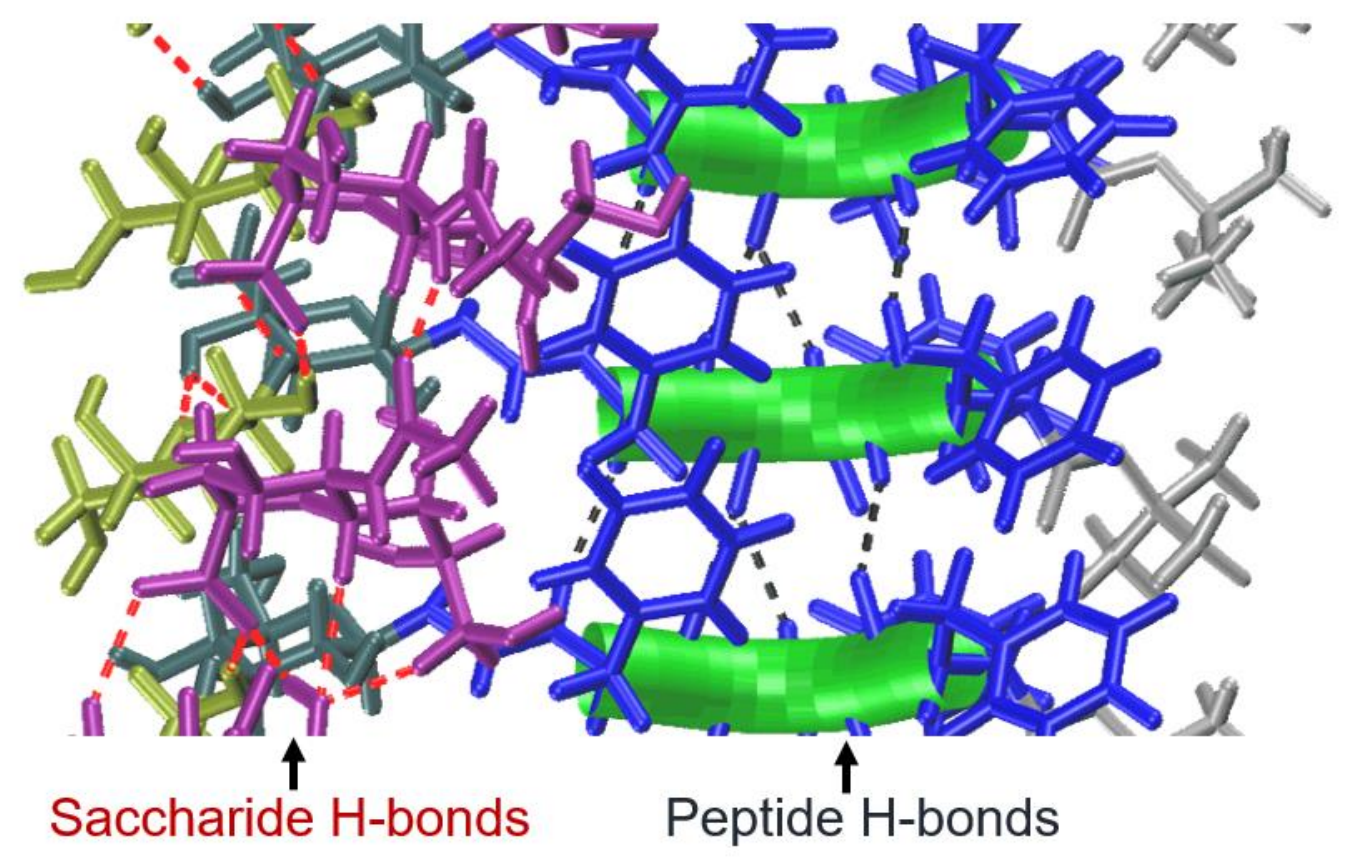

Scheme S4 Schematic illustration for the synergistical stabilization of saccharide H-bonds (red dashed line) and peptide H-bonds (black dashed line) on the starting structure while the SL-3F adopting parallel packing mode. 


\section{Glyco-peptide Synthesis}
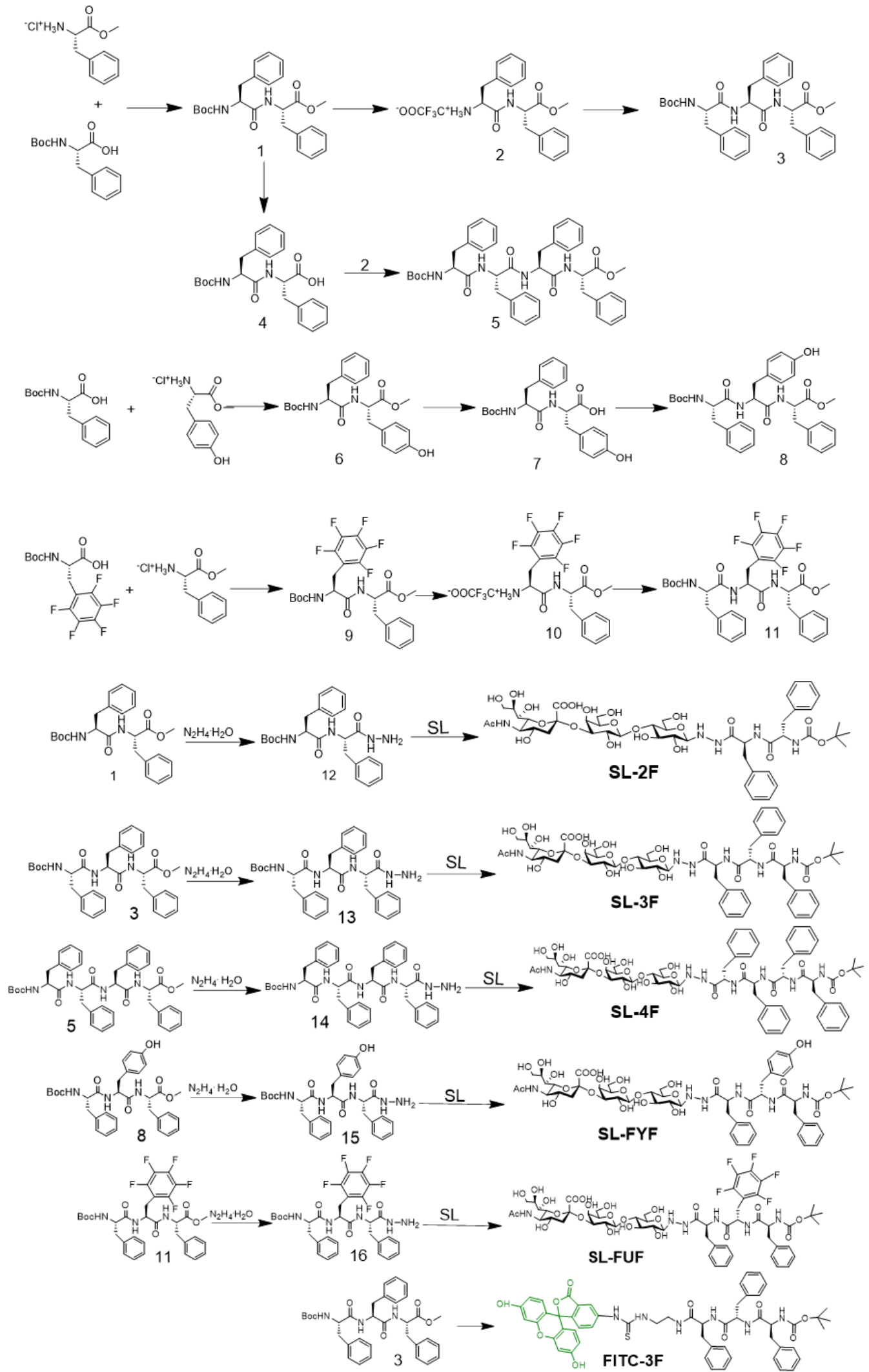

Scheme S5 The synthesis of various glyco-peptide models. 


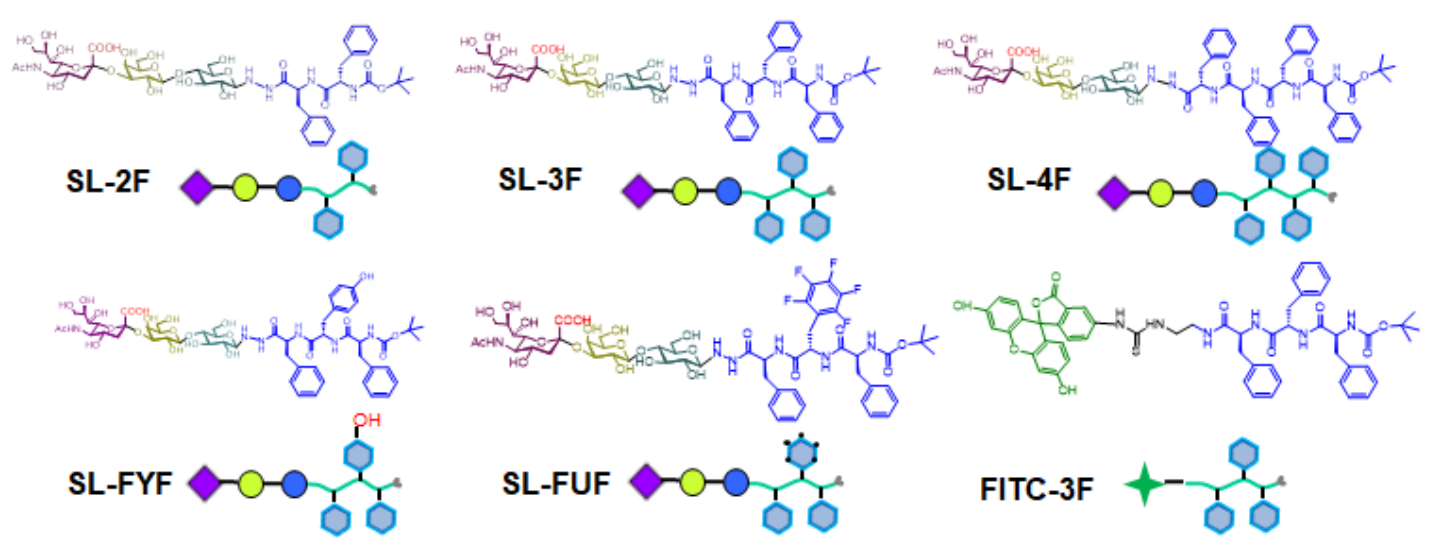
sialic acid
$\mathrm{OH}^{\mathrm{H}}$ tyrosine
phenylalanine $\downarrow$ FITC
galactose
$\leadsto$ fluorophenylalanine residue
amide bond " Boc group

Scheme S6 Five types of glyco-peptide models and FITC-3F used in this work.

We prepared a library of glyco-peptide models with a variable number of phenylalanine units, such as SL-2F, SL-3F and SL-4F as well as SL-FYF, SL-FUF via replaced the phenylalanine at some positions with either tyrosine, fluorophenylalanine. All models were synthesized by simple solution-phase peptide coupling and then linked the sialyllactose to oligopeptides through forming a hydrazine bond. 


\section{The fibril association behaviors of SL-3F}
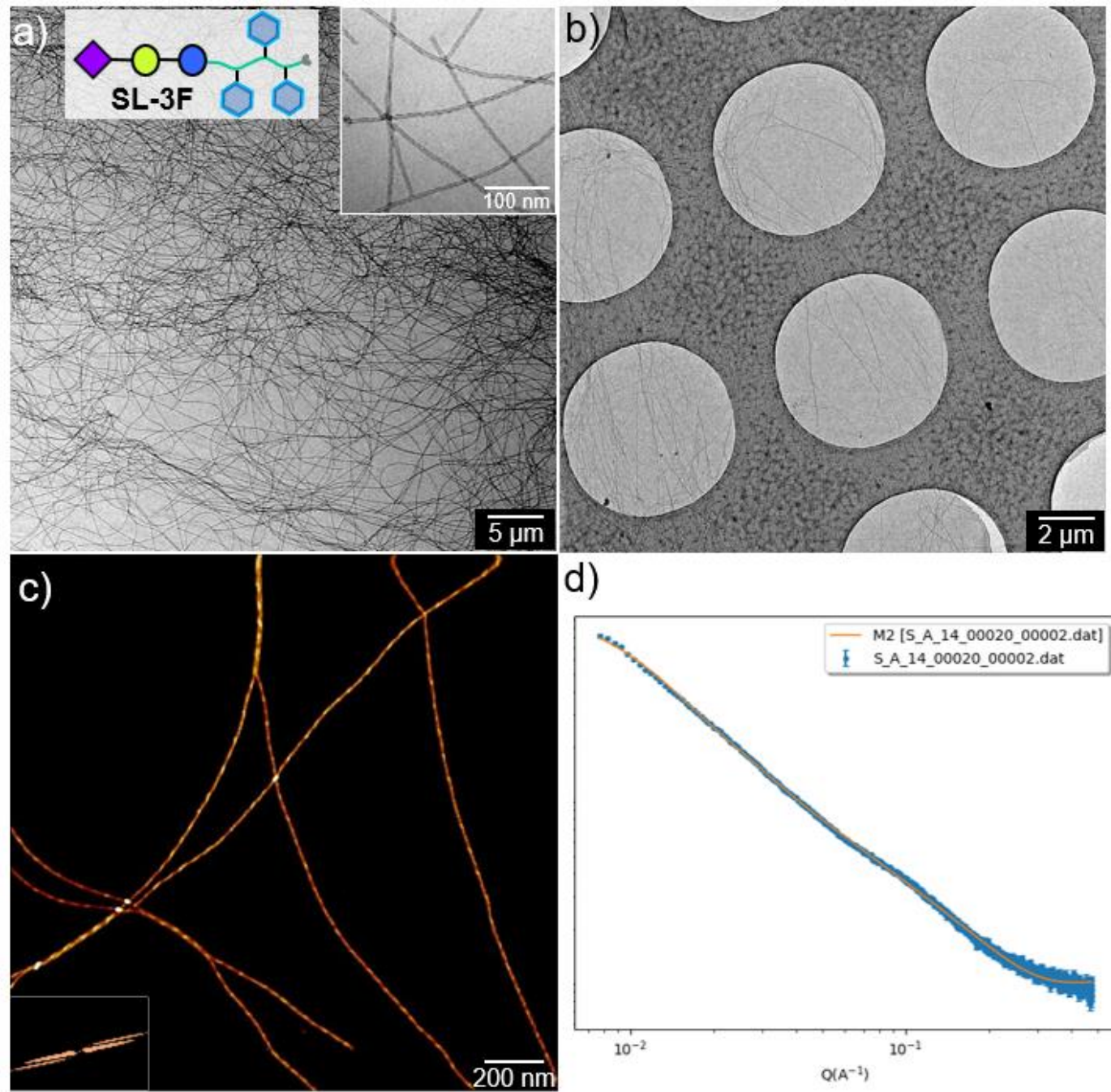

d)

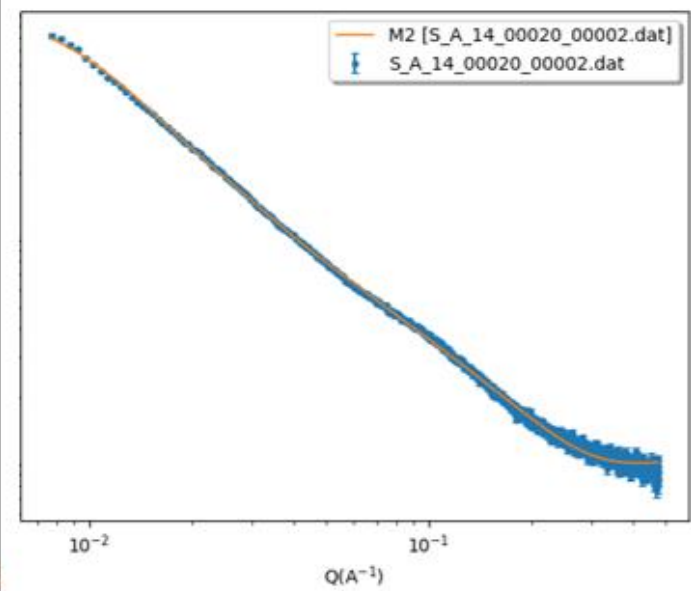

Figure S1 The a) Negatively stained TEM image b) cryo-EM image c) AFM height image d) small-angle-X ray-scattering result of double-strand fibrils of SL-3F. 


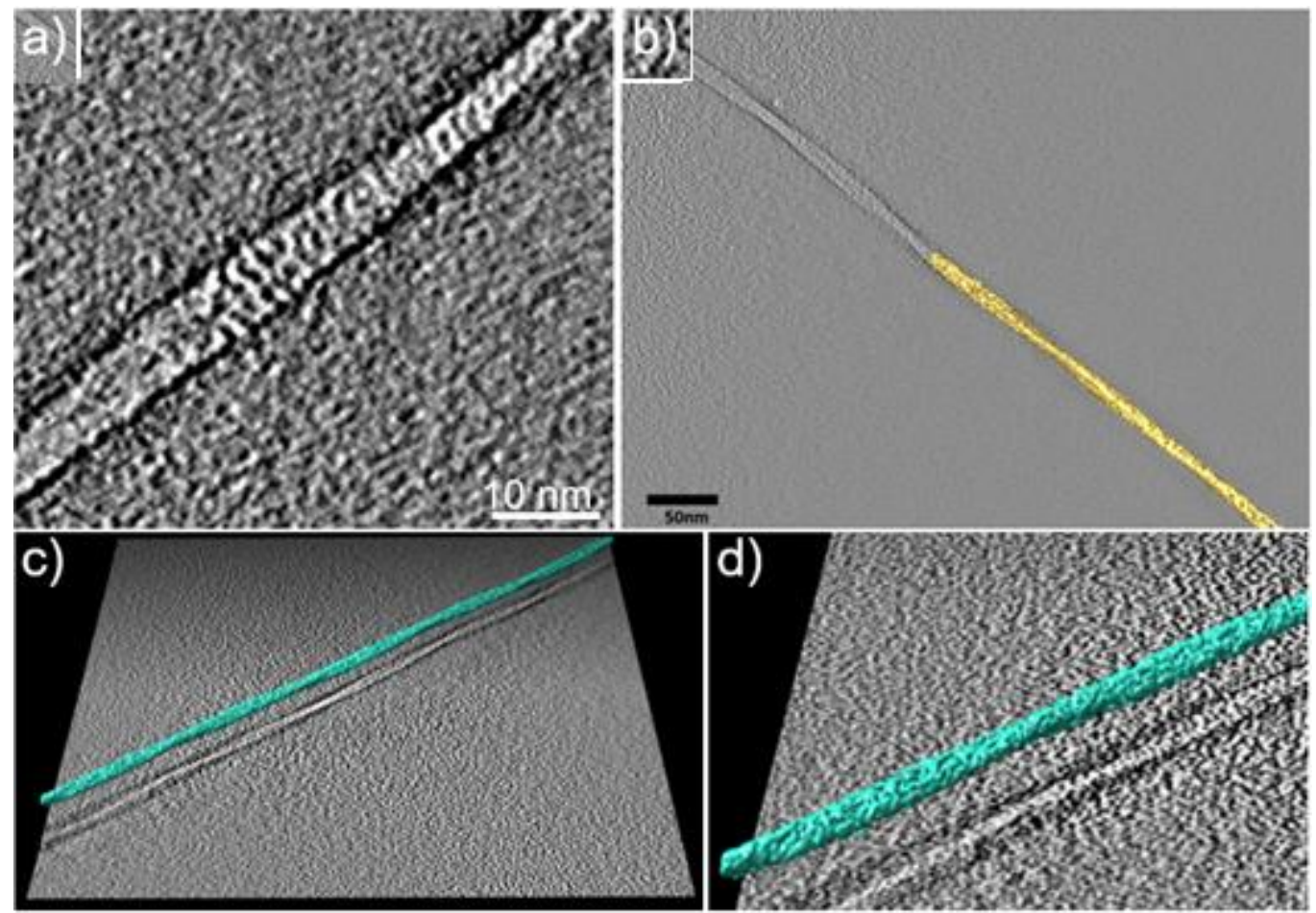

Figure S2 Representative negative stain tomography of double-strand fibrils of SL-3F. a) Central tomographic $\mathrm{XY}$ slice through the tomographic reconstruction of an individual negatively stained double-stranded fibril of SL-3F. b) Central tomographic XY slice through the tomographic reconstruction of an individual negatively stained double-stranded fibril of SL-3F showing a 3D volume rendering of a part of the fibril (yellow). c, d) 3D volume renderings of a double-stranded fibril of SL-3F (cyan) shown together with their central tomographic slices, but slightly tilted around the $\mathrm{X}$ axis. 

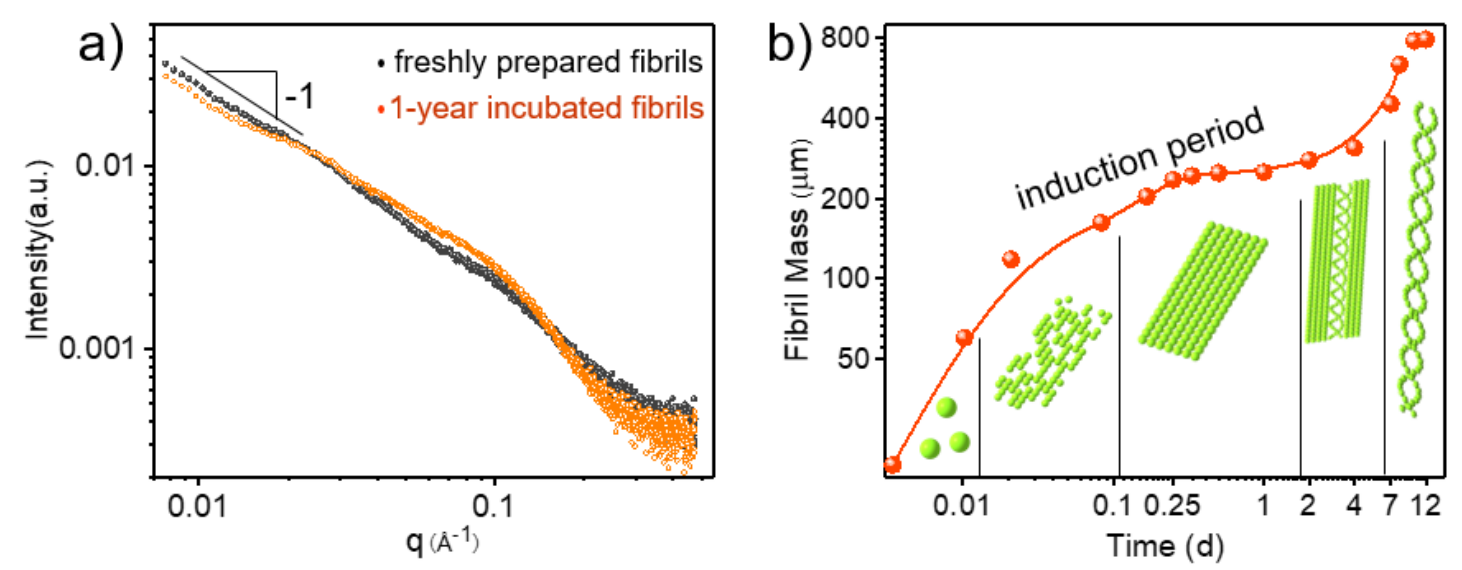

Figure S3 a) The comparison in SAXS results between freshly prepared fibrils and 1-year incubated fibrils of SL-3F, The $q^{-1}$ intensity decay indicates a cylindrical structure. b) experimental measurements of fibril kinetics at $800 \mu \mathrm{M}$ SL-3F $(1 \mathrm{mg} / \mathrm{mL}$ in water).

The measurement of fibril kinetics was performed as following procedures: 1) Firstly, the optimal centrifugal speed was determined to be $3000 \mathrm{rpm}$, because at this centrifugal speed, only the double-strand fibrils of SL-3F could be centrifuged but other species such as oligomers, protofilaments could not. 2) Then the samples that have been incubated for different times were centrifuged. 


\begin{tabular}{clccccc}
\hline Item & \multicolumn{1}{c}{ Name } & Molecular Weight $(\mathrm{Da})$ & Contour Length $(\mathrm{nm})$ & Diameter $(\mathrm{nm})$ & Aspect Ratio & Reference \\
\hline 1 & FF Nanotube & 426 & 8000 & 125 & 64.00 & 6,7 \\
2 & Peptide Amphiphiles & 1068 & 9000 & 7 & 1285.71 & $8,9,10$ \\
3 & PEO - F $_{4}$-OEt & 1080 & 1500 & 4.4 & 340.91 & 11 \\
4 & SL-3F & 1189 & 500000 & 6.5 & 76923.08 & 1898.73 \\
5 & IAPP & 4736 & 15000 & 7.9 & 781.25 & 12,13 \\
6 & a-synuclein & 17920 & 5000 & 6.4 & 13 \\
7 & B-lactoglobulin & 18400 & 5500 & 4 & 13 \\
8 & MUC5B & 30000 & 10000 & 5 & 2000.00 & 16,17 \\
9 & Actin Filament & 42000 & 1000 & 5 & 200.00 & $18,19,20$ \\
10 & PFS-b-PDMS-b-PFS & 64000 & 1000 & 7.7 & 129.87 & 21,22 \\
11 & Bovine Serum Albumin & 66463 & 2000 & 6.5 & 307.69 & 23
\end{tabular}

*Divide the contour length by the diameter to get the aspect ratio directly

Table S1 The comparison of aspect ratio of SL-3F fibrils with those of diverse fibrous species reported in literatures. 


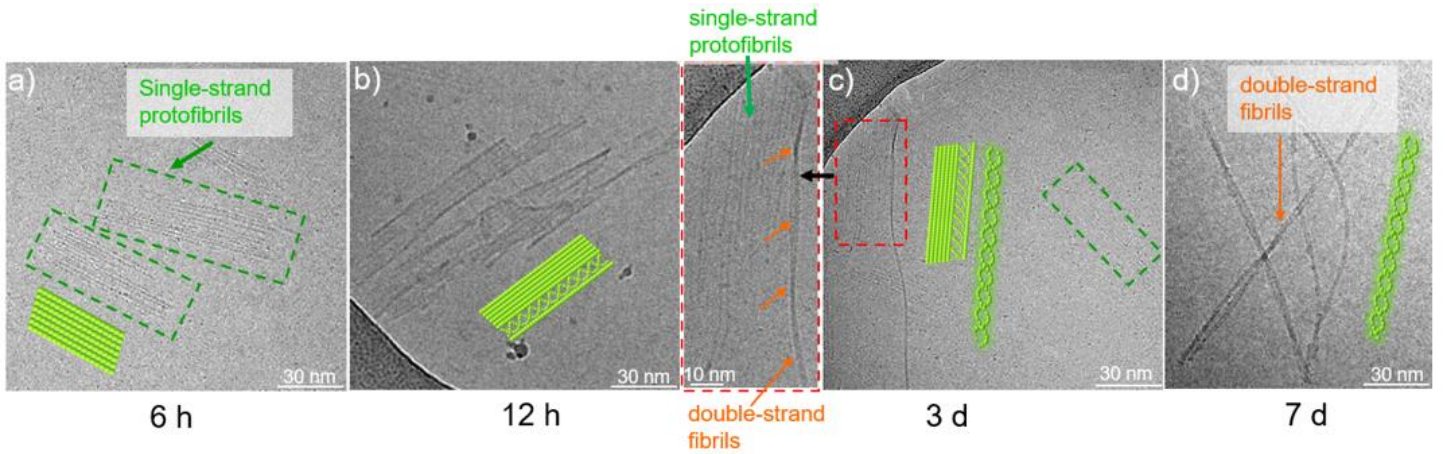

Figure S4 The track for the formation processes of double stranded fibril of SL-3F by cryo-EM. 


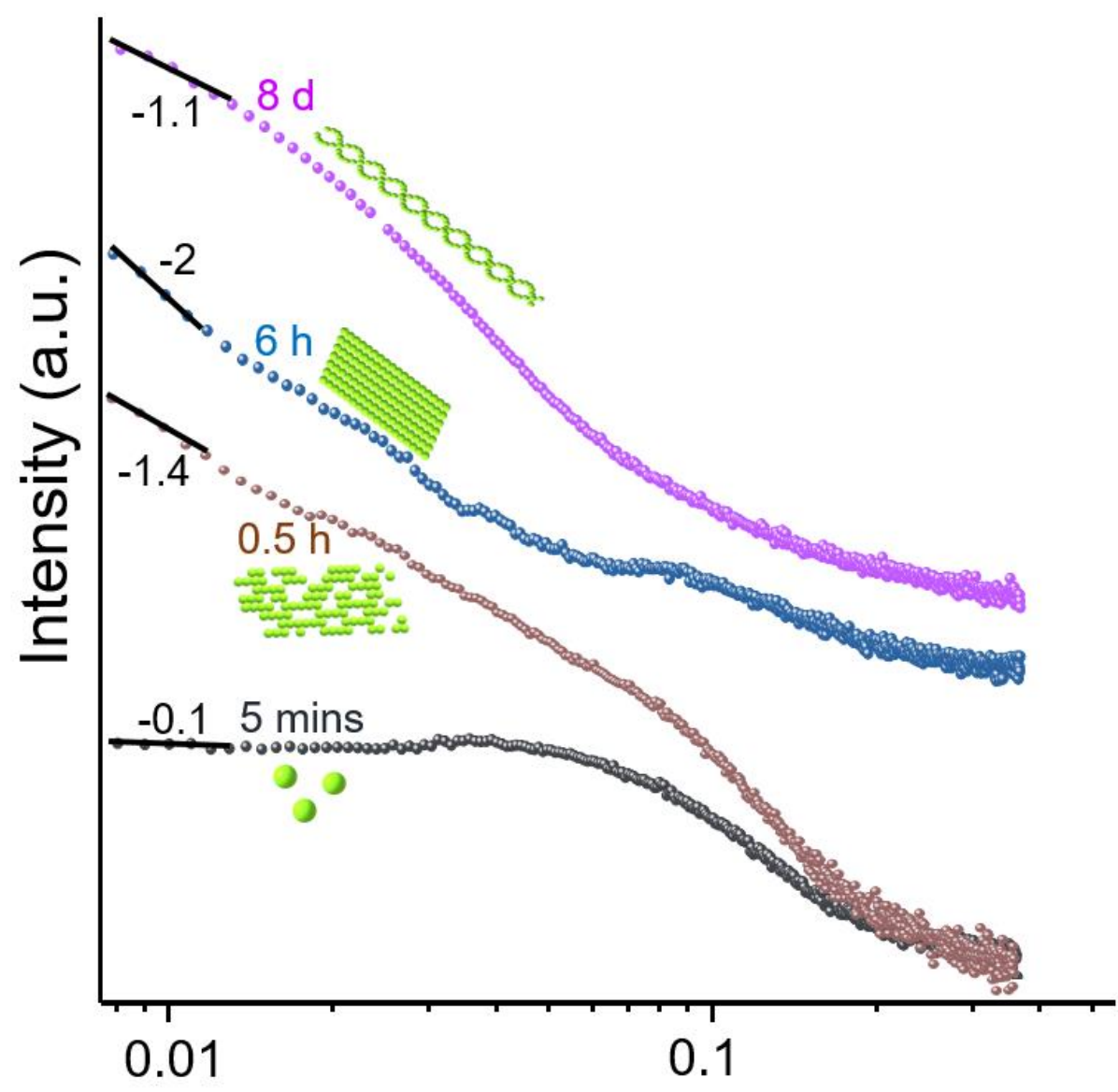

Figure S5 The SAXS results of SL-3F association processes as a function of incubation time. 

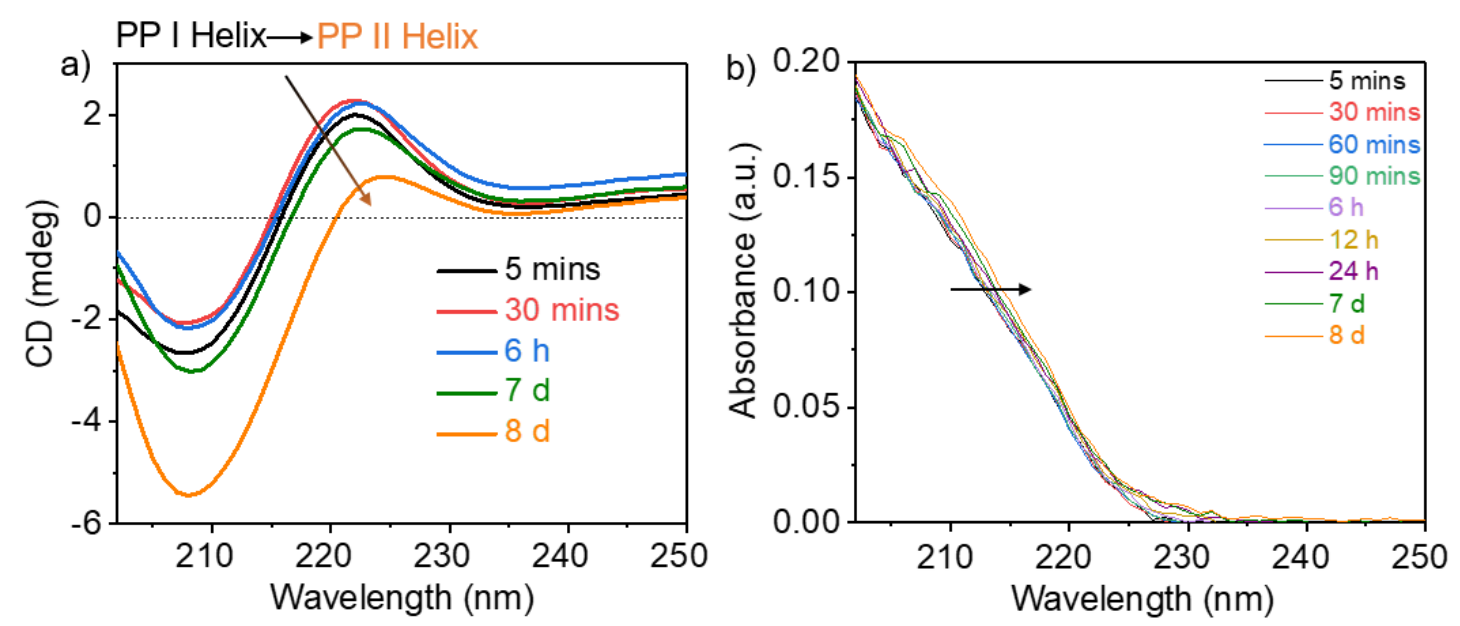

Figure S6 The a) circular dichroism (CD) detection b) UV-vis detection for fibril kinetics of SL-3F.

Both the gradual weaken and a perceptible red-shift of signal at $222 \mathrm{~nm}$ experimentally suggested that a transformation of fibril secondary structure from hydrophobic PP I helix to relatively hydrophilic PP II helix was involved in the double-strand process (Figure S6a). The slight red-shift observed in Uv-vis spectrum indicated that the arrangement of phenylalanine residue tend to become more regular accompanied by the growth of fibrils (Figure S6b). 


\section{Direct simulation (no constraints)}

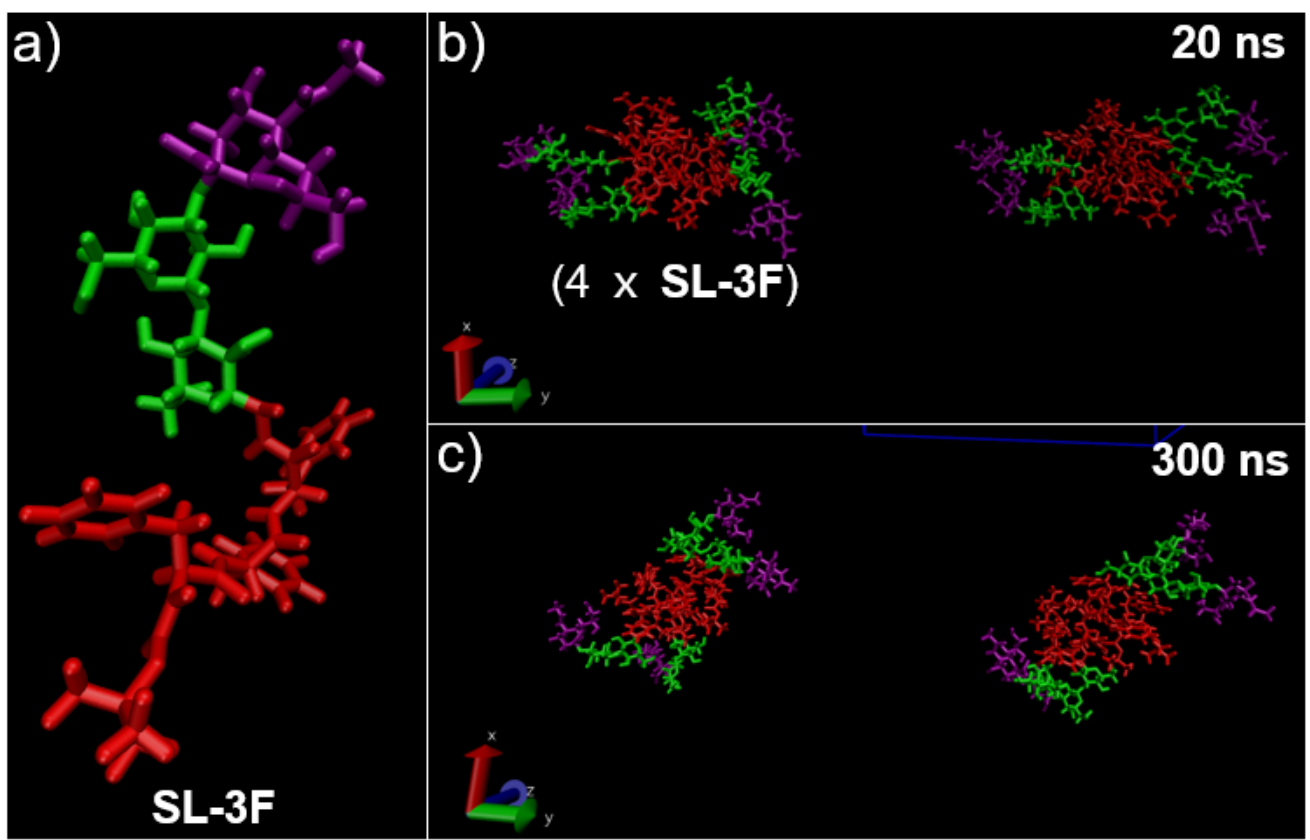

Model color: sialic acid (purple), Lactose (green), FFF-Boc (red)

Force field type: CHARMM (charmm36.ff, without other force field blending)

Simulation condition: explicit solvent, 4 chains, sialic acid is negatively charged.

Figure S7 a) the optimized structure of SL-3F, the direct all-atom molecular dynamics simulation results after b) $20 \mathrm{~ns}$ c) $300 \mathrm{~ns}$ relaxation while 4 SL-3F were directly put into the box while no constraints were imposed.

We initially attempted to perform this study with direct all-atom simulation in which no constraints were imposed on the starting structure, whereas the atomistic complexity of this calculation tended to prevent the generation of a converged fiber structure. 


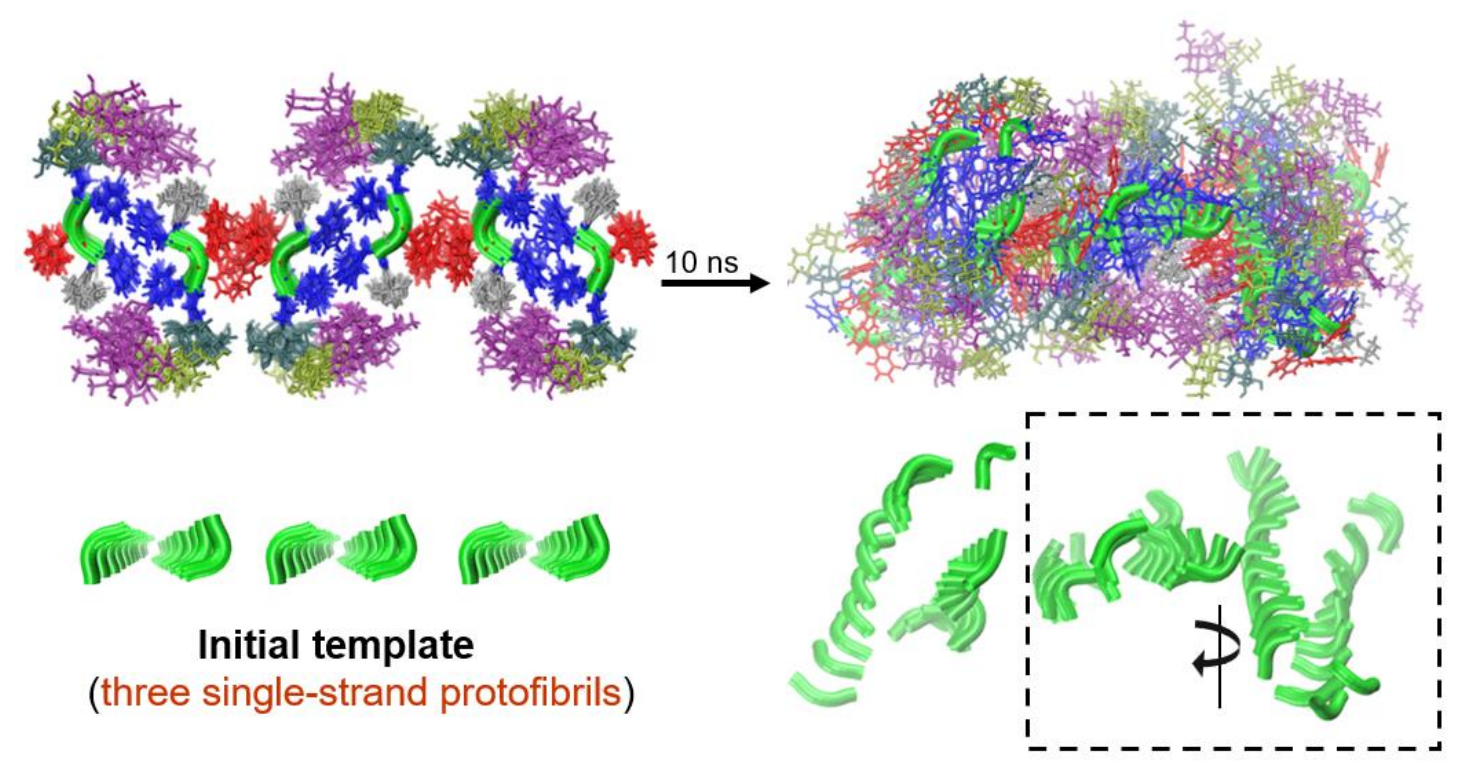

Figure S8 The all-atom molecular dynamics simulation results while the initial template comprising three single-strand protofibrils of SL-3F. 

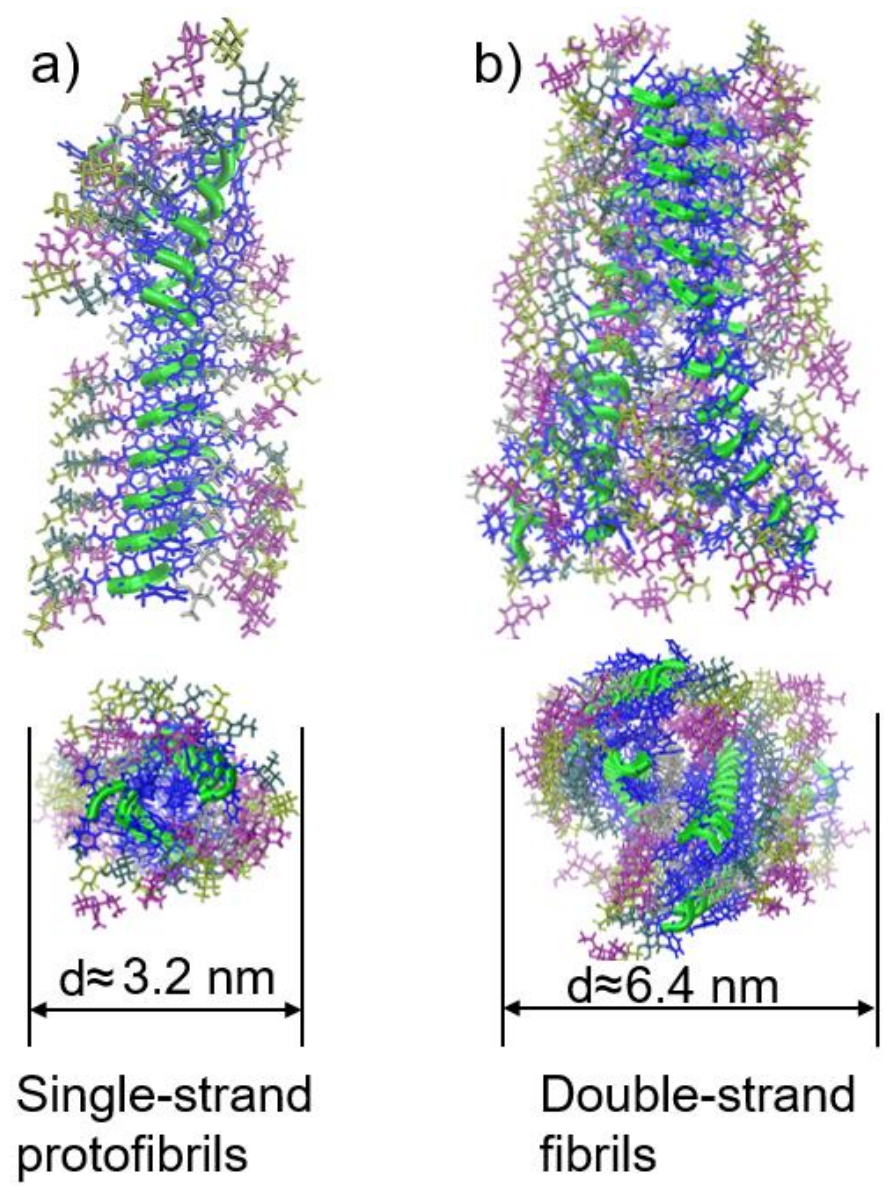

Figure S9 The measured diameter of single-strand protofibril and double-strand fibril of SL-3F based on all-atom molecular dynamics simulation results. 

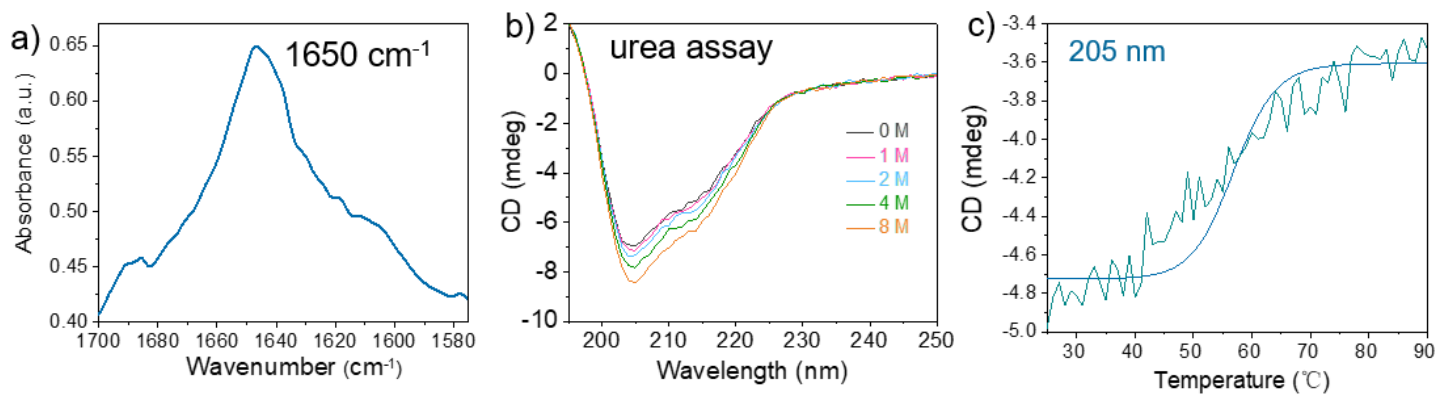

Figure S10 a) FT-IR spectrum, b) urea addition assay results and c) varied temperature results (detected at $205 \mathrm{~nm}$ ) of double strand fibrils of SL-3F.

A strong absorption band at about $1650 \mathrm{~cm}^{-1}$ in solid-phase infrared spectra are considered to be the typical features of PP II helix conformation (Figure S10a) ${ }^{[24]}$, in addition, the observations of a strong increase of the negative band at $208 \mathrm{~nm}$ upon addition $8 \mathrm{M}$ urea and a decrease of this band on increasing temperature further supported the existence of PP II helix (Figure S10b,c ) ${ }^{[25]}$. 


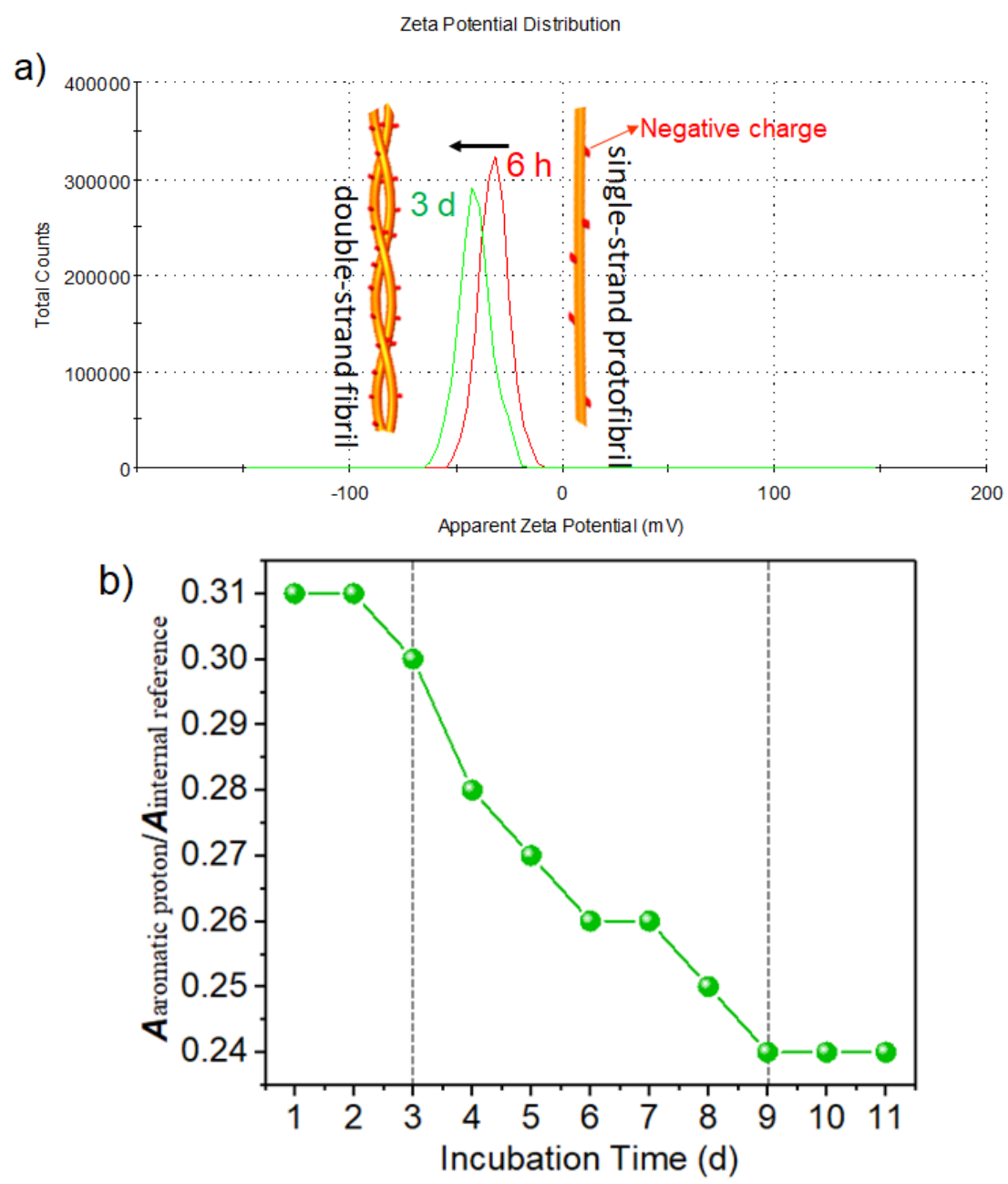

Figure S11 a) The zeta-potential results of SL-3F before (6h) and after (3d) partially undergo double-strand processes, b) the ratio of integral area of aromatic protons to that of internal reference evolved with incubation time.

Here we selected to dissolve $4 \mathrm{mg}$ of SL-3F into $1 \mathrm{~mL} \mathrm{D}_{2} \mathrm{O}$, and the ratio of integral area of aromatic protons to that of $\mathrm{D}_{2} \mathrm{O}$ as internal reference ( $A$ aromatic proton/Ainternal reference) was defined as a parameter to quantify the interactions between hydrophobic moieties. As shown in Figure S11b, in the beginning ( $<3$ days), the ratio of $\boldsymbol{A}$ aromatic proton/Ainternal reference seems nearly constant, suggesting that the hydrophobic interaction is not significantly enhanced during the early growth of the fibrils. For the middle stage ( 3 days $\sim 9$ days), the ratio of $\boldsymbol{A}$ aromatic proton/Ainternal reference shows a significant decrease, indicating that the process of fibril association might be accompanied by an increased hydrophobic interaction. When the fibril association approaches completion ( $>9$ days), the interfibril hydrophobic interaction also tends not to change. 

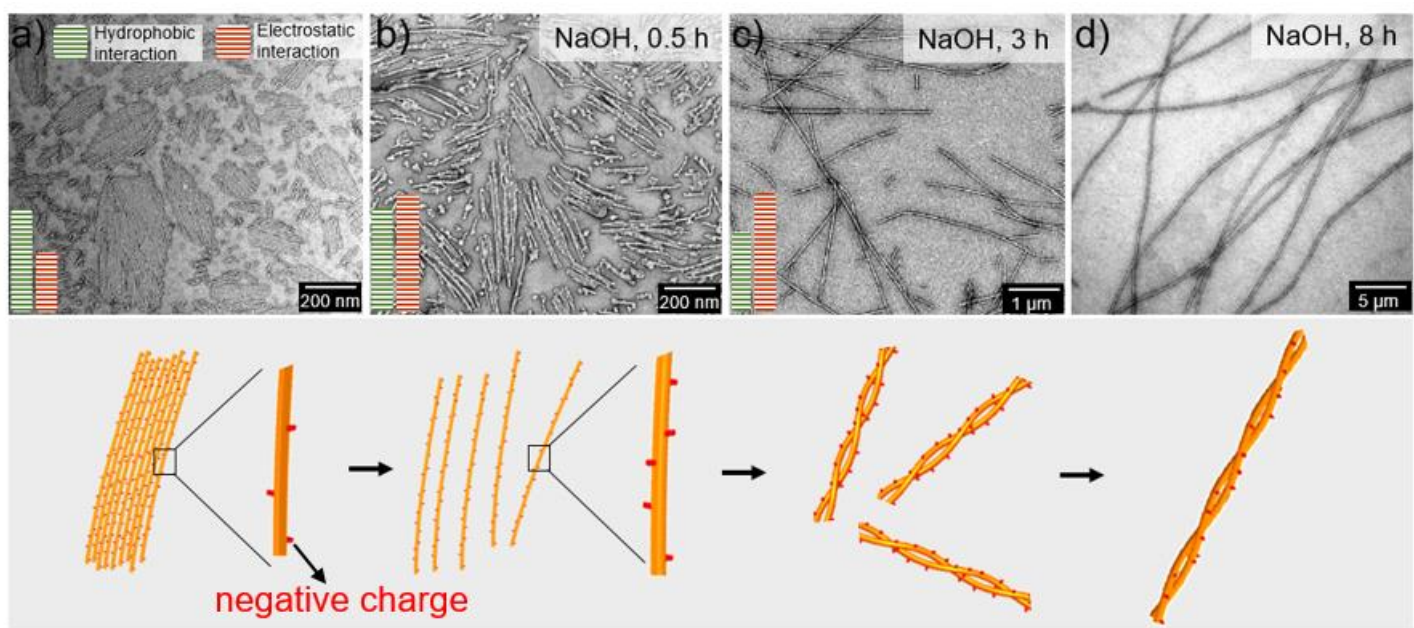

Figure S12 (a-d) The structural evolution of ribbon-like structure of SL-3F with incubation time in the presence of $\mathrm{NaOH}$. (Detailly, added $1 \mu \mathrm{L} 0.5 \mathrm{M} \mathrm{NaOH}$ into the $1 \mathrm{~mL}$ of ribbon-like structure of SL-3F) 

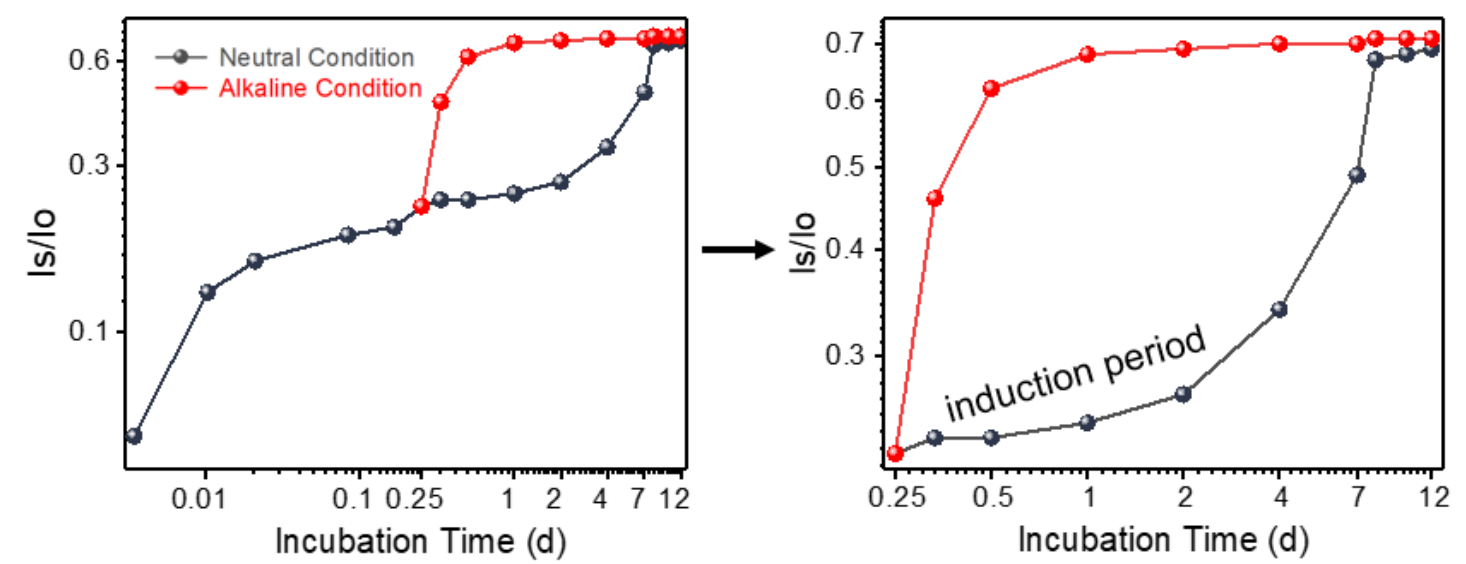

Figure S13 The varying of scattered light intensity $\left\langle I_{\mathrm{s}}\right\rangle \mid\left\langle I_{0}\right\rangle$ upon incubation time in neutral condition and alkaline condition. 

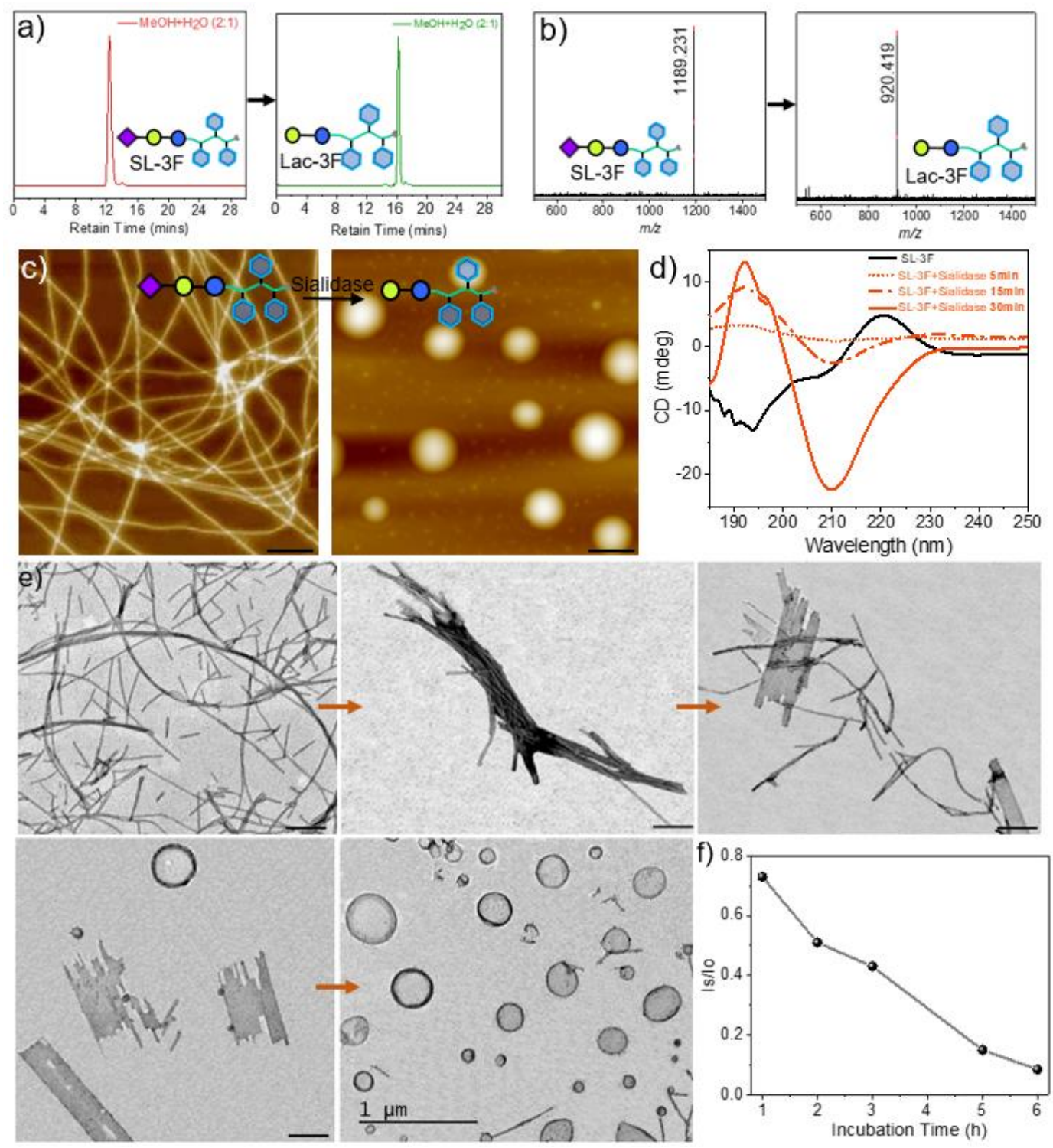

Figure S14 a) HPLC profile b) Maldi-TOF result c) AFM height images of SL-3F before and after addition of sialidase, d) the evolution of $\mathrm{CD}$ with incubation time in the presence of sialidase, e) the trace for the structural evolution process in the presence of sialidase performed by negatively stained TEM, f) the variation of $\left\langle I_{\mathrm{s}}\right\rangle \mid\left\langle I_{0}\right\rangle$ upon incubation time in the presence of sialidase. 


\section{The fibril association behaviors of SL-4F}
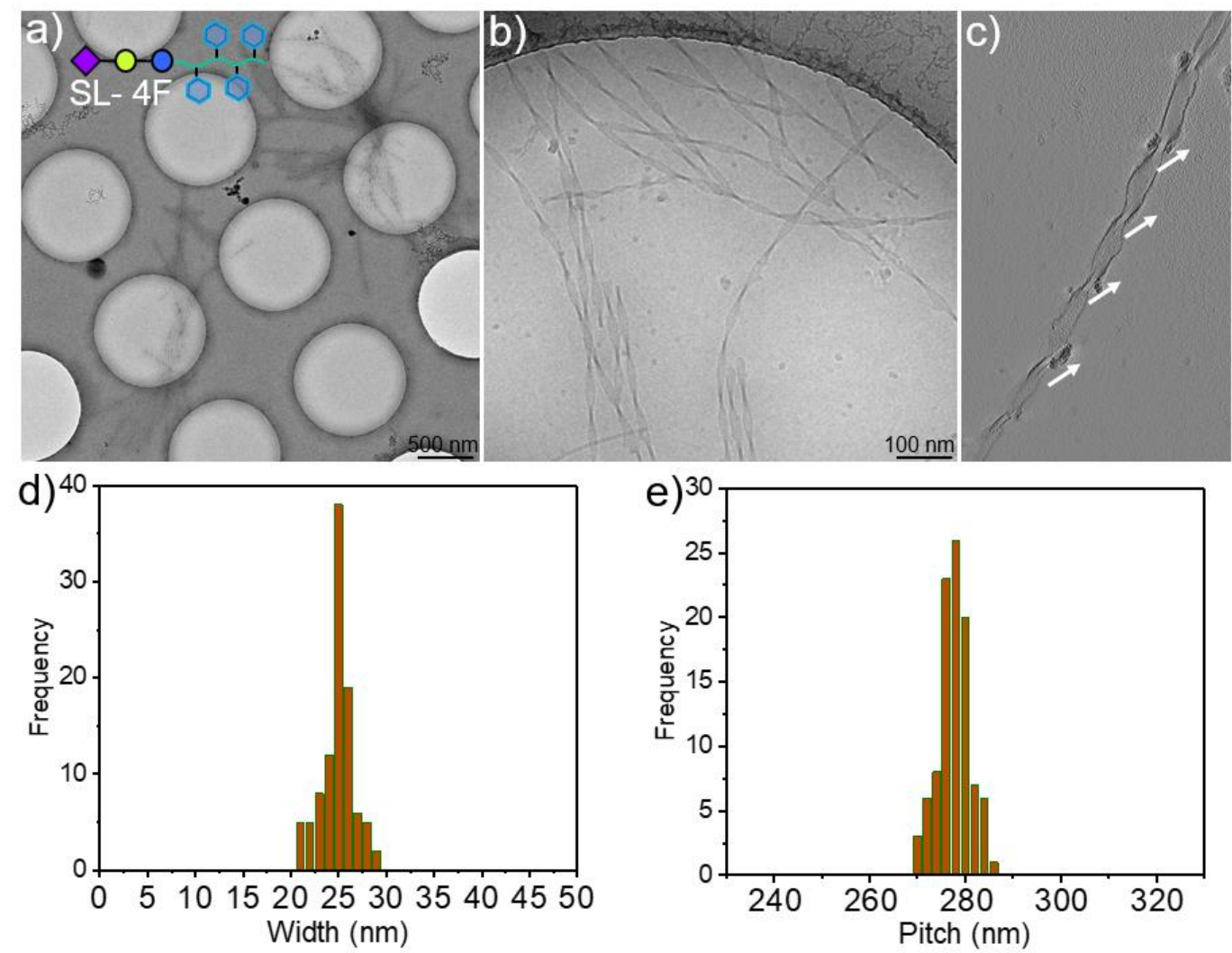

Figure S15 a, b) cryo-EM images c) Central tomographic XY slice through the tomographic reconstruction of a negatively stained twisted right-handed nanoribbon of SL-4F, the statistical results of d) width e) pitch of twistedly right-handed nanoribbon of SL-4F. 
a)
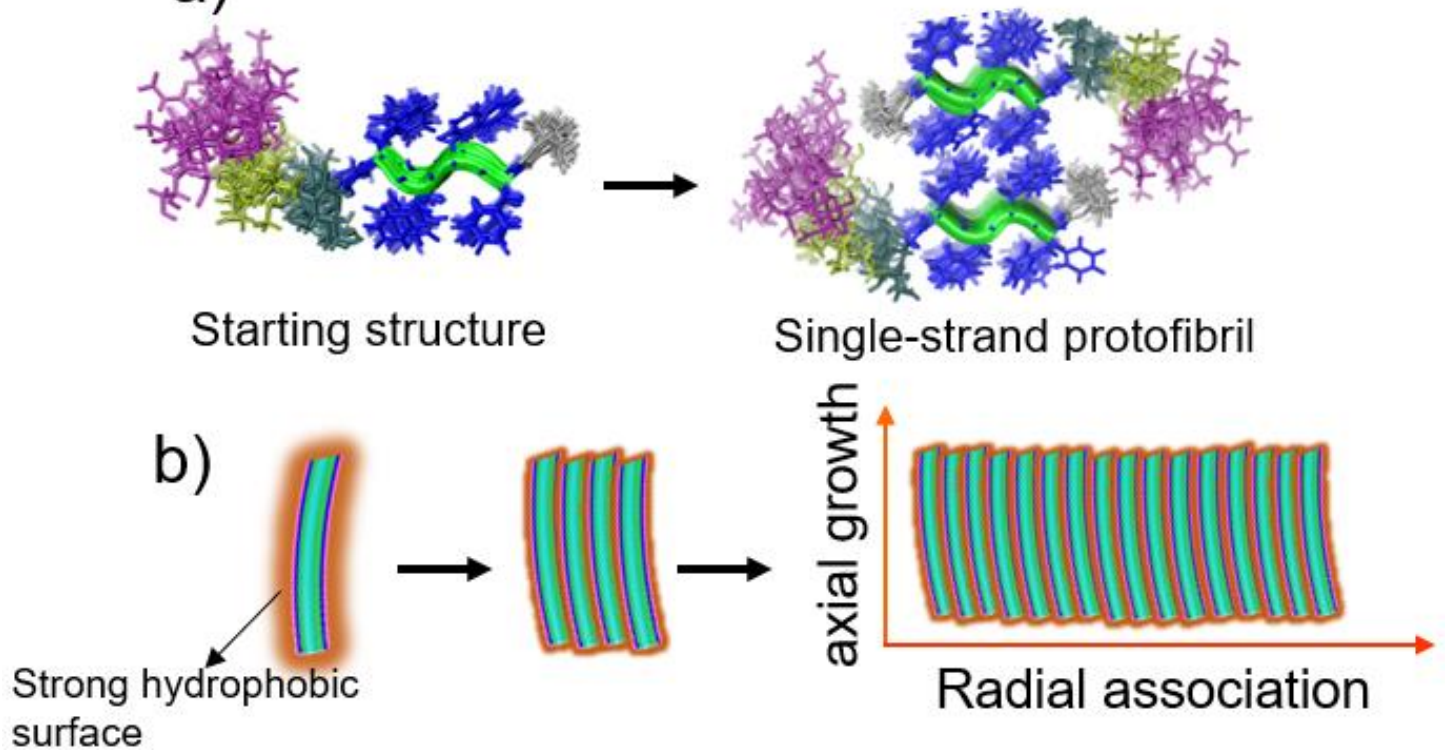

Figure S16 a) schematic illustration for the formation of SL-4F single-strand protofibril, b) schematic illustration for the competitive event between axial growth and radial association of protofibrils of SL-4F.

Detailly, firstly packed 12 of such SL-4F into a single-strand protofibril in parallel manner, then 8 such single-strand protofibril $(8 \times 12)$ were radially arranged into a ribbon structure in an antiparallel manner to form the starting structure. 


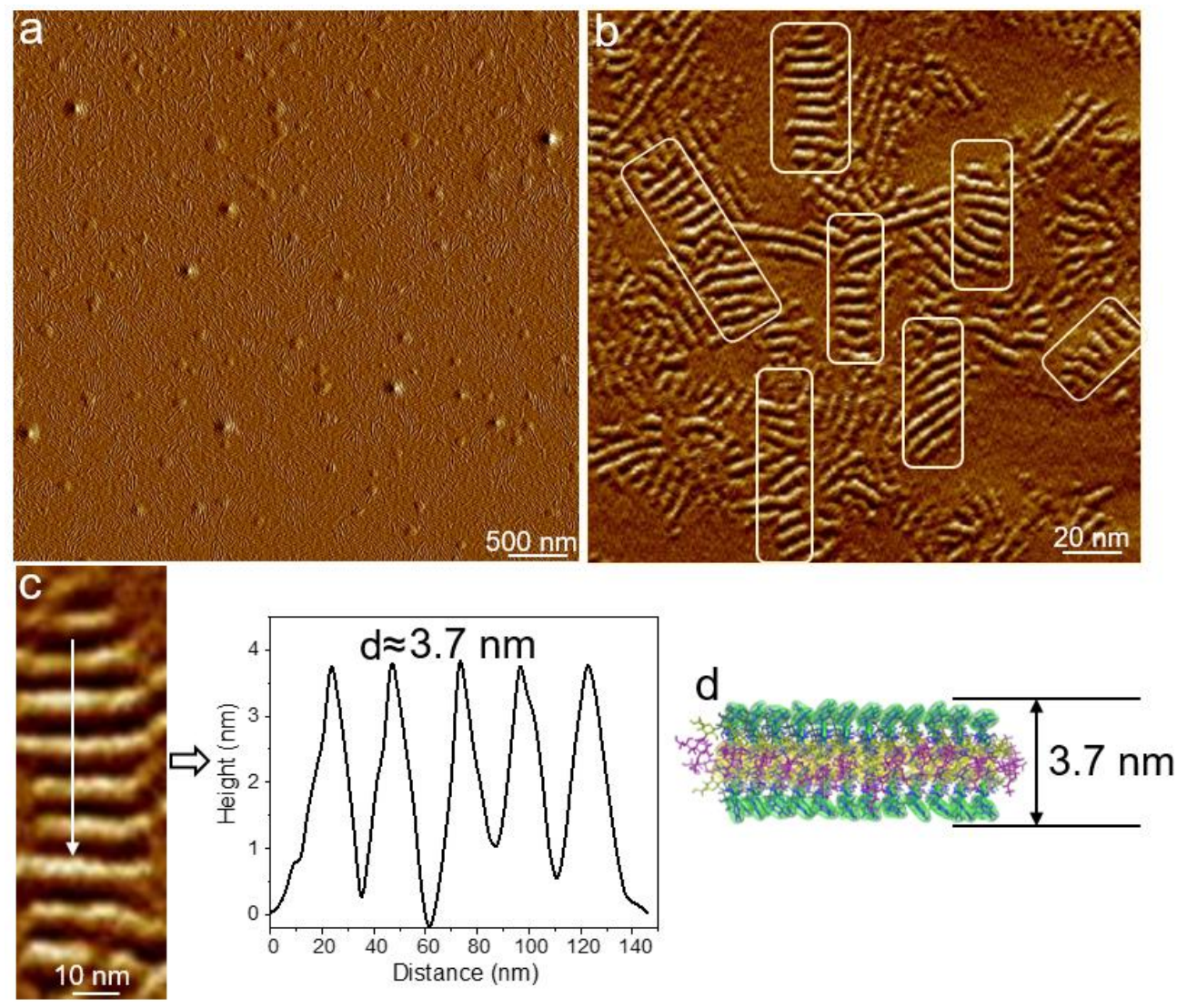

Figure S17 a, b, c) The AFM height images for visualizing the radial association of SL-4F protofibrils. d) the diameter of single-strand protofibrils of SL-4F measured by molecular dynamics simulation. 


\section{The fibril association behaviors of SL-2F}
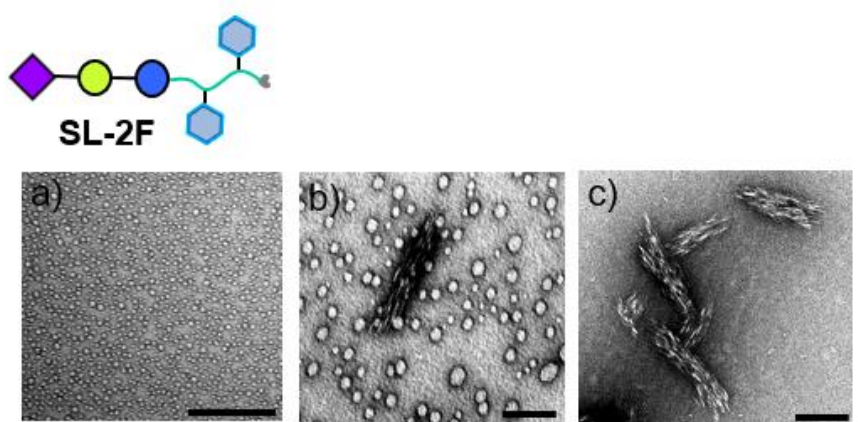

d)

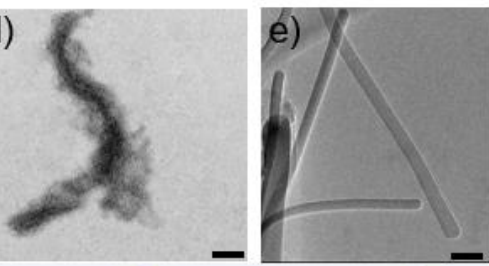

1.
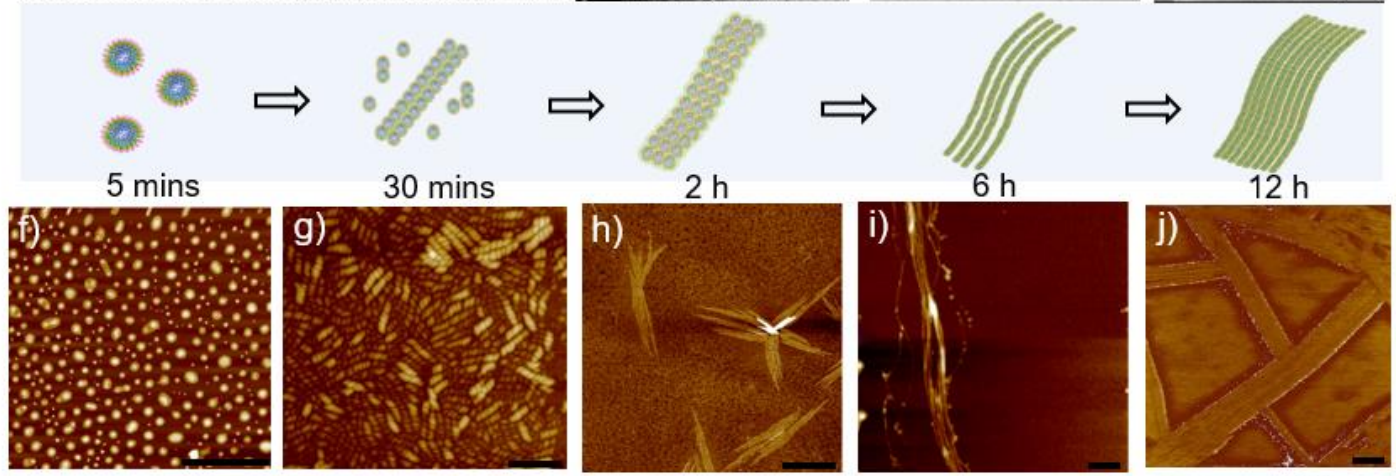

Scale bar $100 \mathrm{~nm}$

Figure S18 The a-e) negatively stained TEM images f-j) AFM height images for tracing the association behaviors of SL-2F. 


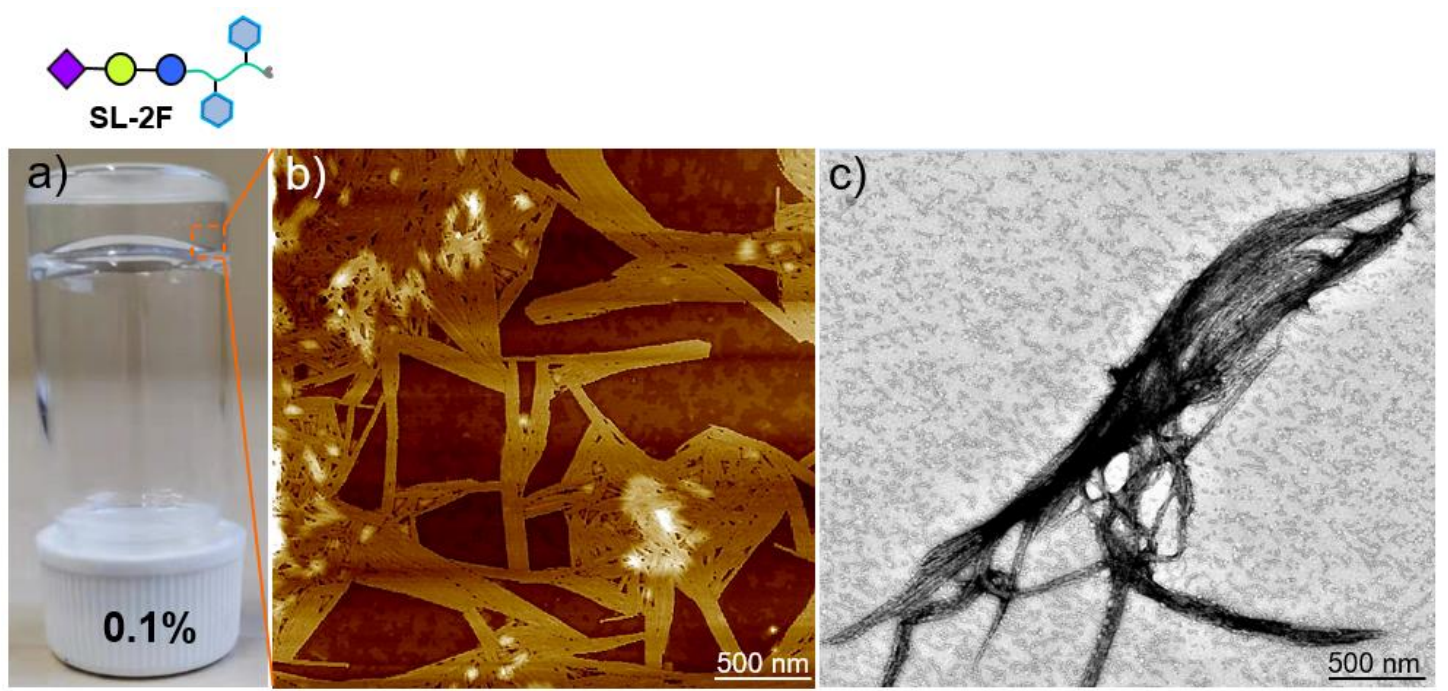

Figure S19 The a) photograph, b) AFM height image and c) Negatively stained TEM image of hydrogel formed by SL-2F. 
a) $0 \mathrm{~ns}$

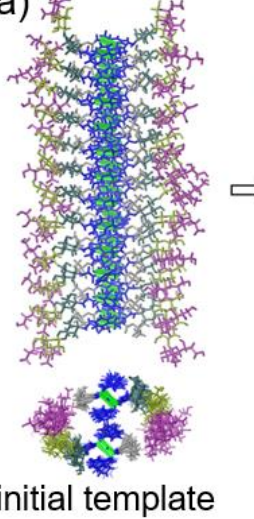

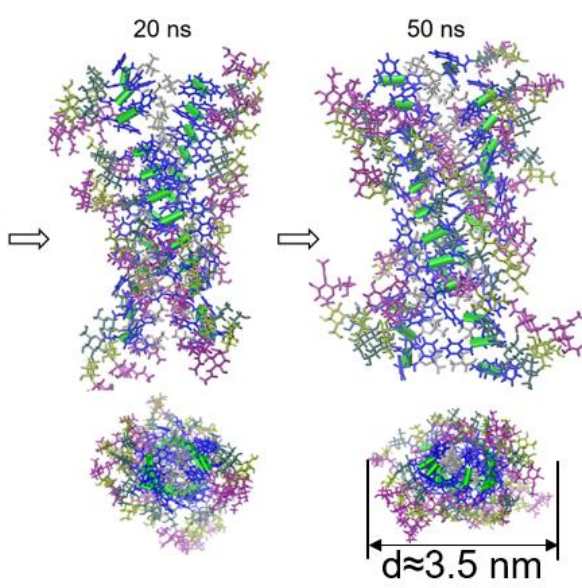

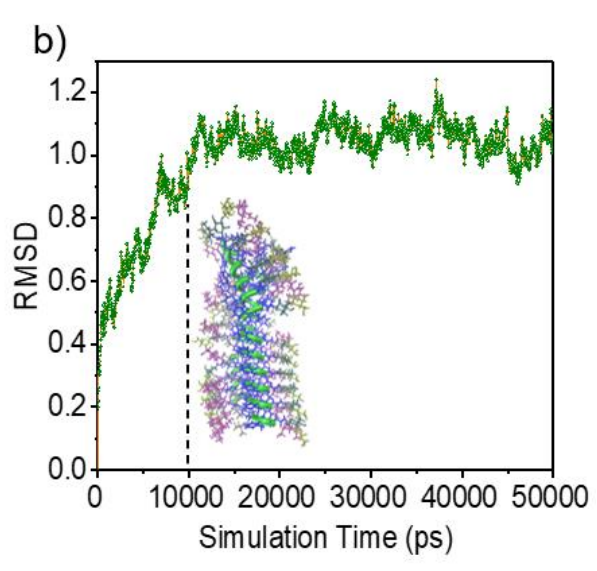

Figure S20 a) relaxation process of single-strand protofibril of SL-2F, b) the corresponding RMSD varying with simulation time.

Detailly, the SL-2F models were initially packed into a starting structure in parallel manner like SL-3F, then two of such starting structure tend to form the initial template of single-strand protofibril (Figure S20a) in a way that the two hydrophobic ends of SL-2F close together. 


\section{The fibril association behaviors of SL-FYF and SL-FUF}
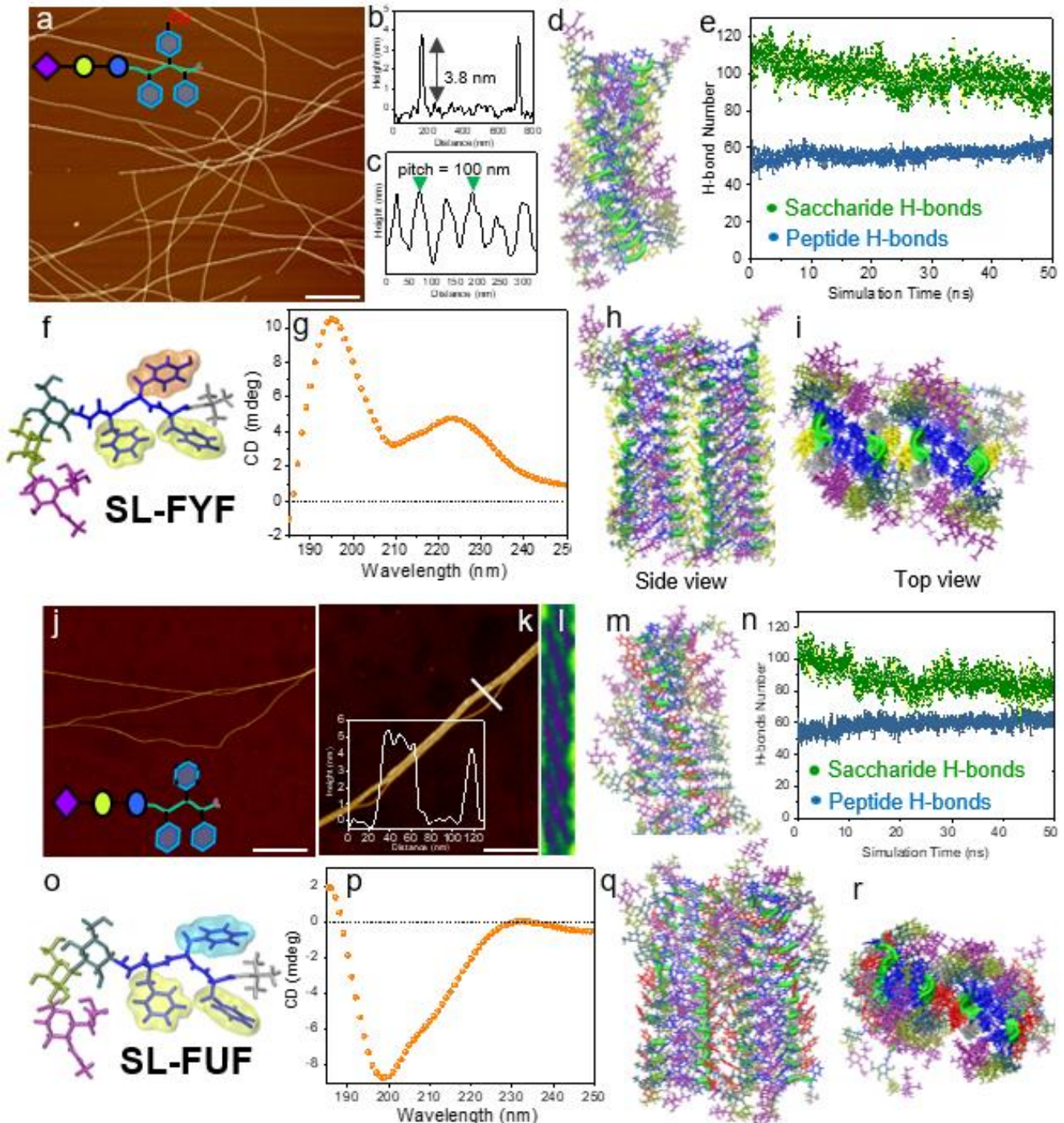

Side view

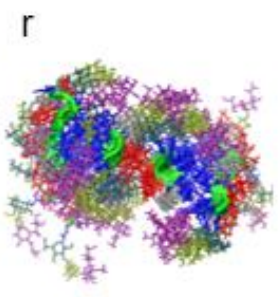

Top view

Figure S21 a) AFM height image b, c) corresponding profile d) all-atom simulation result e) the statistical results of two types of H-bonds involved in protofibrils of SL-FYF, f) the lowest energy state of a SL-FYF molecule, g) CD result of single-strand protofibril of SL-FYF, h, i) simulation result of double-strand fibril of SL-FYF. j, k, 1) AFM height image m) all-atom simulation result m) CD result of single-strand protofibril of SL-FUF, n) ) the statistical results of two types of H-bonds involved in protofibrils of SL-FUF, o) the lowest energy state of a SL-FUF molecule, p) CD result of single-strand protofibril of SL-FUF q, r) simulation result of double-strand fibril of SL-FUF. 


\section{The correlation between fibril association with hydrogelation}

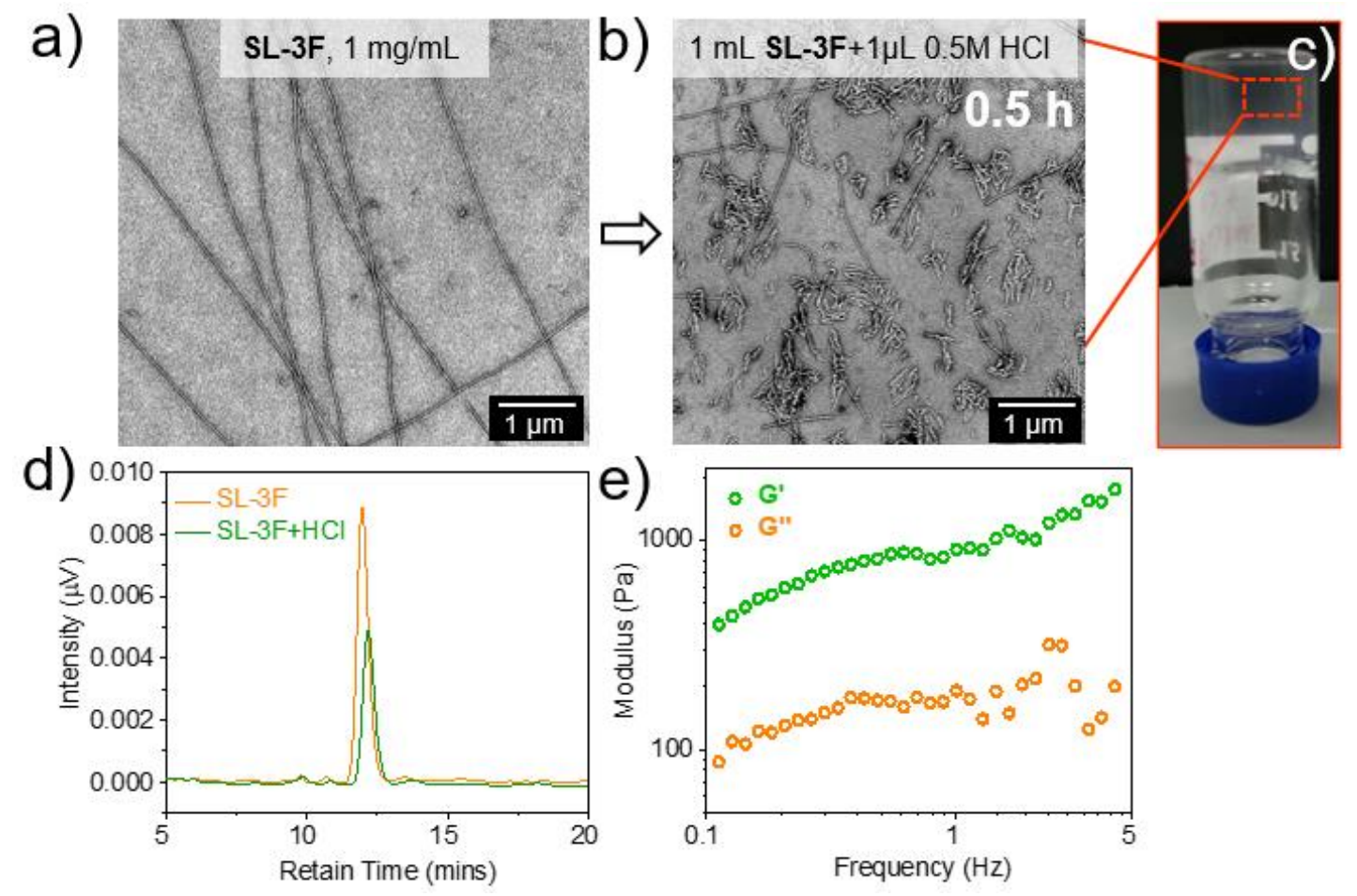

Figure S22 The negatively stained TEM images of ribbon-like structure of SL-3F a) in the absence b) in the presence of $\mathrm{HCl}, \mathrm{c}$ ) the photograph of formed hydrogel after addition of $\mathrm{HCl}$ into ribbon-like structure, d) High performance liquid chromatography (HPLC) profile, e) rheological behavior of formed hydrogel.

As shown in Figure S22d, the HPLC results indicate that the addition of $\mathrm{HCl}$ will not give new glyco-peptide species, namely, the SL-3F could survive in this acidic condition. However, the weakened negative charge on the surface of fibrils of SL-3F will in turn trigger the collapse of these fibrils. 


\section{The correlation between fibril association with anticancer activities}

Cell line: B16F10
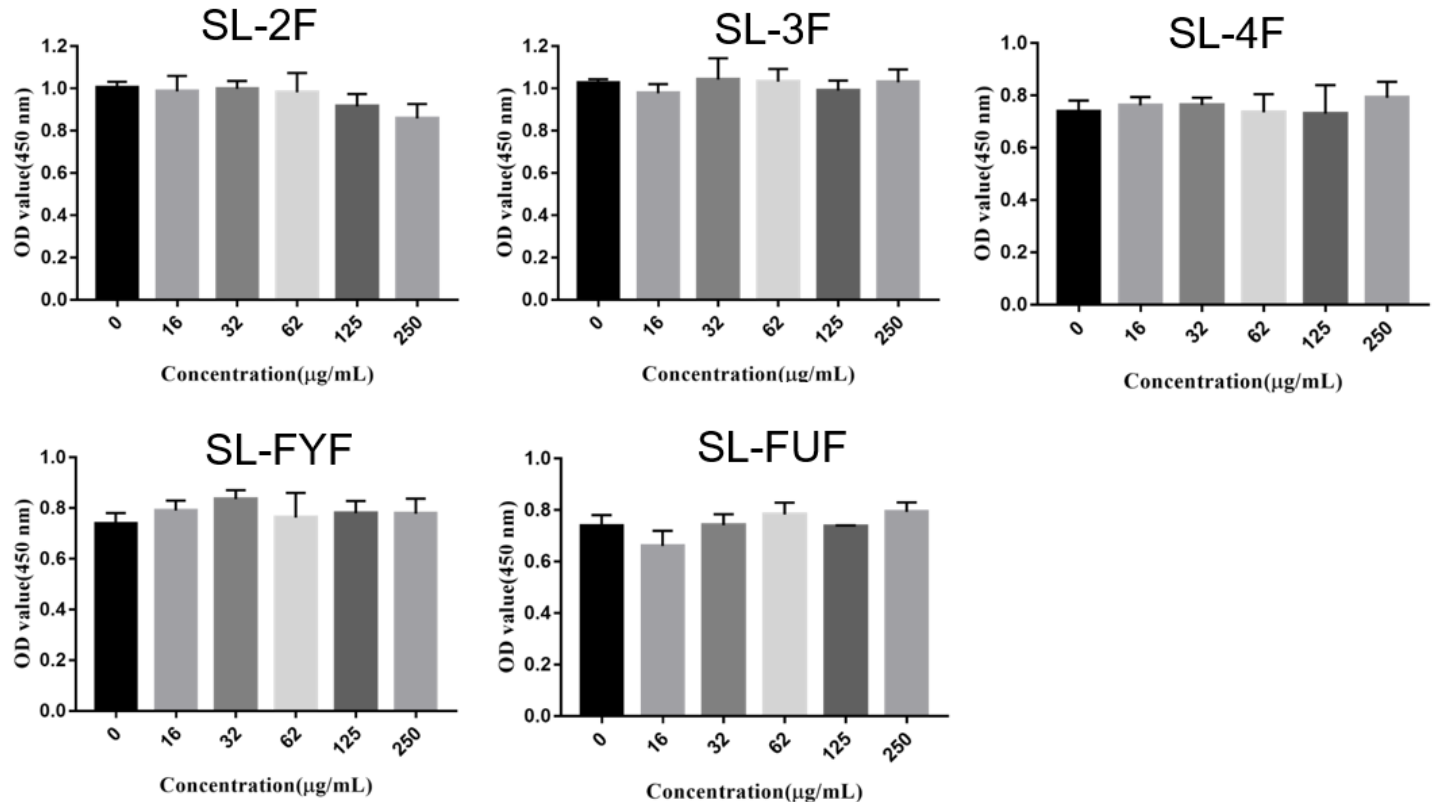

Figure S23 The cytotoxicity results of B16F10 cell line with a wider range of doses ranging between 16 and $250 \mu \mathrm{g} / \mathrm{mL}$ of diverse of fibrous species (incubation time: $48 \mathrm{~h}$ ). 
Cell line: B16F10

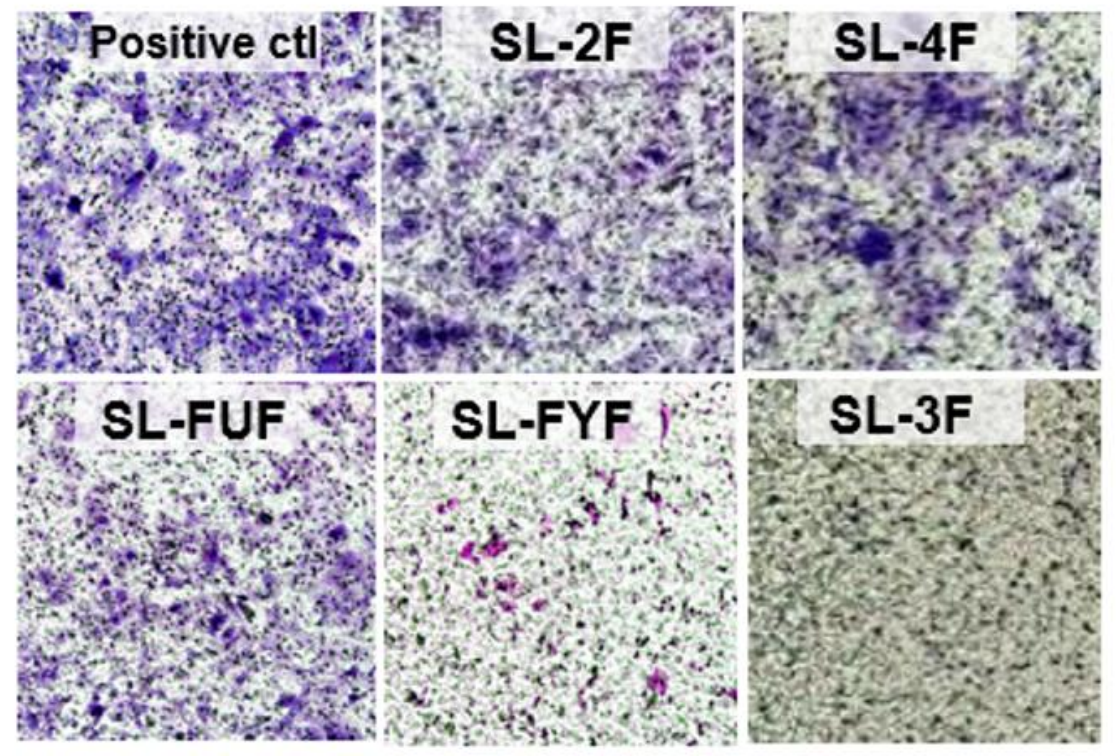

Figure S24 The trans-well assay results after incubating diverse fibrous species with B16F10 cell line for $72 \mathrm{~h}$. 

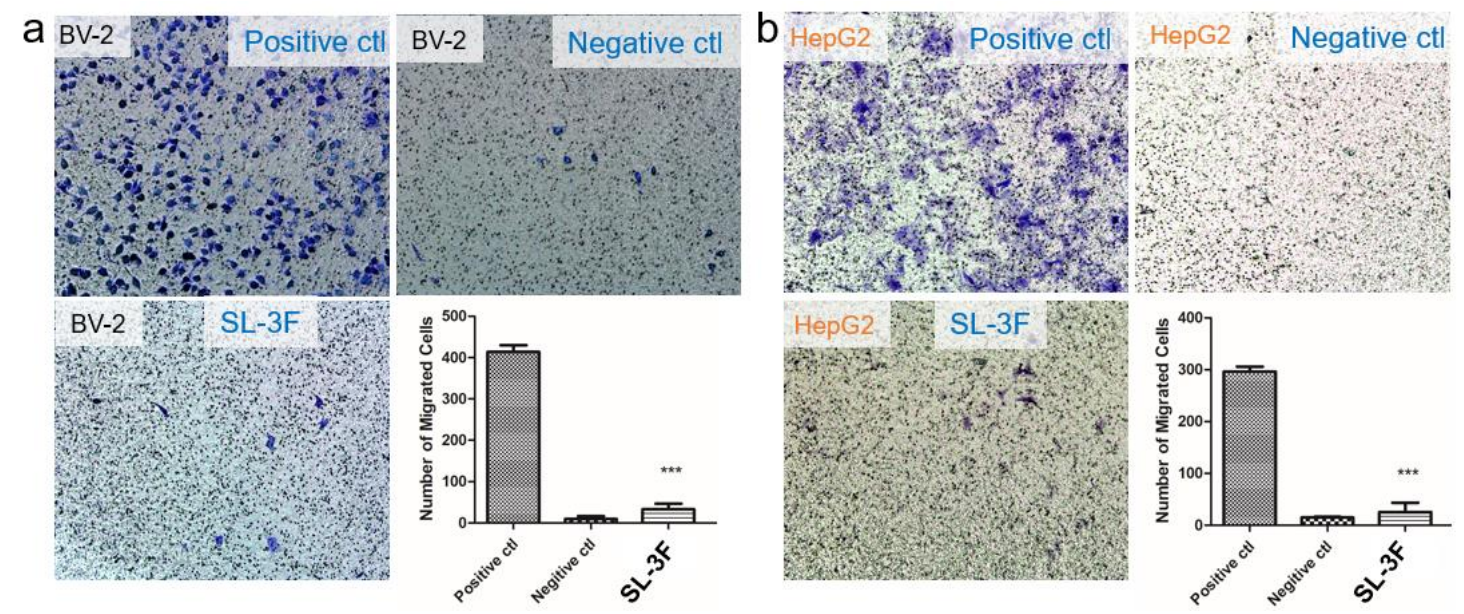

Figure S25 The trans-well assay results after incubating fibrous species of SL-3F with a) BV-2 cell line or b) HepG2 cell line for $72 \mathrm{~h}$.

Positive ctl: RPMI $1640+10 \%$ FBS (fetal bovine serum)

Negative ctl: RPMI $1640+0.5 \%$ BSA (Bovine serum albumin)

Data are presented as means \pm s.e.m. Statistical significance was calculated by Student's t-test:

${ }^{* * *} \mathrm{P}<0.001,{ }^{* *} \mathrm{P}<0.01,{ }^{*} \mathrm{P}<0.05$. 
a)
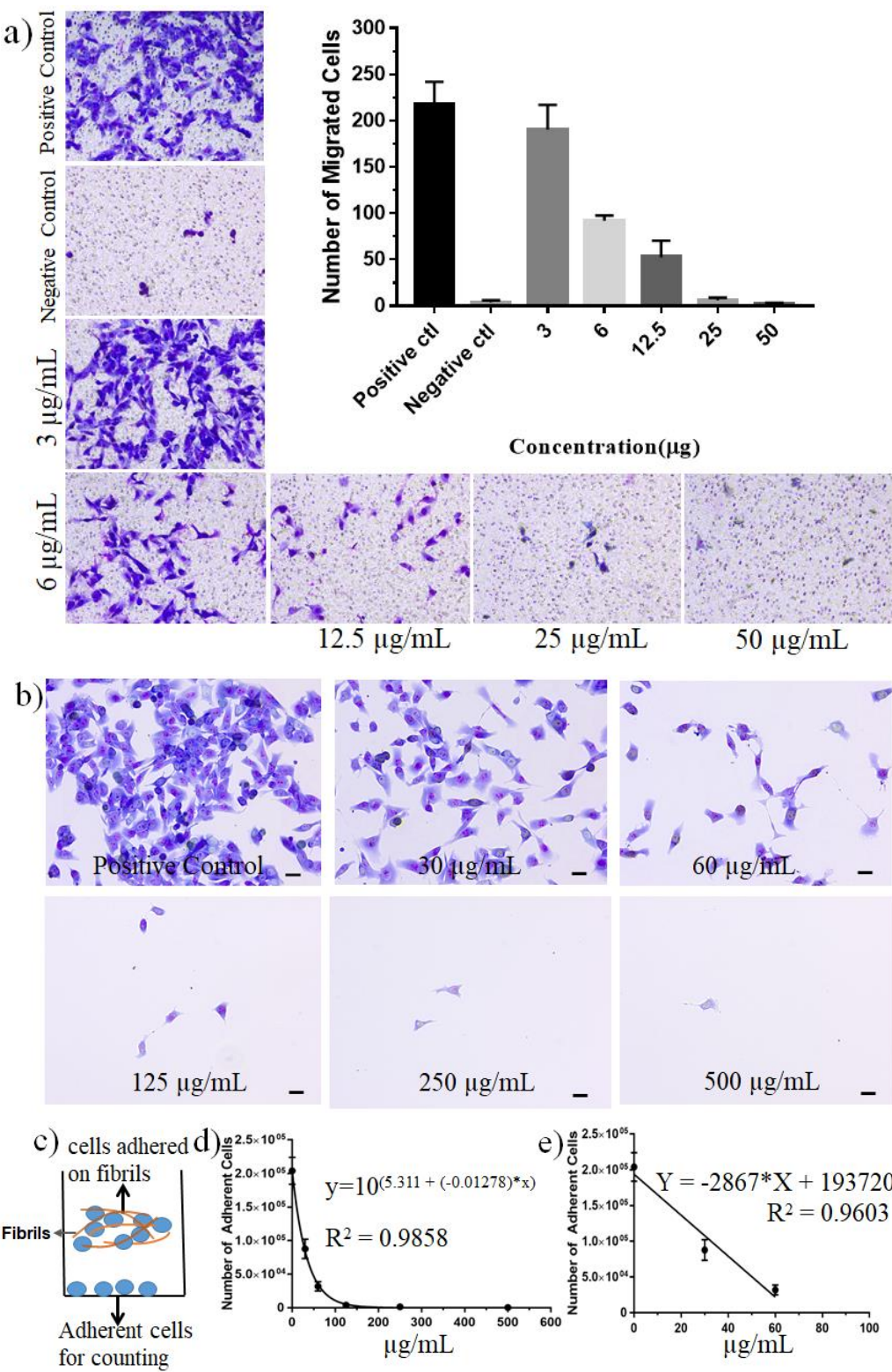

Figure S26 a) The trans-well assay results after incubating B16F10 cell line with different concentration of SL-3F fibrils, b) directly incubating B16F10 cell line with different concentration of SL-3F fibrils on 24-well plate, c) the schematic illustration for cells adhered on fibrils as well as adherent cells for counting, $d$, e) the quantitative analysis for the adhesion ability of fibrils to B16F10 cell.

B16F10 cells were seeded into 24-well cell culture plates at $2.5 \times 10^{5} / \mathrm{mL}$, different amounts of SL-3F fibrils were subsequently added, then incubated overnight. Washed $2 \mathrm{x}$ with PBS solution, then the cells were fixed with $4 \%$ paraformaldehyde for 15 minutes, washed $2 \mathrm{x}$ with PBS solution again, the cells were stained with Giemsa stain for 20 minutes, and washed $2 x$ with PBS solution. Finally, the adherent cells at the bottom were counted. 

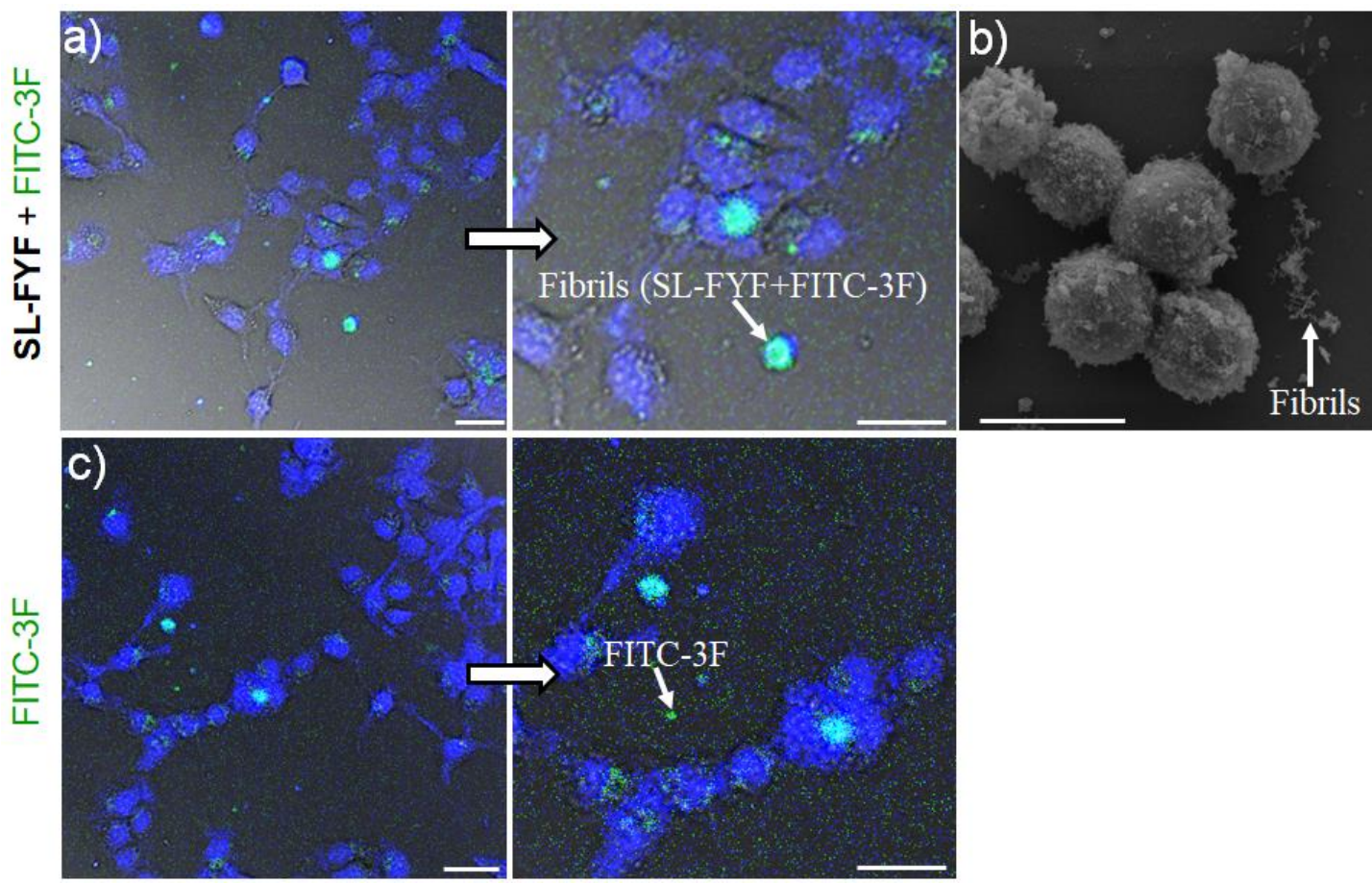

Figure S27 The visualization of interaction between SL-FYF fibrils and B16F10 cells by a) CLSM and b) FE-SEM, c) the visualization of interaction between FITC-3F and B16F10 cells by CLSM. All the scale bars are $5 \mu \mathrm{m}$. 


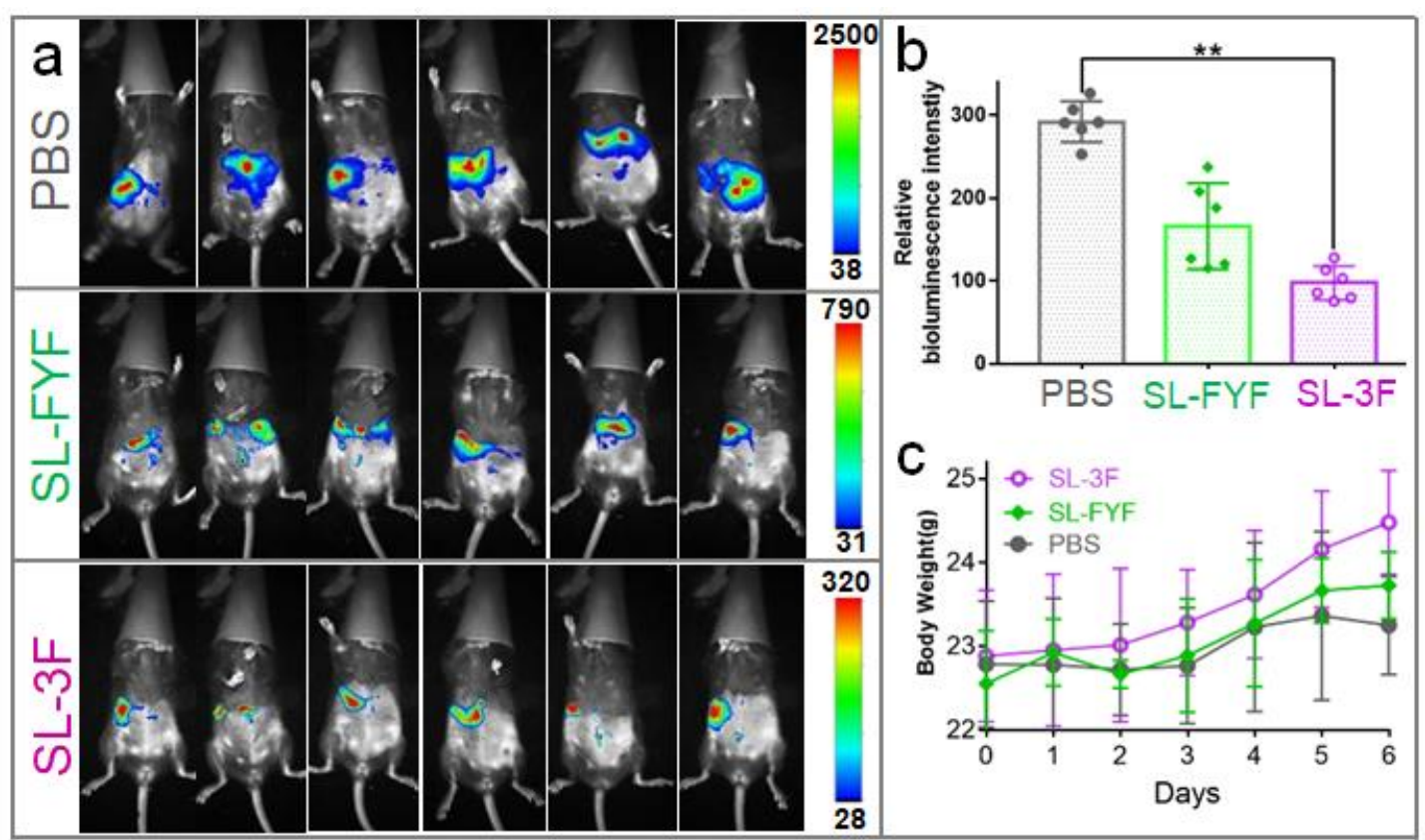

Figure S28 a) In vivo inhibition of B16F10 cell migration by fibrous species of SL-FYF as well as SL-3F. b) The quantified results of relative luminescence intensity of three sets of assays in Figure a. c) The body weight of mouse as a function of incubation time. Data are presented as means \pm s.e.m. Statistical significance was calculated by Student's t-test: $* * * \mathrm{P}<0.001, * * \mathrm{P}<0.01$, $* \mathrm{P}<0.05$.

Considering that the fibrils used here cannot be injected intravenously like ordinary drugs, the orthotopic metastasis model seems not to be suitable for the existing fibril system. Therefore, here we selected to investigate the inhibitory effect of fibrils on tumor cell migration via injecting B16F10 cells into the abdominal cavity of mice. 


\section{Synthesis and Characterization}

Synthesis of 1. Dissolved $4 \mathrm{~g}$ (15.1 mmol) Boc-protected phenylalanine, $2.44 \mathrm{~g}$ (18.0 mmol) Hydroxybenzotriazole (HOBT), and $3.46 \quad \mathrm{~g} \quad\left(\begin{array}{llll}18.0 & \mathrm{mmol}\end{array}\right)$ 1-(3-Dimethylaminopropyl)-3-ethylcarbodiimide hydrochloride (EDC) in $200 \mathrm{~mL}$ dry dichloromethane under ice bath conditions, and then added $7.5 \mathrm{~mL}(45.0 \mathrm{mmol})$ of N,N-Diisopropylethylamine (DIPEA) to the above mixed solution, and finally added $3.25 \mathrm{~g}$ (15.1 mmol) of phenylalanine methyl ester hydrochloride. The reaction mixture was stirred at $34{ }^{\circ} \mathrm{C}$ for $24 \mathrm{~h}$. Then the solvent was evaporated to $100 \mathrm{~mL}$ remaining, washed with $100 \mathrm{~mL}$ of $2 \mathrm{M}$ hydrochloric acid, $2 \mathrm{M}$ sodium hydroxide and saturated brine successively, separated and dried with anhydrous magnesium sulfate. The product was purified with 200-300 mesh silica gel column, using petroleum ether: ethyl acetate $=4: 1$ as the eluent to obtain a white solid product of $\mathbf{1}(5.23 \mathrm{~g}, 72 \%)$.

${ }^{1}$ H NMR (400 MHz, DMSO-d $\boldsymbol{d}_{\mathbf{6}}, 295$ K) 8.33 (d, $\left.J=7.6 \mathrm{~Hz}, 1 \mathrm{H}, \mathrm{NH}\right) 7.21-7.29$ (2m, $10 \mathrm{H}, \mathrm{CH}$-arom), 6.85 (d, J=8.8 Hz, 1H, NH), $4.58-4.46(\mathrm{~m}, 1 \mathrm{H}, \alpha-\mathrm{CH}), 4.25-4.13$ (m, 1H, $\alpha-\mathrm{CH}), 3.59$ (s, 3H, $\left.\mathrm{CH}_{3}\right), 3.06(\mathrm{dd}, J=13.86 .0 \mathrm{~Hz}, 1 \mathrm{H}), 2.97$ (dd, $J=13.9$ $8.5 \mathrm{~Hz}, 1 \mathrm{H}), 2.89$ (dd, $J=13.94 .4 \mathrm{~Hz}, 1 \mathrm{H}), 2.68$ (dd, $J=13.810 .5 \mathrm{~Hz}, 1 \mathrm{H}), 1.29$ (s, $9 \mathrm{H}, \mathrm{CH}_{3}$-Boc).<smiles>COC(=O)C(Cc1ccccc1)NC(=O)[C@H](Cc1ccccc1)NC(=O)OCc1ccccc1</smiles>

Synthesis of 2. Dissolved $1.4 \mathrm{~g}$ (3.3 mmol) of compound 1 in $30 \mathrm{~mL}$ dichloromethane, then added $7.35 \mathrm{~mL}(98.4 \mathrm{mmol})$ of trifluoroacetic acid, stirred at room temperature $\left(34{ }^{\circ} \mathrm{C}\right.$ ) for $3 \mathrm{~h}$, removed the solvent under reduced pressure to obtain a white solid product of $2(1.42 \mathrm{~g}, 98 \%)$.

${ }^{1}$ H NMR (400 MHz, DMSO-d $\left.\boldsymbol{d}_{\mathbf{6}}, 295 \mathrm{~K}\right) \delta 9.01$ (d, $\left.J=7.63 \mathrm{~Hz}, 1 \mathrm{H}, \mathrm{NH}\right), 8.15$ (br s, $3 \mathrm{H}, \mathrm{NH}_{3}$ ), $7.36-7.22$ (m, 10H, CH-arom), 4.58 (m, $\left.1 \mathrm{H}, \alpha-\mathrm{CH}\right), 4.05$ (br s, $1 \mathrm{H}, \alpha-\mathrm{CH}$ ), 3.61 (s, 3H, $\mathrm{CH}_{3}$ ), 3.16-3.04 (m, 2H, $\mathrm{CH}_{2}-\mathrm{Phe}$ ), 3.02 - 2.89 (m, 2H, $\mathrm{CH}_{2}-\mathrm{Phe}$ ).<smiles>COCO[C@@H](C)NC(Cc1ccccc1)C(=O)NC(Cc1ccccc1)C(=O)OC</smiles>

Synthesis of 3. Dissolved $1.1 \mathrm{~g}$ of Boc-protected phenylalanine $(4.1 \mathrm{mmol}), 0.66 \mathrm{~g}$ (4.9 mmol) of HOBT, and $0.94 \mathrm{~g}$ of EDC (4.9 mmol) in $50 \mathrm{~mL}$ dry dichloromethane 
under ice bath conditions, and then added $2.0 \mathrm{~mL}(12.3 \mathrm{mmol})$ of DIPEA to the above mixed solution, and finally added $1.8 \mathrm{~g}(4.1 \mathrm{mmol})$ of compound 2 . The reaction mixture was stirred at $34{ }^{\circ} \mathrm{C}$ for $24 \mathrm{~h}$. Then the solvent was evaporated to $30 \mathrm{~mL}$ remaining, washed with $30 \mathrm{~mL}$ of $2 \mathrm{M}$ hydrochloric acid, $2 \mathrm{M}$ sodium hydroxide and saturated brine successively, separated and dried with anhydrous magnesium sulfate. The product was purified with a 200-300 mesh silica gel column, using dichloromethane: ethyl acetate $=20: 1$ as the eluent to obtain a white solid product of $3(1.68 \mathrm{~g}, 71 \%)$.

${ }^{1}$ H NMR (400 MHz, DMSO-d ${ }_{6}, 296$ K) $\delta 8.58(\mathrm{~d}, J=7.4 \mathrm{~Hz}, 1 \mathrm{H}), 7.94(\mathrm{~d}, J=8.3$ $\mathrm{Hz}, 1 \mathrm{H}), 7.30-7.15(\mathrm{~m}, 15 \mathrm{H}), 6.88(\mathrm{~d}, J=8.9 \mathrm{~Hz}, 1 \mathrm{H}), 4.59(\mathrm{~m}, 1 \mathrm{H}, \alpha-\mathrm{CH}), 4.50(\mathrm{~m}$, $1 \mathrm{H}, \alpha-\mathrm{CH}), 4.13-4.01(\mathrm{~m}, 1 \mathrm{H}, \alpha-\mathrm{CH}), 3.58\left(\mathrm{~s}, 3 \mathrm{H}, \mathrm{CH}_{3}\right), 3.07-2.92(\mathrm{~m}, 3 \mathrm{H})$, 2.84-2.73 (m, 2H), 2.59 (d, $J=13.9 \mathrm{~Hz}, 1 \mathrm{H}), 1.27$ (s, 9H).

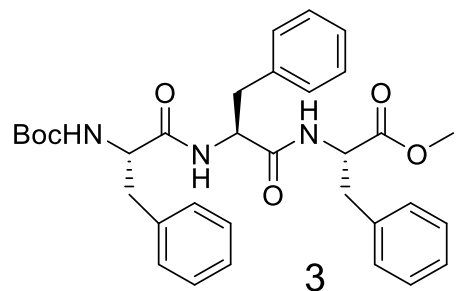

Synthesis of 4. $1.4 \mathrm{~g}$ ( $3.3 \mathrm{mmol})$ of compound 1 was dissolved in $10 \mathrm{~mL}$ of ethyl acetate, and $30 \mathrm{~mL}$ of ethyl acetate hydrochloric acid solution was added dropwise under ice bath conditions. After about 20 minutes, a large amount of white precipitate appeared. After suction filtration, acetic acid ethyl ester was used to wash product, finally obtained white solid of $4(1.27 \mathrm{~g}, 94 \%)$.

${ }^{1}$ H NMR (400 MHz, DMSO-d $\left.\mathbf{d}_{\mathbf{6}}, 295 \mathrm{~K}\right) \delta 12.79(\mathrm{~s}, 1 \mathrm{H}), 8.11(\mathrm{~d}, J=7.9 \mathrm{~Hz}, 1 \mathrm{H})$, $7.29-7.22(\mathrm{~m}, 10 \mathrm{H}), 6.88(\mathrm{~d}, J=8.8 \mathrm{~Hz}, 1 \mathrm{H}), 4.48(\mathrm{td}, J=8.1,5.2 \mathrm{~Hz}, 1 \mathrm{H}), 4.17$ (ddd, $J=10.4,8.7,4.0 \mathrm{~Hz}, 1 \mathrm{H}), 3.09(\mathrm{dd}, J=13.9,5.2 \mathrm{~Hz}, 1 \mathrm{H}), 2.97-2.90(\mathrm{~m}, 2 \mathrm{H})$, $2.64(\mathrm{dd}, J=13.9,10.6 \mathrm{~Hz}, 1 \mathrm{H}), 1.27(\mathrm{~s}, 9 \mathrm{H})$.

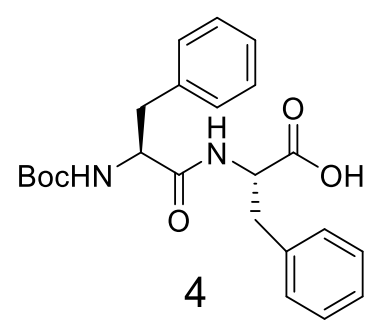

Synthesis of $5.1 .8 \mathrm{~g}$ of compound $4(4.4 \mathrm{mmol}), 0.71 \mathrm{~g}(5.2 \mathrm{mmol})$ of HOBT, $1.0 \mathrm{~g}$ of EDC (5.23 mmol) were dissolved in $50 \mathrm{~mL}$ dry dichloromethane under ice bath conditions, and then $2.2 \mathrm{~mL}$ ( $13.1 \mathrm{mmol}$ ) DIPEA was added to the above mixed solution, and finally $1.5 \mathrm{~g}(3.4 \mathrm{mmol})$ of compound 2 was added. The reaction mixture was stirred at $34{ }^{\circ} \mathrm{C}$ for $24 \mathrm{~h}$. Then the solvent was evaporated to $30 \mathrm{~mL}$ remaining, washed with $30 \mathrm{~mL}$ of $2 \mathrm{M}$ hydrochloric acid, $2 \mathrm{M}$ sodium hydroxide and 
saturated brine successively, separated and dried with anhydrous magnesium sulfate. The product was purified with a 200-300 mesh silica gel column, using dichloromethane: ethyl acetate $=5: 1$ as the eluent to obtain a white solid product of 5 $(2.15 \mathrm{~g}, 68 \%)$.

${ }^{1}$ H NMR (400 MHz, DMSO-d $\left.\boldsymbol{d}_{\mathbf{6}}, 295 \mathrm{~K}\right) \delta 8.54(\mathrm{~d}, J=7.4 \mathrm{~Hz}, 1 \mathrm{H}), 8.22(\mathrm{~d}, J=8.2$ $\mathrm{Hz}, 1 \mathrm{H}), 7.85(\mathrm{~d}, J=8.3 \mathrm{~Hz}, 1 \mathrm{H}), 7.28-7.15(\mathrm{~m}, 20 \mathrm{H}), 6.88(\mathrm{~d}, J=8.9 \mathrm{~Hz}, 1 \mathrm{H}), 4.55$ (m, 3H), 4.07 (m, 1H), $3.58(\mathrm{~s}, 3 \mathrm{H}), 3.04-2.93(\mathrm{~m}, 4 \mathrm{H}), 2.81-2.73(\mathrm{~m}, 3 \mathrm{H}), 2.67$ (m, $1 \mathrm{H}), 1.24(\mathrm{~s}, 9 \mathrm{H})$.<smiles>COC(=O)[C@H](Cc1ccccc1)NC(=O)[C@H](Cc1ccccc1)NC(=O)[C@H](Cc1ccccc1)NC(=O)[C@H](Cc1ccccc1)NC(=O)[O-]</smiles>

Synthesis of $\mathbf{6}$ and 7. The synthesis method of $\mathbf{6}$ and $\mathbf{7}$ was very similar to that of $\mathbf{1}$ and 4. Finally obtained white solid of $6(0.86 \mathrm{~g}, 58 \%)$ and $7(0.83 \mathrm{~g}, 96 \%)$.
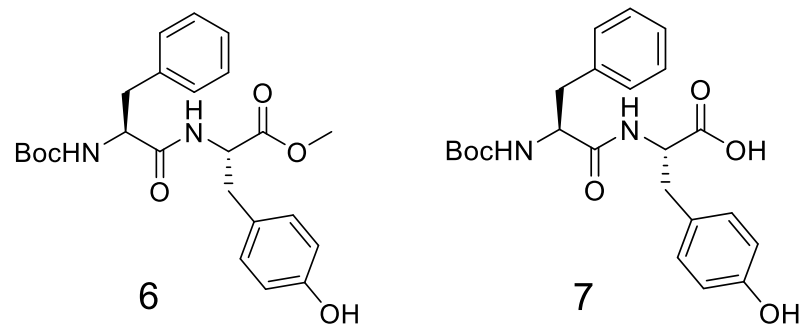

Synthesis of 8. $1.84 \mathrm{~g}$ of compound 7 (4.3 mmol), $0.68 \mathrm{~g}(5.1 \mathrm{mmol})$ of HOBT, $0.97 \mathrm{~g}$ of EDC $(5.1 \mathrm{mmol})$ were dissolved in $60 \mathrm{~mL}$ of dry dichloromethane under ice bath conditions, and then $2.2 \mathrm{~mL}(13.0 \mathrm{mmol})$ of DIPEA was added to the above mixed solution, and finally $0.91 \mathrm{~g}(4.3 \mathrm{mmol})$ of phenylalanine methyl ester hydrochloride was added. The reaction mixture was stirred at $32{ }^{\circ} \mathrm{C}$ for $24 \mathrm{~h}$. Then the solvent was evaporated to $30 \mathrm{~mL}$ remaining, washed with $30 \mathrm{~mL}$ of $2 \mathrm{M}$ hydrochloric acid, $2 \mathrm{M}$ sodium hydroxide and saturated brine successively, separated and dried with anhydrous magnesium sulfate. The product was purified with 200-300 mesh silica gel column, using dichloromethane: ethyl acetate $=4: 1$ as the eluent to obtain a white solid product of $8(1.66 \mathrm{~g}, 64 \%)$.

${ }^{1}$ H NMR (400 MHz, DMSO-d $\boldsymbol{d}_{\mathbf{6}}, 295$ K) $\delta 9.14(\mathrm{~s}, 1 \mathrm{H}), 8.49(\mathrm{~d}, 1 \mathrm{H}), 7.84-7.81(\mathrm{~d}$, 1H), $7.27-7.18(\mathrm{~m}, 12 \mathrm{H}), 7.02-7.00(\mathrm{~m}, 2 \mathrm{H}), 6.87(\mathrm{~d}, J=8.8 \mathrm{~Hz}, 1 \mathrm{H}), 6.65-6.62$ $(\mathrm{d}, 2 \mathrm{H}), 4.59-4.44(\mathrm{~m}, 2 \mathrm{H}, \alpha-\mathrm{CH}), 4.13-4.07(\mathrm{~m}, 1 \mathrm{H}, \alpha-\mathrm{CH}), 3.58\left(\mathrm{~s}, 3 \mathrm{H}, \mathrm{CH}_{3}\right)$, $3.07-2.91(\mathrm{~m}, 4 \mathrm{H}), 2.88-2.58(\mathrm{~m}, 2 \mathrm{H}), 1.28(\mathrm{~s}, 9 \mathrm{H})$. 


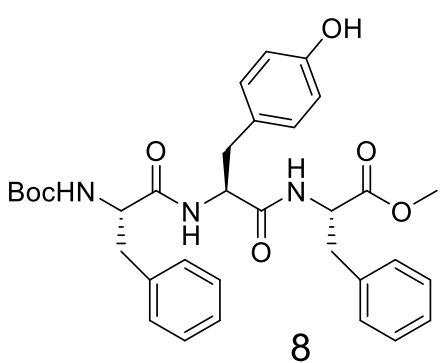

Synthesis of 9 and 10. The synthesis method of 9 and $\mathbf{1 0}$ was very similar to that of $\mathbf{1}$ and 2. Finally obtained white solid of $\mathbf{9}(1.07 \mathrm{~g}, 63 \%)$ and $\mathbf{1 0}(1.01 \mathrm{~g}, 94 \%)$.
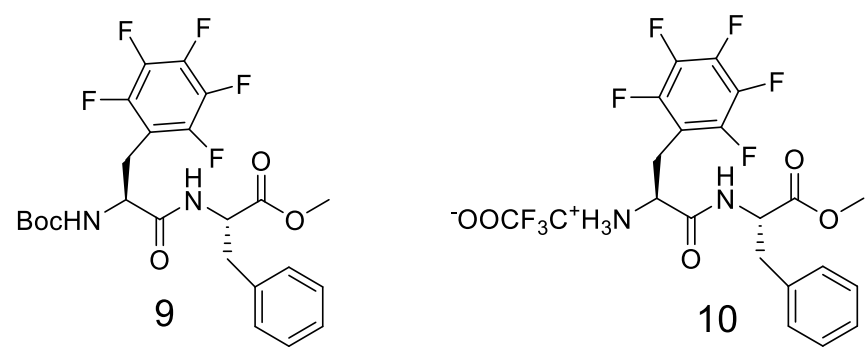

Synthesis of 11. Dissolved $0.83 \mathrm{~g}$ of Boc-protected phenylalanine $(3.1 \mathrm{mmol}), 0.49 \mathrm{~g}$ ( $3.7 \mathrm{mmol})$ of HOBT, and $0.71 \mathrm{~g}$ of EDC $(3.7 \mathrm{mmol})$ in $40 \mathrm{~mL}$ dry dichloromethane under ice bath conditions, and then added $1.5 \mathrm{~mL}(9.2 \mathrm{mmol})$ of DIPEA to the above mixed solution, and finally added $1.6 \mathrm{~g}(3.1 \mathrm{mmol})$ of compound $\mathbf{1 0}$. The reaction mixture was stirred at $34{ }^{\circ} \mathrm{C}$ for $24 \mathrm{~h}$. Then the solvent was evaporated to $30 \mathrm{~mL}$ remaining, washed with $25 \mathrm{~mL}$ of $2 \mathrm{M}$ hydrochloric acid, $2 \mathrm{M}$ sodium hydroxide and saturated brine successively, separated and dried with anhydrous magnesium sulfate. The product was purified with a 200-300 mesh silica gel column, using dichloromethane: ethyl acetate $=30: 1$ as the eluent to obtain a white solid product of $11(1.19 \mathrm{~g}, 58 \%)$.

${ }^{1}$ H NMR (400 MHz, DMSO-d 6 , 296 K) $\delta 8.69(\mathrm{~d}, J=7.7 \mathrm{~Hz}, 1 \mathrm{H}), 8.17(\mathrm{~d}, J=8.7$ $\mathrm{Hz}, 1 \mathrm{H}), 7.26-7.16(\mathrm{~m}, 10 \mathrm{H}), 6.89(\mathrm{~d}, J=8.5 \mathrm{~Hz}, 1 \mathrm{H}), 4.71(\mathrm{~m}, 1 \mathrm{H}, \alpha-\mathrm{CH}), 4.52(\mathrm{~m}$, $1 \mathrm{H}, \alpha-\mathrm{CH}), 4.06-4.02(\mathrm{~m}, 1 \mathrm{H}, \alpha-\mathrm{CH}), 3.58(\mathrm{~s}, 3 \mathrm{H}), 3.04-2.98(\mathrm{~m}, 2 \mathrm{H}), 2.97-2.86$ (m, 2H), $2.78(\mathrm{dd}, J=13.8,3.6 \mathrm{~Hz}, 1 \mathrm{H}), 2.64-2.58(\mathrm{~m}, 1 \mathrm{H}), 1.25(\mathrm{~s}, 9 \mathrm{H})$.

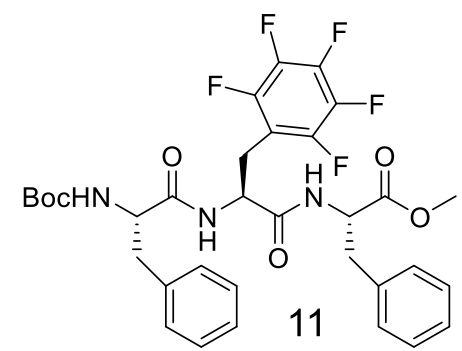

Synthesis of 12, 13, 14, 15 and 16. The synthesis methods of 12, 13, 14, 15 and 16 are highly similar. The typical synthesis process was as follows: The corresponding oligopeptide such as $\mathbf{1}, \mathbf{3}, \mathbf{5}, \mathbf{8}$ or $\mathbf{1 1}$ was dissolved in methanol or a mixed solvent of methanol and dichloromethane to obtain a transparent solution. Then added 20 times 
equivalent of $98 \%$ hydrazine hydrate to the above transparent solution. Generally, a large amount of white precipitate will appear after stirring for 5 minutes. The obtained white solid was filtered with suction, washed with water, and finally lyophilized to obtain the corresponding white powder of 12, 13, 14, 15 and 16 (all the yields approached $98 \%)$.

12: ${ }^{1}$ H NMR (400 MHz, DMSO-d 6 , 296 K) $\delta 9.17$ (s, 1H), $7.99(\mathrm{~d}, J=8.3 \mathrm{~Hz}, 1 \mathrm{H})$, $7.21-7.15(\mathrm{~m}, 10 \mathrm{H}), 6.90(\mathrm{~d}, J=8.5 \mathrm{~Hz}, 1 \mathrm{H}), 4.51-4.47(\mathrm{~m}, 1 \mathrm{H}), 4.22(\mathrm{~s}, 2 \mathrm{H}), 4.14$ $-4.08(\mathrm{~m}, 1 \mathrm{H}), 2.97-2.92(\mathrm{~m}, 1 \mathrm{H}), 2.86-2.80(\mathrm{~m}, 2 \mathrm{H}), 2.66-2.60(\mathrm{~m}, 1 \mathrm{H}), 1.29$ (s, $9 \mathrm{H})$.

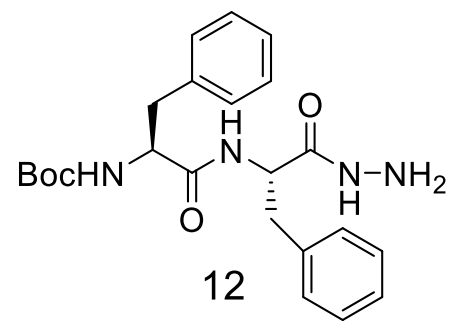

13: ${ }^{1}$ H NMR (400 MHz, DMSO-d $\left.\mathbf{d}_{\mathbf{6}}, 295 \mathrm{~K}\right) \delta 9.14(\mathrm{~s}, 1 \mathrm{H}), 8.27(\mathrm{~d}, J=8.3 \mathrm{~Hz}, 1 \mathrm{H})$, $7.88(\mathrm{~d}, J=8.6 \mathrm{~Hz}, 1 \mathrm{H}), 7.25-7.18(\mathrm{~m}, 15 \mathrm{H}), 6.90(\mathrm{~d}, J=8.9 \mathrm{~Hz}, 1 \mathrm{H}), 4.56-4.55$ (m, 1H), $4.49-4.48(\mathrm{~m}, 1 \mathrm{H}), 4.22(\mathrm{~s}, 2 \mathrm{H}), 4.11-4.07(\mathrm{~m}, 1 \mathrm{H}), 3.03-2.89(\mathrm{~m}, 2 \mathrm{H})$, 2.87-2.73 (m, 3H), $2.60(\mathrm{dd}, J=13.810 .6 \mathrm{~Hz}, 1 \mathrm{H}), 1.27$ (s, 9H).

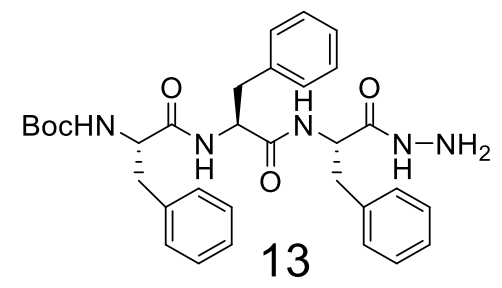

14: ${ }^{1}$ H NMR (400 MHz, DMSO-d 6 , 295 K) $\delta 9.11(\mathrm{~s}, 1 \mathrm{H}), 8.20(\mathrm{~d}, J=8.2 \mathrm{~Hz}, 1 \mathrm{H})$, $8.14(\mathrm{~d}, J=8.2 \mathrm{~Hz}, 1 \mathrm{H}), 7.87(\mathrm{~d}, J=8.3 \mathrm{~Hz}, 1 \mathrm{H}), 7.24-7.16(\mathrm{~m}, 20 \mathrm{H}), 6.86(\mathrm{~d}, J=$ $8.2 \mathrm{~Hz}, 1 \mathrm{H}), 4.63-4.44(\mathrm{~m}, 3 \mathrm{H}), 4.21(\mathrm{~s}, 1 \mathrm{H}), 4.09-4.08(\mathrm{~m}, 1 \mathrm{H}), 3.00-2.90(\mathrm{~m}$, $3 \mathrm{H}), 2.89-2.71(\mathrm{~m}, 4 \mathrm{H}), 2.58(\mathrm{dd}, J=14.010 .6 \mathrm{~Hz}, 1 \mathrm{H}), 1.27(\mathrm{~s}, 9 \mathrm{H})$.

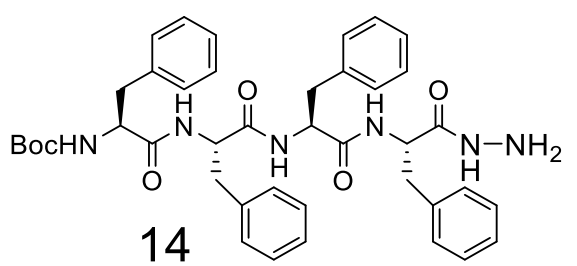

15: ${ }^{1}$ H NMR (400 MHz, DMSO-d 6 , 295 K) $\delta 9.12(\mathrm{~s}, 1 \mathrm{H}), 8.18(\mathrm{~d}, J=8.5 \mathrm{~Hz}, 1 \mathrm{H})$, $7.78(\mathrm{~d}, J=8.3 \mathrm{~Hz}, 1 \mathrm{H}), 7.25-7.17(\mathrm{~m}, 12 \mathrm{H}), 6.98(\mathrm{~d}, J=8.5 \mathrm{~Hz}, 2 \mathrm{H}), 6.90(\mathrm{~d}, J=8.8$ $\mathrm{Hz}, 1 \mathrm{H}), 6.62(\mathrm{~d}, J=8.5 \mathrm{~Hz}, 2 \mathrm{H}), 4.50-4.42(\mathrm{~m}, 2 \mathrm{H}), 4.21(\mathrm{~s}, 2 \mathrm{H}), 4.11-4.08(\mathrm{~m}, 1 \mathrm{H})$, 2.94(dd, $J=13.75 .8 \mathrm{~Hz}, 1 \mathrm{H}), 2.89-2.76(\mathrm{~m}, 3 \mathrm{H}), 2.71-2.57(\mathrm{~m}, 2 \mathrm{H}), 1.28(\mathrm{~s}, 9 \mathrm{H})$. 


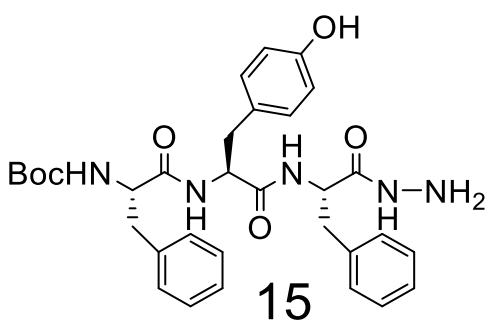

16: ${ }^{1}$ H NMR (400 MHz, DMSO- $\left.\boldsymbol{d}_{6}, 295 \mathrm{~K}\right) \delta 8.88(\mathrm{~s}, 1 \mathrm{H}), 7.94(\mathrm{~s}, 1 \mathrm{H}), 7.76(\mathrm{~s}, 1 \mathrm{H})$, $7.33-7.16(\mathrm{~m}, 10 \mathrm{H}), 6.01(\mathrm{~s}, 1 \mathrm{H}), 4.58-4.40(\mathrm{~m}, 2 \mathrm{H}), 4.09(\mathrm{~s}, 1 \mathrm{H}), 3.22-3.02(\mathrm{~m}$, $4 \mathrm{H}), 2.80(\mathrm{~d}, \mathrm{~J}=12.3 \mathrm{~Hz}, 1 \mathrm{H}), 1.27(\mathrm{~s}, 9 \mathrm{H})$.

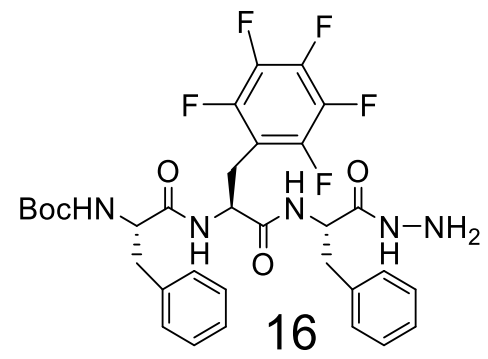

Synthesis of SL-3F. $0.4 \mathrm{~g}(0.69 \mathrm{mmol})$ of compound 13 and $0.45 \mathrm{~g}(0.68 \mathrm{mmol})$ of $(2,3)$ sialyllactose were dissolved in $8 \mathrm{~mL}$ of anhydrous methanol, and $0.11 \mathrm{~g}$ of yttrium trifluoromethanesulfonate $(0.21 \mathrm{mmol})$ was added, the reaction mixture was stirred at $50{ }^{\circ} \mathrm{C}$ under nitrogen protection for $48 \mathrm{~h}$. Then the solvent was removed under reduced pressure, and the product was purified with a 200-300 mesh silica gel column, using dichloromethane:methanol $=2: 3$ as the eluent to obtain a white solid product of SL-3F (0.48 g, 59\%).

${ }^{1}$ H NMR (400 MHz, DMSO-d $\left.\mathbf{d}_{\mathbf{6}}, 295 \mathrm{~K}\right) \delta 9.63(\mathrm{~d}, 1 \mathrm{H}), 8.37$ (d, $\left.J=8.6 \mathrm{~Hz}, 1 \mathrm{H}\right), 8.17$ $(\mathrm{s}, 1 \mathrm{H}), 7.87(\mathrm{~d}, 1 \mathrm{H}), 7.26-7.16(\mathrm{~m}, 15 \mathrm{H}), 6.90(\mathrm{~d}, J=8.9,1 \mathrm{H}), 5.73-5.65(\mathrm{~m}, 1 \mathrm{H})$, $5.15(\mathrm{~d}, J=3.6 \mathrm{~Hz}, 1 \mathrm{H}), 4.89(\mathrm{~d}, J=6.0,1 \mathrm{H}), 4.72(\mathrm{~d}, J=5.8,1 \mathrm{H}), 4.63-4.48(\mathrm{~m}$, $7 \mathrm{H}), 4.42(\mathrm{~s}, 1 \mathrm{H}), 4.35(\mathrm{t}, J=5.7,1 \mathrm{H}), 4.28(\mathrm{t}, J=5.4,1 \mathrm{H}), 4.18-4.11(\mathrm{~m}, 1 \mathrm{H}), 4.11$ $-4.03(\mathrm{~m}, 1 \mathrm{H}), 4.02-3.93(\mathrm{~m}, 1 \mathrm{H}), 3.81-3.72(\mathrm{~m}, 2 \mathrm{H}), 3.70(\mathrm{~s}, 1 \mathrm{H}), 3.66-3.54(\mathrm{~m}$, $7 \mathrm{H}), 3.53-3.42(\mathrm{~m}, 4 \mathrm{H}), 3.22-3.17(\mathrm{~m}, 4 \mathrm{H}), 3.03-3.00(\mathrm{~m}, 2 \mathrm{H}), 2.95-2.90(\mathrm{~m}$, 1H), $2.89-2.85(\mathrm{~m}, 1 \mathrm{H}), 2.84-2.73(\mathrm{~m}, 4 \mathrm{H}), 2.64-2.57(\mathrm{~m}, 1 \mathrm{H}), 1.90(\mathrm{~s}, 3 \mathrm{H}), 1.26$ $(\mathrm{s}, 9 \mathrm{H})$.

${ }^{13}$ C NMR (100 MHz, DMSO-d6) $\delta$ 172.79, 171.66, 171.06, 170.82, 170.73, 155.44, $138.56,137.79,137.58,129.84,129.66,129.56,128.55,128.49,128.40,126.79$, $126.68,126.54,104.69,100.12,90.97,81.53,78.54,76.56,76.36,75.31,73.71,71.65$, $71.20,70.24,68.98,67.72,67.12,63.84,61.14,60.74,56.33,53.67,53.42,52.71$, 42.48, 38.46, 38.27, 37.99, 28.56, 28.15, 22.98.

Maldi-tof (THAP, Methanol) $(\mathbf{m} / \mathbf{z})$ : calculated for $\left[\mathrm{C}_{55} \mathrm{H}_{76} \mathrm{~N}_{6} \mathrm{O}_{23}+\mathrm{Na}\right]^{+}=1212.23$; found: 1212.41

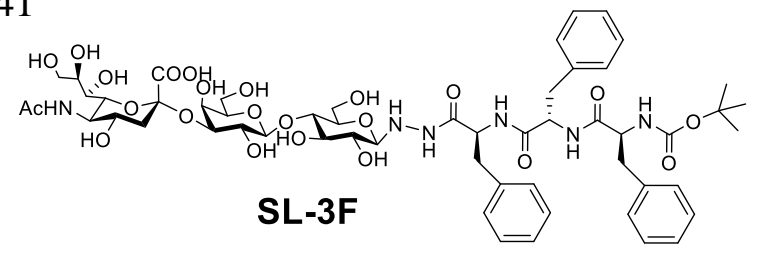


Synthesis of SL-4F. $0.3 \mathrm{~g}(0.42 \mathrm{mmol})$ of compound 14 and $0.27 \mathrm{~g}(0.42 \mathrm{mmol})$ of $(2,3)$ sialyllactose were dissolved in $6 \mathrm{~mL}$ of anhydrous methanol, and $0.067 \mathrm{~g}$ of yttrium triflate $(0.13 \mathrm{mmol})$ was added, the reaction mixture was stirred at $60{ }^{\circ} \mathrm{C}$ under nitrogen protection for $48 \mathrm{~h}$. Then the solvent was removed under reduced pressure, and the product was purified with a 200-300 mesh silica gel column, using dichloromethane:methanol $=2: 3$ as the eluent to get a white solid product of SL-4F $(0.24 \mathrm{~g}, 42 \%)$.

${ }^{1}$ H NMR (400 MHz, DMSO-d ${ }_{6}, 295$ K) $\delta 9.61(\mathrm{~d}, 1 \mathrm{H}), 8.30(\mathrm{~d}, J=8.1 \mathrm{~Hz}, 1 \mathrm{H}), 8.16$ $(\mathrm{d}, J=8.0 \mathrm{~Hz}, 1 \mathrm{H}), 8.08(\mathrm{~s}, 1 \mathrm{H}), 7.85(\mathrm{~d}, J=8.8 \mathrm{~Hz}, 1 \mathrm{H}), 7.35-7.09$ (m, 20H), 6.86 $(\mathrm{d}, J=8.8 \mathrm{~Hz}, 1 \mathrm{H}), 5.66(\mathrm{~s}, 1 \mathrm{H}), 5.18-5.13(\mathrm{~m}, 1 \mathrm{H}), 4.84(\mathrm{~m}, 1 \mathrm{H}), 4.72(\mathrm{~m}, 1 \mathrm{H})$, $4.68-4.65(\mathrm{~m}, 2 \mathrm{H}), 4.62-4.58(\mathrm{~m}, 3 \mathrm{H}), 4.54-4.52(\mathrm{~d}, 3 \mathrm{H}), 4.44(\mathrm{~s}, 1 \mathrm{H}), 4.35-4.31$ $(\mathrm{m}, 1 \mathrm{H}), 4.26(\mathrm{t}, 1 \mathrm{H}), 4.19-4.16(\mathrm{~m}, 1 \mathrm{H}), 4.11-4.05(\mathrm{~m}, 1 \mathrm{H}), 3.98-3.95(\mathrm{~d}, 1 \mathrm{H})$, $3.85-3.83(\mathrm{~m}, 1 \mathrm{H}), 3.72(\mathrm{~s}, 3 \mathrm{H}), 3.68-3.56(\mathrm{~m}, 6 \mathrm{H}), 3.52-3.46(\mathrm{~m}, 4 \mathrm{H}), 3.41-3.36$ $(\mathrm{m}, 2 \mathrm{H}), 3.28-3.13(\mathrm{~m}, 4 \mathrm{H}), 3.00-2.86(\mathrm{~m}, 4 \mathrm{H}), 2.83-2.68(\mathrm{~m}, 4 \mathrm{H}), 2.8(\mathrm{dd}, J=$ 14.0, $10.9 \mathrm{~Hz}, 1 \mathrm{H}), 1.90(\mathrm{~s}, 3 \mathrm{H}), 1.26(\mathrm{~s}, 9 \mathrm{H})$.

${ }^{13}$ C NMR (100 MHz, DMSO-d6) $\delta$ 174.80, 173.02, 172.83, 172.77, 171.86, 155.90, $138.09,137.33,130.34,130.29,129.49,127.73,105.03,99.44,82.13,79.40,78.63$, $77.00,76.95,75.13,74.75,74.05,72.99,72.23,72.12,70.06,68.80,67.85,63.25$, 62.80, 61.74, 55.19, 54.68, 53.43, 52.73, 39.93, 38.44, 38.27, 38.06, 28.10, 22.61.

Maldi-tof (THAP, Methanol) $(\mathbf{m} / \mathbf{z})$ : calculated for $\left[\mathrm{C}_{64} \mathrm{H}_{85} \mathrm{~N}_{7} \mathrm{O}_{24}+\mathrm{Na}\right]^{+}=1359.41$; found:1359.62.

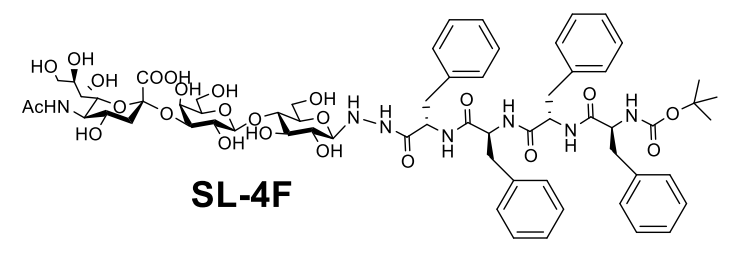

Synthesis of SL-2F. Dissolved $0.20 \mathrm{~g}(0.47 \mathrm{mmol})$ of compound 12 and $0.20 \mathrm{~g}(0.31$ mmol) of $(2,3)$ sialyllactose in $4 \mathrm{~mL}$ of anhydrous methanol, and added $0.074 \mathrm{~g}$ of yttrium trifluoromethanesulfonate $(0.14 \mathrm{mmol})$, the reaction mixture was stirred at $32{ }^{\circ} \mathrm{C}$ under nitrogen protection for $48 \mathrm{~h}$. Then the solvent was removed under reduced pressure, and the product was purified with a 200-300 mesh silica gel column, using dichloromethane: methanol=2:3 as the eluent to obtain a white solid product of SL-2F $(0.21 \mathrm{~g}, 63 \%)$.

${ }^{1}$ H NMR (400 MHz, DMSO-d $\left.\boldsymbol{d}_{\mathbf{6}}, 295 \mathrm{~K}\right) \delta 9.61(\mathrm{~d}, J=4.1 \mathrm{~Hz}, 1 \mathrm{H}), 8.13-8.02(\mathrm{~m}$, $2 \mathrm{H}), 7.26-7.19(\mathrm{~m}, 10 \mathrm{H}), 6.85(\mathrm{~d}, J=4.5 \mathrm{~Hz}, 1 \mathrm{H}), 6.25(\mathrm{~s}, 1 \mathrm{H}), 5.64(\mathrm{~s}, 1 \mathrm{H}), 5.12(\mathrm{~s}$, $1 \mathrm{H}), 4.79(\mathrm{~d}, J=6.0 \mathrm{~Hz}, 1 \mathrm{H}), 4.63(\mathrm{~s}, 1 \mathrm{H}), 4.59(\mathrm{~s}, 2 \mathrm{H}), 4.51(\mathrm{~s}, 1 \mathrm{H}), 4.47(\mathrm{~d}, J=5.0$ $\mathrm{Hz}, 1 \mathrm{H}), 4.43(\mathrm{~s}, 1 \mathrm{H}), 4.32$ (t, $J=5.8 \mathrm{~Hz}, 1 \mathrm{H}), 4.21(\mathrm{t}, J=6.1 \mathrm{~Hz}, 1 \mathrm{H}), 4.15(\mathrm{~d}, J=$ $8.1 \mathrm{~Hz}, 2 \mathrm{H}), 3.99(\mathrm{~d}, J=9.8 \mathrm{~Hz}, 1 \mathrm{H}), 3.80-3.72(\mathrm{~m}, 1 \mathrm{H}), 3.70(\mathrm{~s}, 1 \mathrm{H}), 3.66-3.53$ 
(m, 4H), $3.51-3.41(\mathrm{~m}, 2 \mathrm{H}), 3.39(\mathrm{~s}, 3 \mathrm{H}), 3.28-3.25(\mathrm{~m}, 5 \mathrm{H}), 3.21-3.15(\mathrm{~m}, 4 \mathrm{H})$, $2.98-2.93(\mathrm{~m}, 1 \mathrm{H}), 2.91-2.88(\mathrm{~m}, 3 \mathrm{H}), 2.80-2.73(\mathrm{~m}, 1 \mathrm{H}), 2.72-2.62(\mathrm{~m}, 1 \mathrm{H})$, 1.90 (s, 3H), 1.29 (s, 9H).

${ }^{13}$ C NMR (100 MHz, DMSO-d6) $\delta$ 172.74, 171.78, 155.51, 138.48, 137.56, 129.79, $129.63,128.52,128.45,126.78,126.58,104.70,100.10,91.02,78.53,76.28,75.33$, 73.68, 71.64, 69.06, 67.76, 60.73, 56.10, 53.38, 38.58, 37.98, 28.58, 28.22, 22.99.

Maldi-tof (THAP, Methanol) $(\mathbf{m} / \mathbf{z})$ : calculated for $\left[\mathrm{C}_{46} \mathrm{H}_{67} \mathrm{~N}_{5} \mathrm{O}_{22}+\mathrm{Na}\right]^{+}=1065.06$; found:1065.36

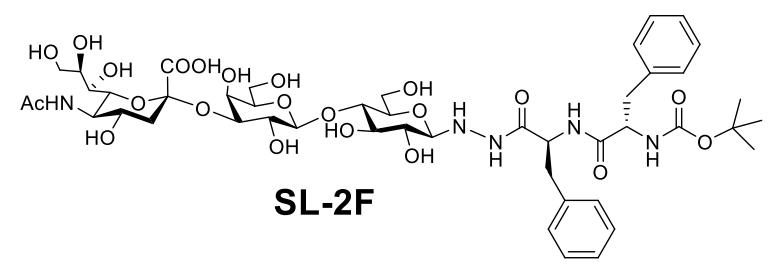

Synthesis of SL-FYF. $0.3 \mathrm{~g}(0.49 \mathrm{mmol})$ of compound 15 and $0.28 \mathrm{~g}(0.43 \mathrm{mmol})$ of $(2,3)$ sialyllactose were dissolved in $6 \mathrm{~mL}$ of anhydrous methanol, and $0.079 \mathrm{~g}$ of yttrium trifluoromethanesulfonate $(0.14 \mathrm{mmol})$ was added. After reacting for $48 \mathrm{~h}$ at $50{ }^{\circ} \mathrm{C}$ under nitrogen protection, the solvent was removed under reduced pressure, and the product is purified with a 200-300 mesh silica gel column, using dichloromethane: methanol $=2: 3$ as the eluent to obtain a white solid product of SL-FYF $(0.29 \mathrm{~g}, 56 \%)$. ${ }^{1}$ H NMR (400 MHz, DMSO-d $\left.\mathbf{6}_{\mathbf{6}}, 295 \mathrm{~K}\right) \delta 9.54(\mathrm{~d}, J=4.7 \mathrm{~Hz}, 1 \mathrm{H}), 9.16(\mathrm{~s}, 1 \mathrm{H}), 8.10$ $(\mathrm{d}, J=8.3 \mathrm{~Hz}, 1 \mathrm{H}), 8.08(\mathrm{~d}, J=6.2 \mathrm{~Hz}, 1 \mathrm{H}), 7.82(\mathrm{~m}, 1 \mathrm{H}), 7.26-7.14(\mathrm{~m}, 14 \mathrm{H}), 7.01$ $(\mathrm{d}, J=8.2 \mathrm{~Hz}, 3 \mathrm{H}), 6.88(\mathrm{~d}, J=8.8 \mathrm{~Hz}, 1 \mathrm{H}), 6.68-6.62(\mathrm{~m}, 2 \mathrm{H}), 5.66(\mathrm{~s}, 1 \mathrm{H}), 5.11$ $(\mathrm{d}, J=4.3 \mathrm{~Hz}, 1 \mathrm{H}), 4.81(\mathrm{~d}, J=5.9 \mathrm{~Hz}, 1 \mathrm{H}), 4.65(\mathrm{t}, J=5.4 \mathrm{~Hz}, 1 \mathrm{H}), 4.62-4.56(\mathrm{~m}$, $1 \mathrm{H}), 4.55-4.42(\mathrm{~m}, 4 \mathrm{H}), 4.32(\mathrm{t}, J=5.7 \mathrm{~Hz}, 1 \mathrm{H}), 4.23(\mathrm{t}, J=5.9 \mathrm{~Hz}, 1 \mathrm{H}), 4.14-4.05$ (m, 2H), $3.96(\mathrm{dd}, J=10.1,2.9 \mathrm{~Hz}, 1 \mathrm{H}), 3.76(\mathrm{dd}, J=11.1,6.4 \mathrm{~Hz}, 1 \mathrm{H}), 3.69(\mathrm{~s}, 1 \mathrm{H})$, $3.65-3.53(\mathrm{~m}, 6 \mathrm{H}), 3.52-3.24(\mathrm{~m}, 5 \mathrm{H}), 3.24-3.14(\mathrm{~m}, 4 \mathrm{H}), 3.01-2.96(\mathrm{~m}, 1 \mathrm{H})$, $2.95-2.79(\mathrm{~m}, 4 \mathrm{H}), 2.78-2.72(\mathrm{~m}, 1 \mathrm{H}), 2.70-2.57(\mathrm{~m}, 2 \mathrm{H}), 1.89(\mathrm{~s}, 3 \mathrm{H}), 1.27(\mathrm{~s}$, 9H).

${ }^{13}$ C NMR (100 MHz, DMSO-d $\left.d_{6}\right) \delta 172.78,171.61,170.90,156.19,155.45,138.57$, $137.58,130.72,129.65,129.57,128.56,128.41,127.87,126.78,126.54,115.34$, 104.66, 100.09, 91.04, 81.61, 78.58, 76.53, 76.28, 75.34, 73.68, 71.65, 69.02, 67.74, $67.16,63.77,61.21,60.80,56.31,54.03,53.36,52.67,42.33,38.33,38.01,29.47$, 28.56, 28.16, 22.98.

Maldi-tof (THAP, Methanol) $(\mathbf{m} / \mathbf{z})$ : calculated for $\left[\mathrm{C}_{55} \mathrm{H}_{76} \mathrm{~N}_{6} \mathrm{O}_{24}+\mathrm{Na}\right]^{+}=1228.23$; found: 1228.33

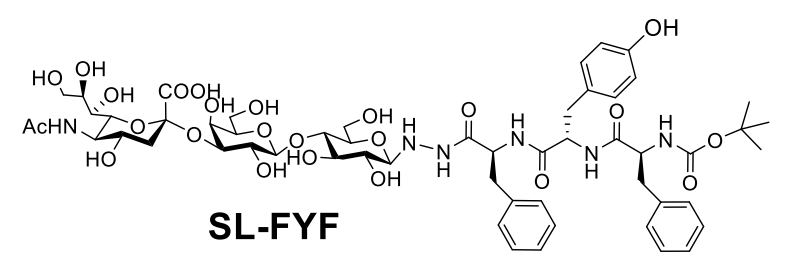


Synthesis of SL-FUF. Dissolved $0.22 \mathrm{~g}(0.33 \mathrm{mmol})$ of compound $\mathbf{1 6}$ and $0.20 \mathrm{~g}$ $(0.31 \mathrm{mmol})$ of $(2,3)$ sialyllactose in $4 \mathrm{~mL}$ of anhydrous methanol, and added $0.053 \mathrm{~g}$ of yttrium trifluoromethanesulfonate $(0.10 \mathrm{mmol})$, the reaction mixture was stirred at $32{ }^{\circ} \mathrm{C}$ under nitrogen protection for $48 \mathrm{~h}$. Then the solvent was removed under reduced pressure, and the product was purified with a 200-300 mesh silica gel column, using dichloromethane: methanol=2:3 as the eluent to obtain a white solid product of SL-FUF (0.19 g, 47\%).

${ }^{1}$ H NMR (400 MHz, DMSO-d 6 , 295 K) $\delta 9.68(\mathrm{~d}, J=5.0 \mathrm{~Hz}, 1 \mathrm{H}), 8.43(\mathrm{~d}, J=8.1$ $\mathrm{Hz}, 1 \mathrm{H}), 8.11-8.04(\mathrm{~m}, 2 \mathrm{H}), 7.25-7.21(\mathrm{~m}, 10 \mathrm{H}), 6.89-6.86(\mathrm{~d}, J=8.6 \mathrm{~Hz}, 1 \mathrm{H})$, $6.22(\mathrm{~s}, 1 \mathrm{H}), 5.64(\mathrm{~s}, 1 \mathrm{H}), 5.14(\mathrm{~d}, J=4.2 \mathrm{~Hz}, 1 \mathrm{H}), 4.90-4.56(\mathrm{~m}, 5 \mathrm{H}), 4.53-4.46$ $(\mathrm{m}, 2 \mathrm{H}), 4.43(\mathrm{~s}, 1 \mathrm{H}), 4.30(\mathrm{t}, J=5.6 \mathrm{~Hz}, 1 \mathrm{H}), 4.23(\mathrm{t}, J=5.8 \mathrm{~Hz}, 1 \mathrm{H}), 4.16(\mathrm{~d}, J=$ $7.9 \mathrm{~Hz}, 1 \mathrm{H}), 4.04-3.94(\mathrm{~m}, 2 \mathrm{H}), 3.80-3.72(\mathrm{~m}, 1 \mathrm{H}), 3.71-3.66(\mathrm{~m}, 1 \mathrm{H}), 3.65-$ $3.52(\mathrm{~m}, 6 \mathrm{H}), 3.52-3.42(\mathrm{~m}, 4 \mathrm{H}), 3.40-3.36(\mathrm{~m}, 3 \mathrm{H}), 3.28-3.23(\mathrm{~m}, 5 \mathrm{H}), 3.20-$ $3.15(\mathrm{~m}, 4 \mathrm{H}), 3.10-2.83(\mathrm{~m}, 4 \mathrm{H}), 2.80-2.71(\mathrm{~m}, 2 \mathrm{H}), 2.65-2.56(\mathrm{~m}, 1 \mathrm{H}), 1.89$ (s, $3 \mathrm{H}), 1.24(\mathrm{~s}, 9 \mathrm{H})$.

${ }^{13}$ C NMR (100 MHz, DMSO-d $\left.\boldsymbol{d}_{\boldsymbol{6}}\right) \delta 172.74,172.02,170.56,169.76,155.59,138.71$, 137.51, 129.64, 129.56, 128.50, 128.43, 126.59, 104.75, 100.16, 91.13, 81.59, 78.37, 76.37, 76.25, 75.35, 73.65, 71.63, 71.38, 68.97, 67.82, 67.13, 60.74, 56.37, 53.39, 42.53, 37.42, 28.41, 26.30, 22.98.

${ }^{19}$ F NMR (400 MHz, DMSO-d6) $\delta-82.34--260.97(\mathrm{~m})$.

Maldi-tof (THAP, Methanol) $(\mathbf{m} / \mathbf{z})$ : calculated for $\left[\mathrm{C}_{56} \mathrm{H}_{74} \mathrm{~F}_{5} \mathrm{~N}_{6} \mathrm{O}_{23}+\mathrm{Na}\right]^{+}=1317.22$; found:1317.35

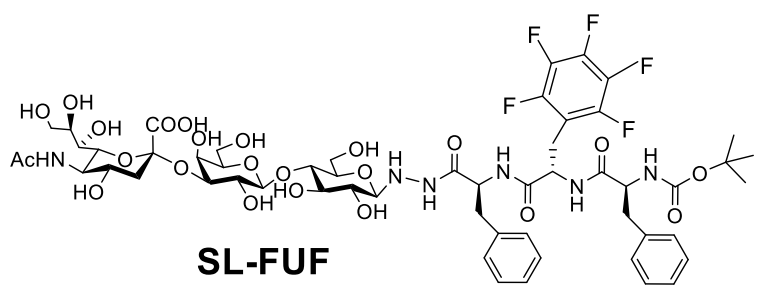

Synthesis of FITC-3F. Ethylenediamine was used as a Spacer to facilitate the synthesis of FITC-3F. Under basic conditions, the isothiocyanate group of FITC can readily interact with the amine group of triphenylalanine. Finally obtained a slight yellow solid of FITC-3F of $(0.21 \mathrm{~g}, 53 \%)$.

${ }^{1}$ H NMR (400 MHz, DMSO-d $\mathbf{6}_{\mathbf{6}}, 295$ K) $\delta 10.12-10.03(\mathrm{~m}, 3 \mathrm{H}), 8.19(\mathrm{~d}, J=1.8 \mathrm{~Hz}$, $1 \mathrm{H}), 8.09-8.07(\mathrm{~m}, 2 \mathrm{H}), 7.90(\mathrm{~d}, J=8.1 \mathrm{~Hz}, 1 \mathrm{H}), 7.73(\mathrm{~d}, J=8.3 \mathrm{~Hz}, 1 \mathrm{H}), 7.23-$ $7.16(\mathrm{~m}, 15 \mathrm{H}), 6.89(\mathrm{~d}, J=8.8 \mathrm{~Hz}, 4 \mathrm{H}), 6.68(\mathrm{~d}, J=2.1 \mathrm{~Hz}, 2 \mathrm{H}), 6.62-6.54(\mathrm{~m}, 4 \mathrm{H})$, $4.60-4.53(\mathrm{~m}, 1 \mathrm{H}), 4.52-4.45(\mathrm{~m}, 1 \mathrm{H}), 4.15-4.06(\mathrm{~m}, 1 \mathrm{H}), 3.51-3.21(\mathrm{~m}, 4 \mathrm{H})$, $3.06-2.95(\mathrm{~m}, 2 \mathrm{H}), 2.89-2.76(\mathrm{~m}, 3 \mathrm{H}), 1.26(\mathrm{~s}, 9 \mathrm{H})$.

Maldi-tof (DHB, Methanol) $(\mathbf{m} / \mathbf{z})$ : calculated for $\left[\mathrm{C}_{55} \mathrm{H}_{54} \mathrm{~N}_{6} \mathrm{O}_{10} \mathrm{~S}\right]=991.13$; found:991.21

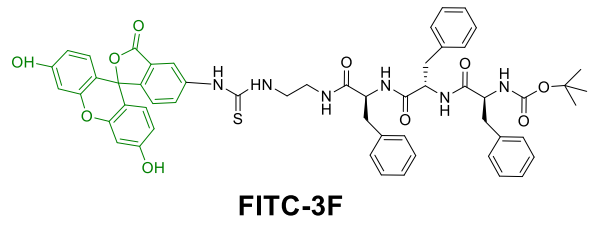




\section{1. ${ }^{1} \mathrm{H}$ and ${ }^{13} \mathrm{C}$ NMR}

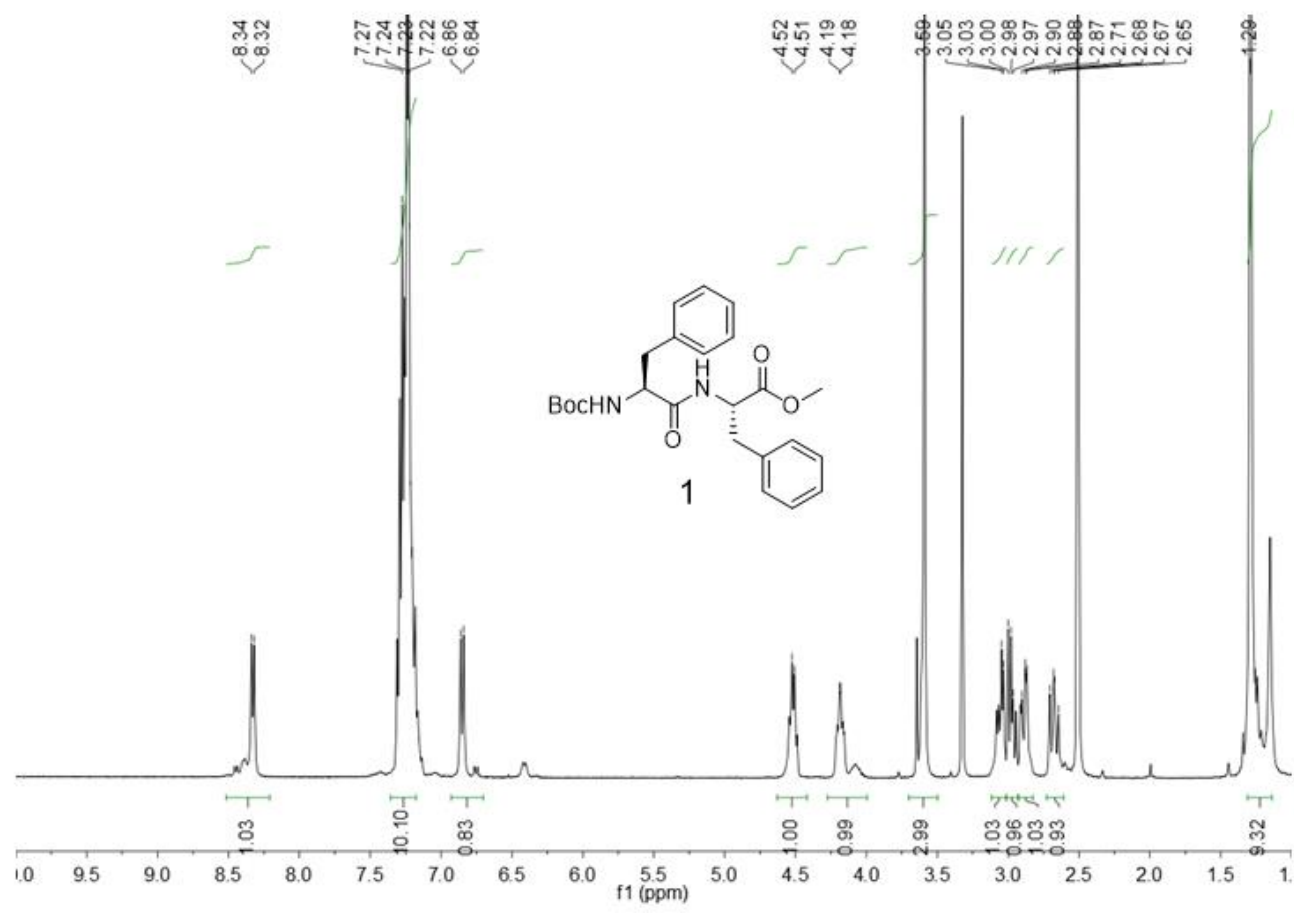

${ }^{1} \mathrm{H}$ NMR spectrum of $\mathbf{1}$ in DMSO- $d_{6}$

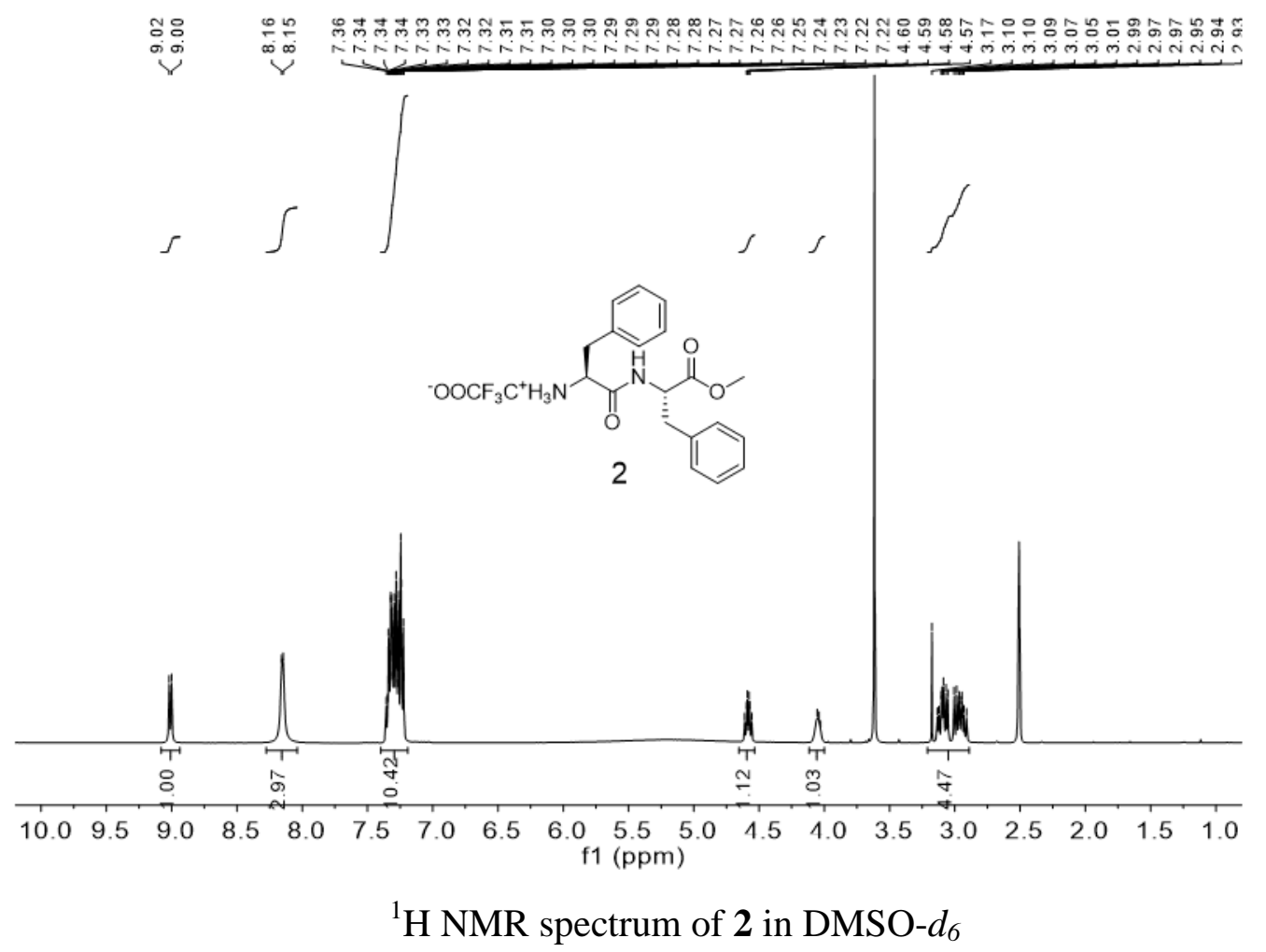




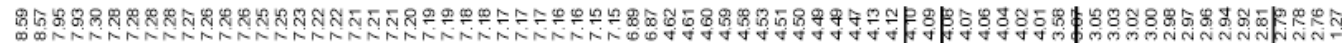

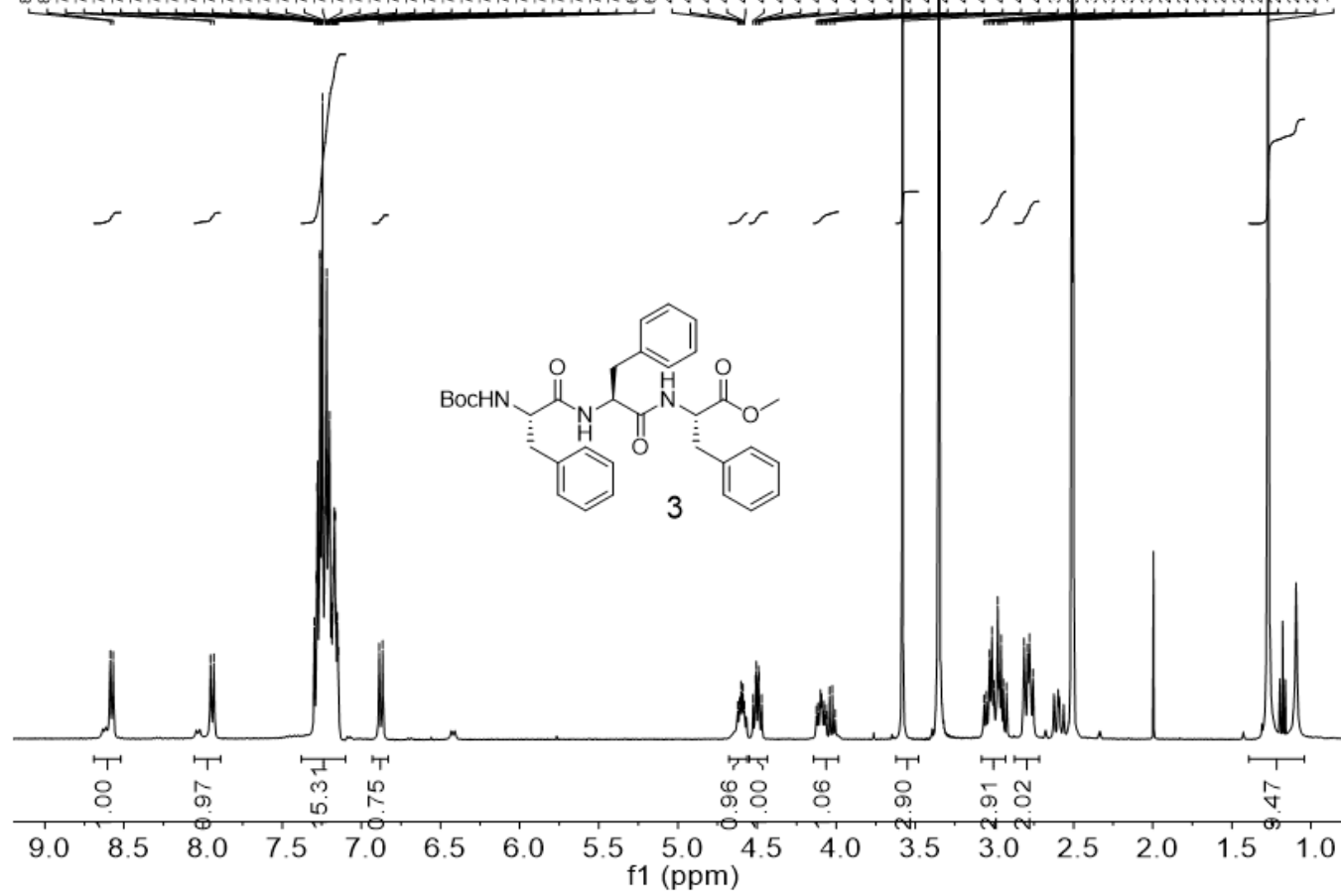

${ }^{1} \mathrm{H}$ NMR spectrum of $\mathbf{3}$ in DMSO- $d_{6}$

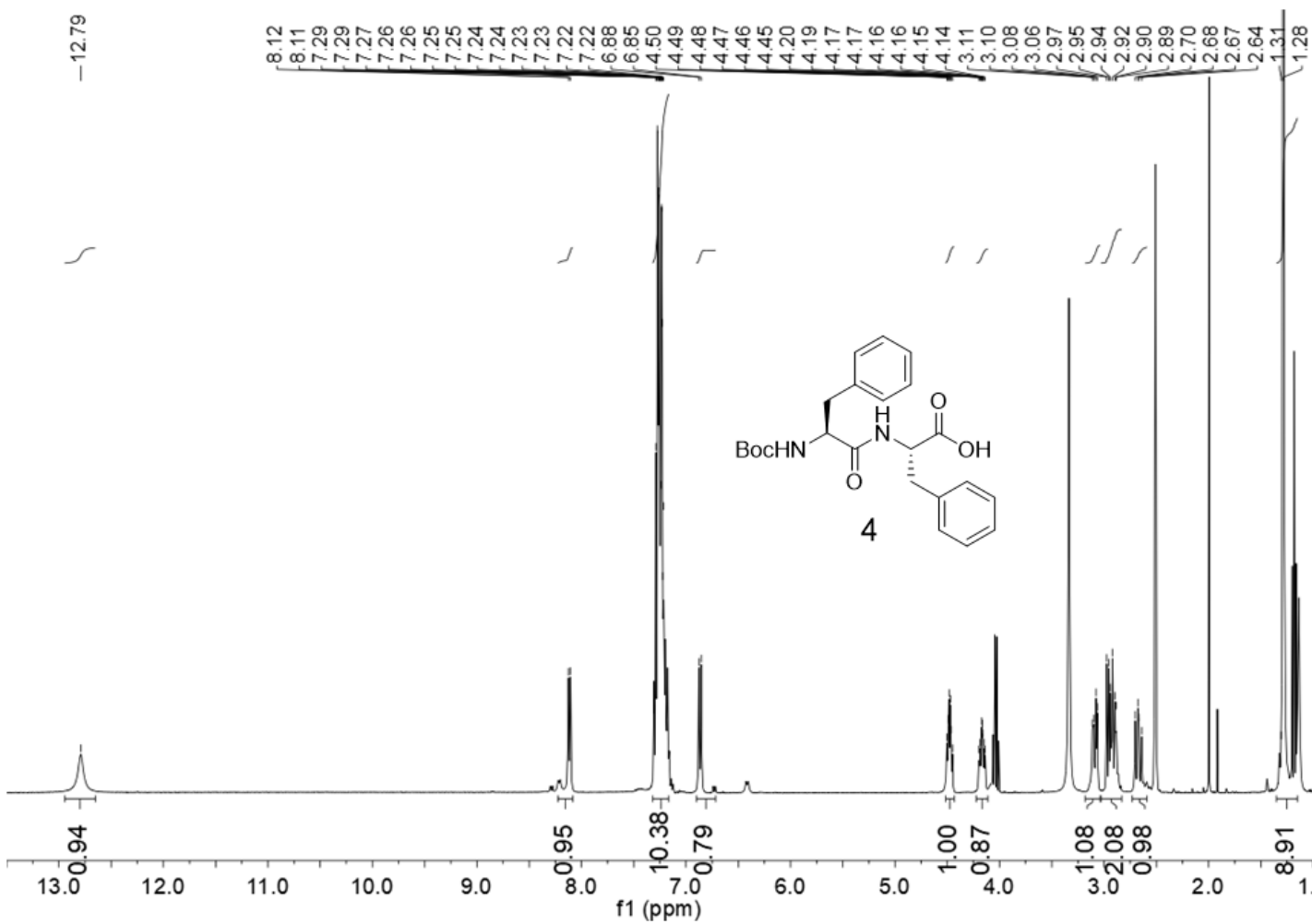

${ }^{1} \mathrm{H}$ NMR spectrum of $\mathbf{4}$ in DMSO- $d_{6}$ 


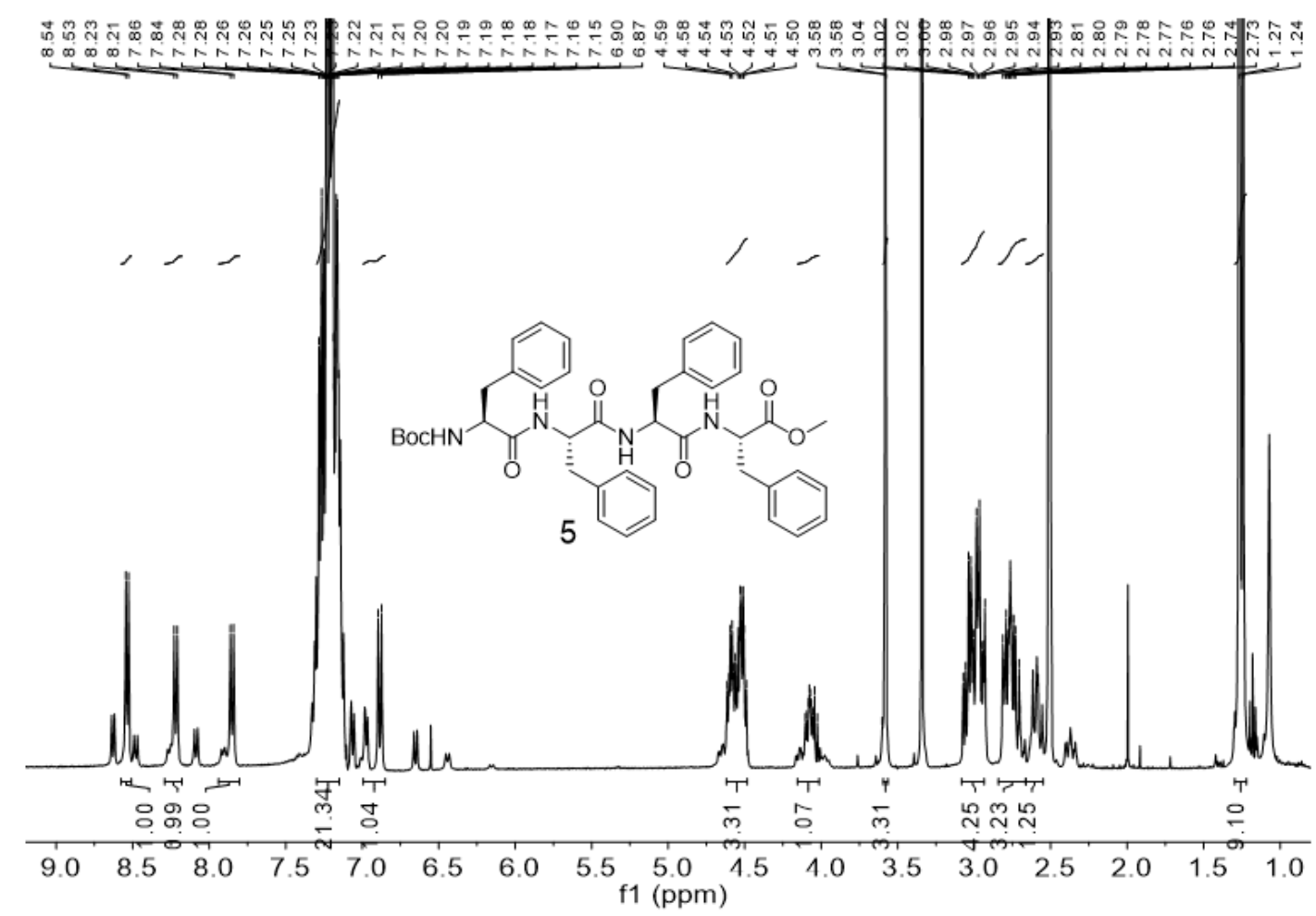

${ }^{1} \mathrm{H}$ NMR spectrum of 5 in DMSO- $d_{6}$

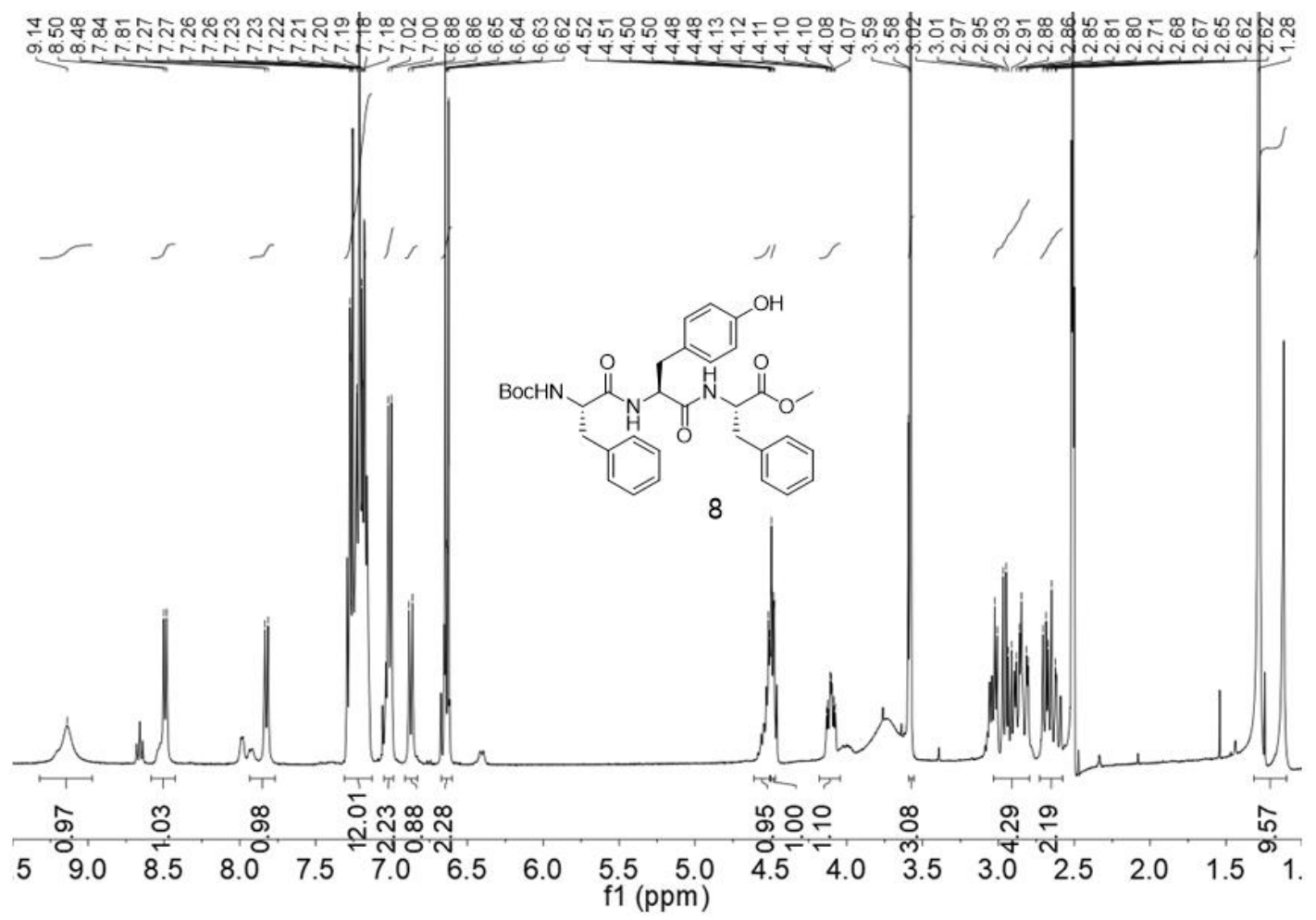

${ }^{1} \mathrm{H}$ NMR spectrum of 8 in DMSO- $d_{6}$ 


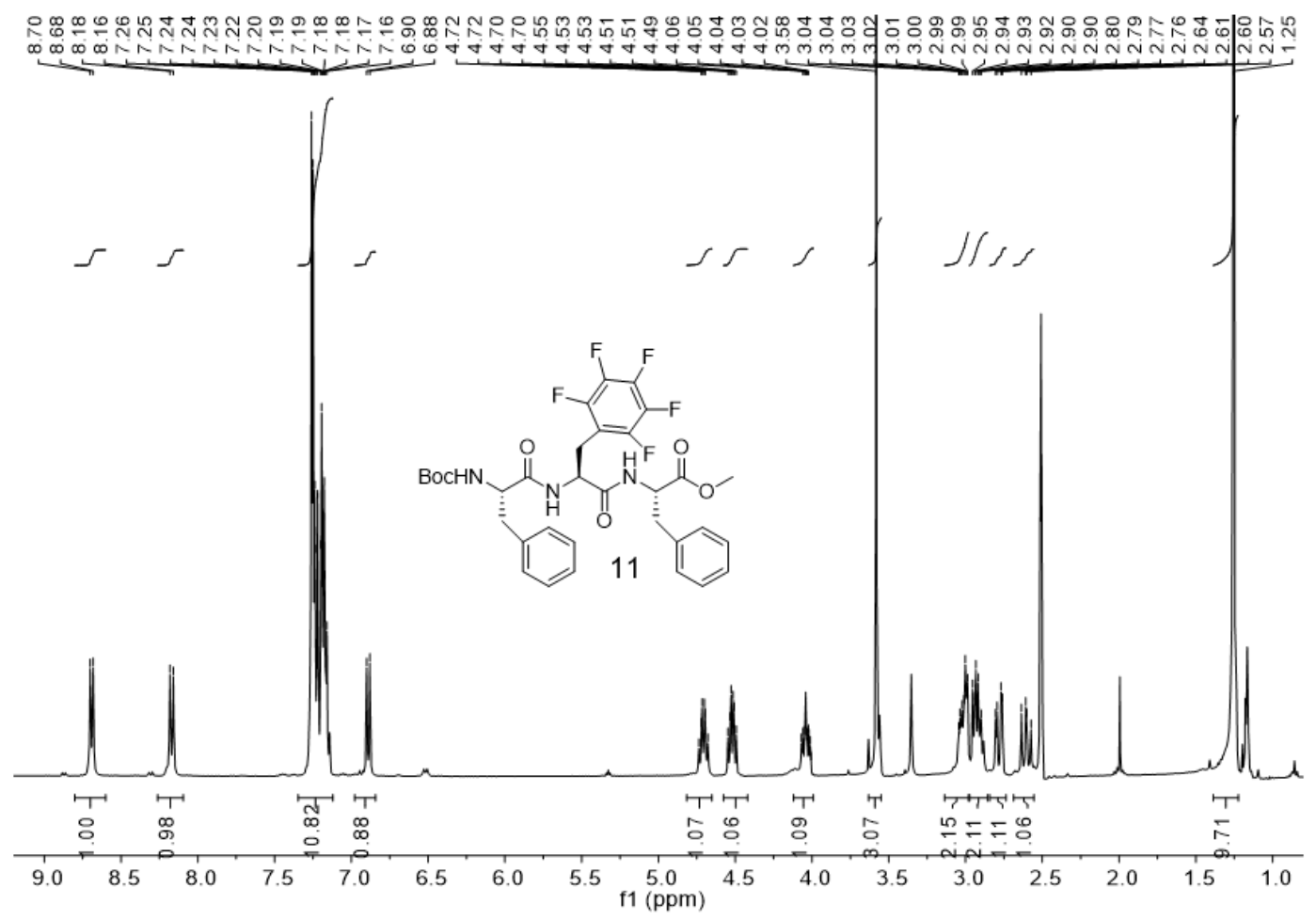

${ }^{1} \mathrm{H}$ NMR spectrum of $\mathbf{1 1}$ in DMSO- $d_{6}$

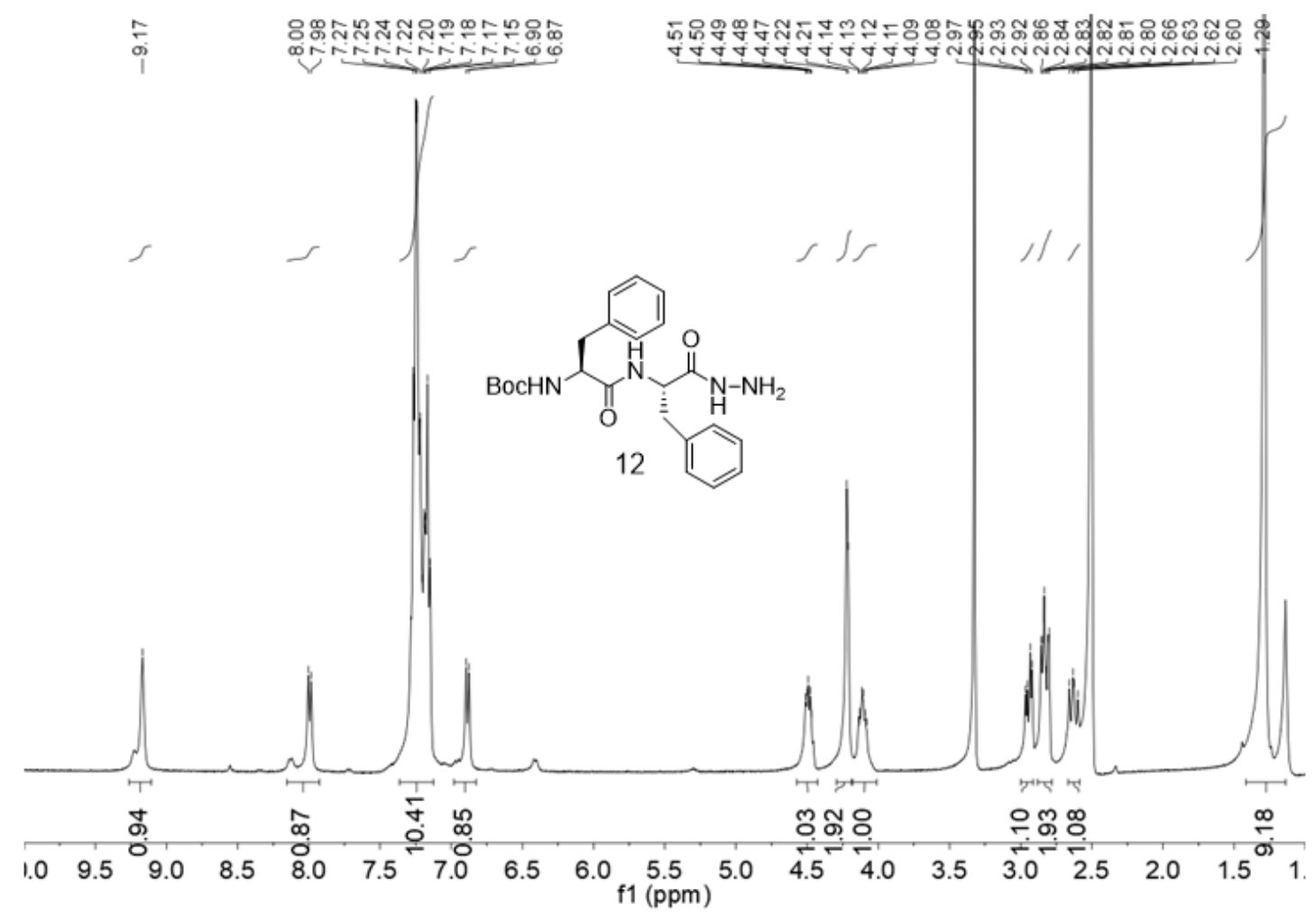

${ }^{1} \mathrm{H}$ NMR spectrum of $\mathbf{1 2}$ in DMSO- $d_{6}$ 


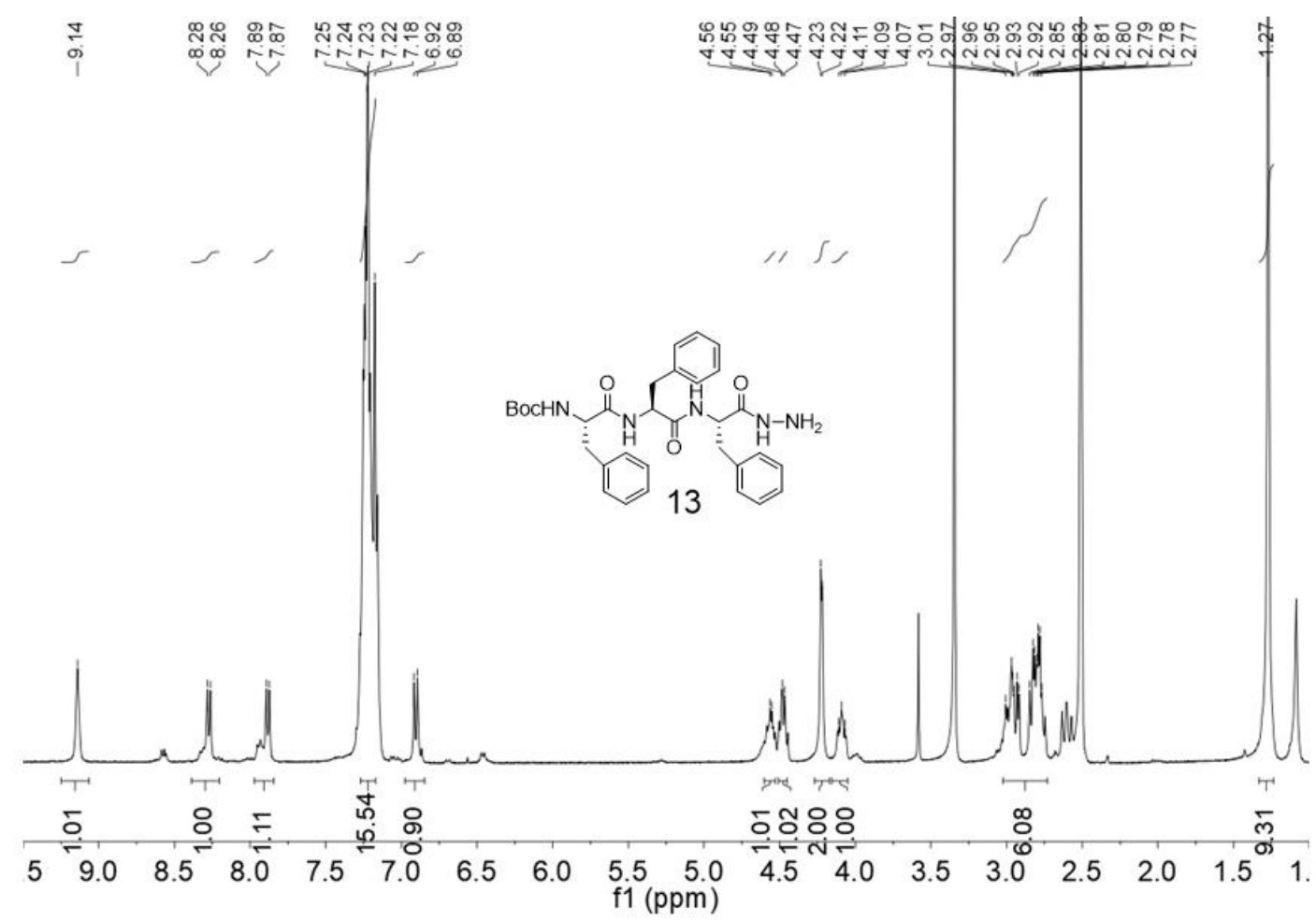

${ }^{1} \mathrm{H}$ NMR spectrum of $\mathbf{1 3}$ in DMSO- $d_{6}$

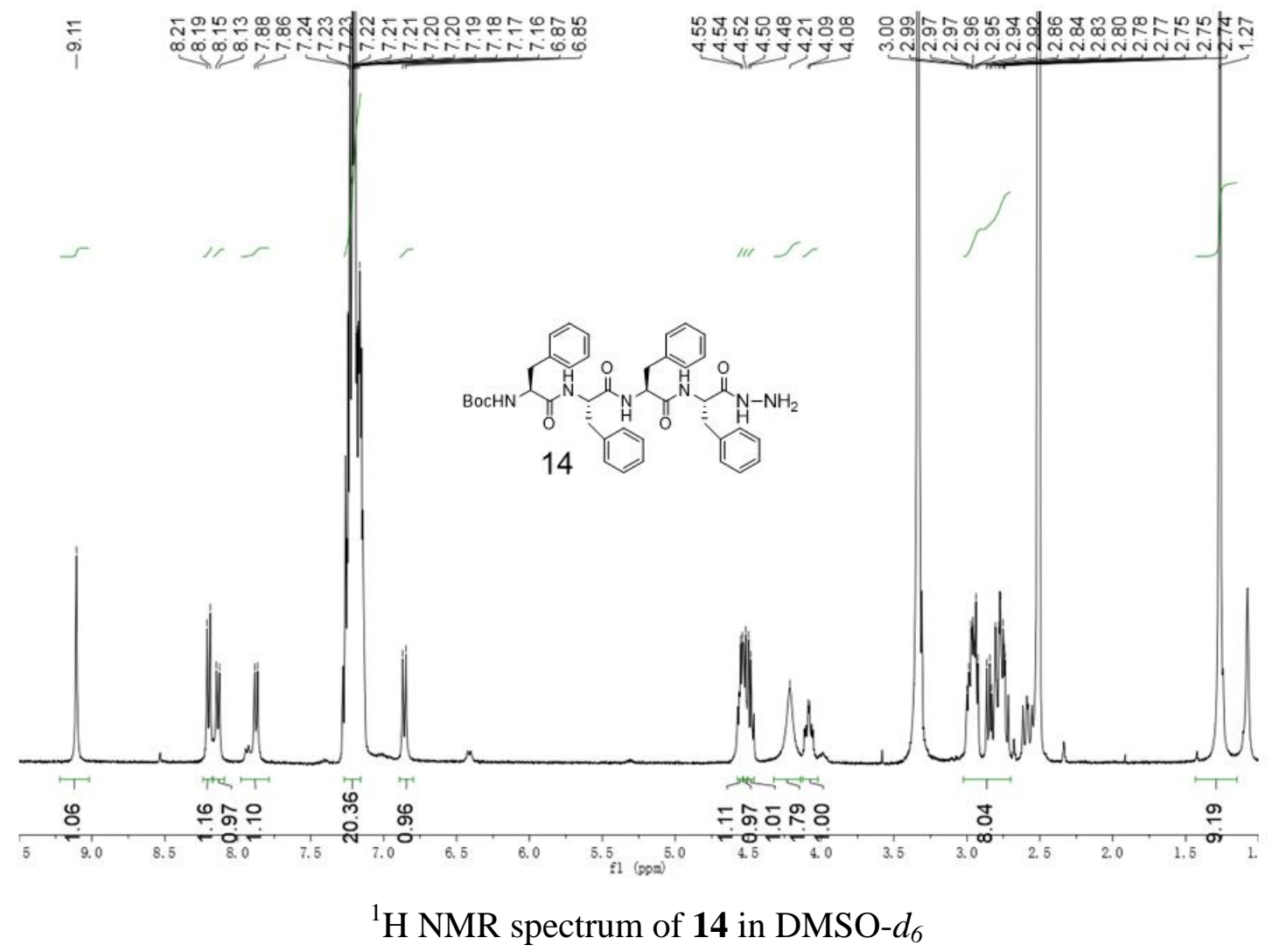




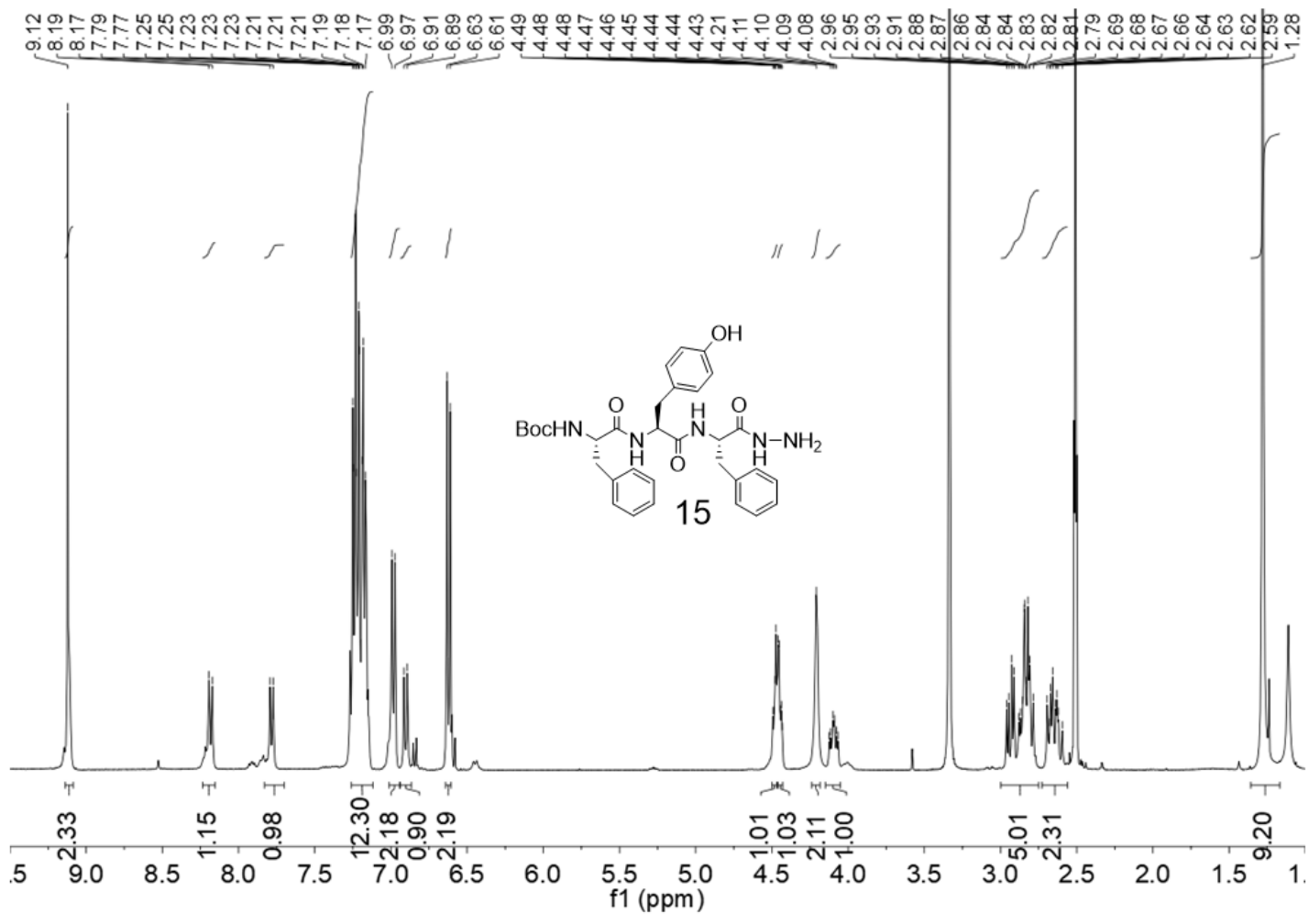

${ }^{1} \mathrm{H}$ NMR spectrum of $\mathbf{1 5}$ in DMSO- $d_{6}$

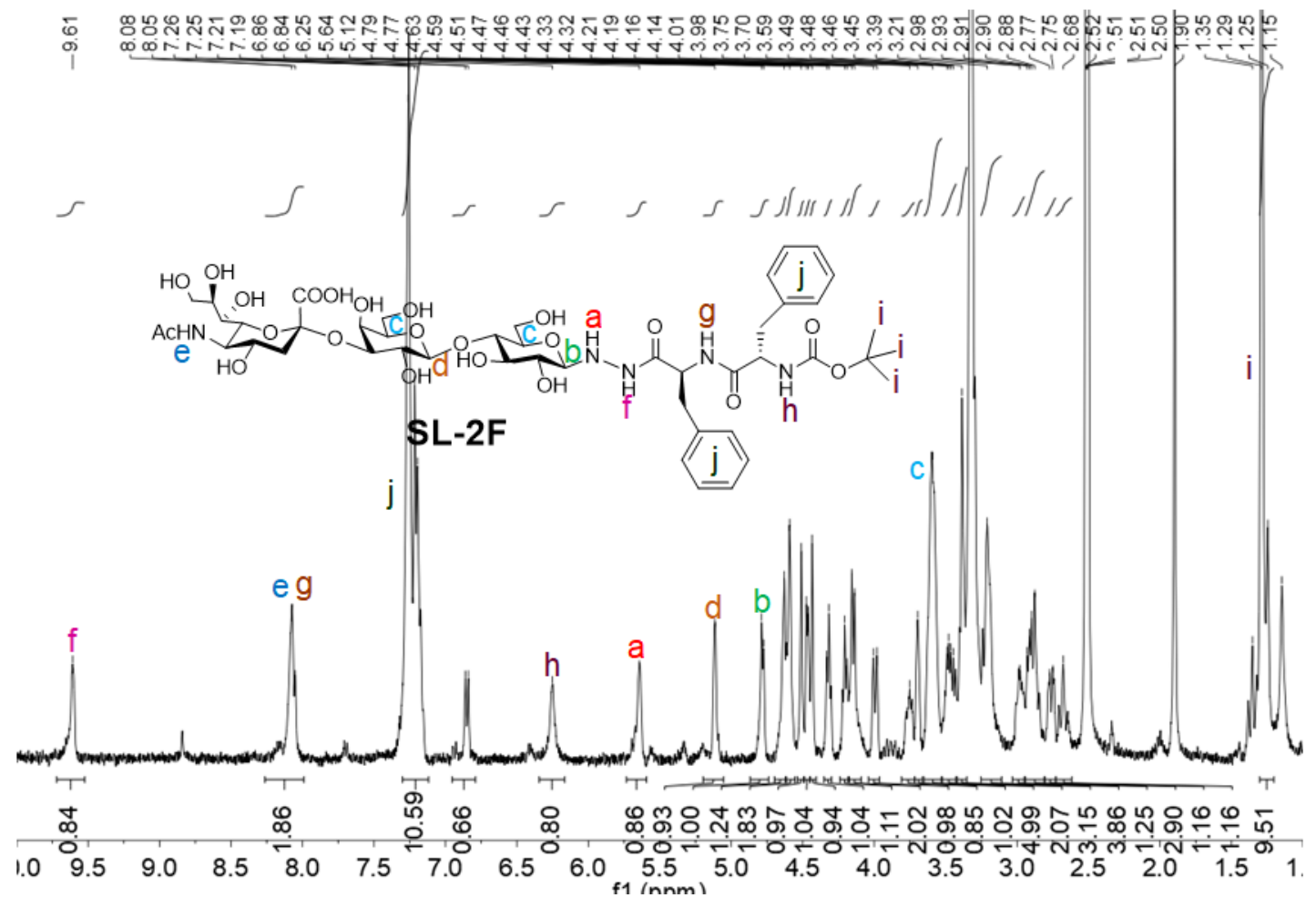

${ }^{1} \mathrm{H}$ NMR spectrum of SL-2F in DMSO- $d_{6}$ 


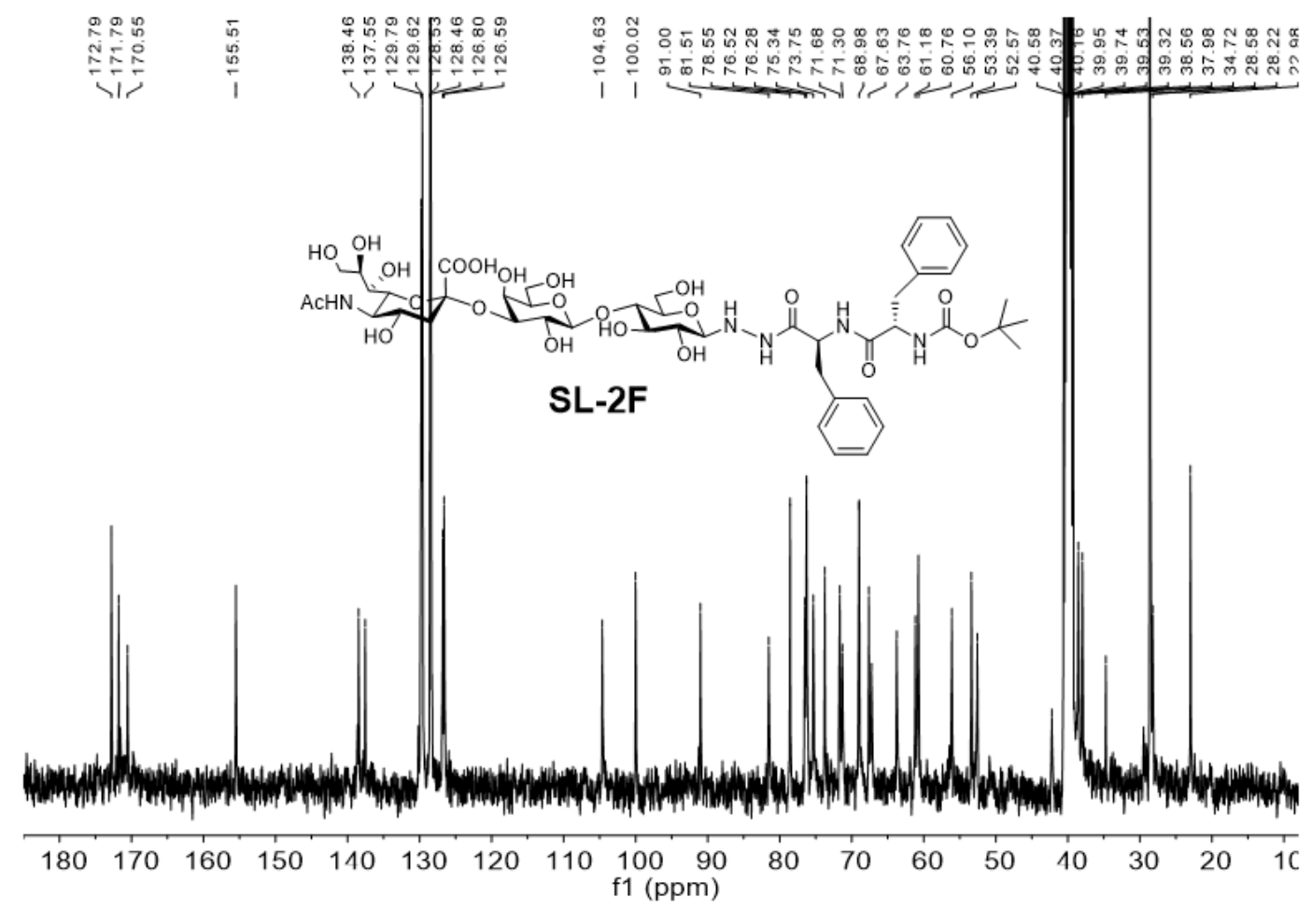

${ }^{13} \mathrm{C}$ NMR spectrum of SL-2F in DMSO- $d_{6}$

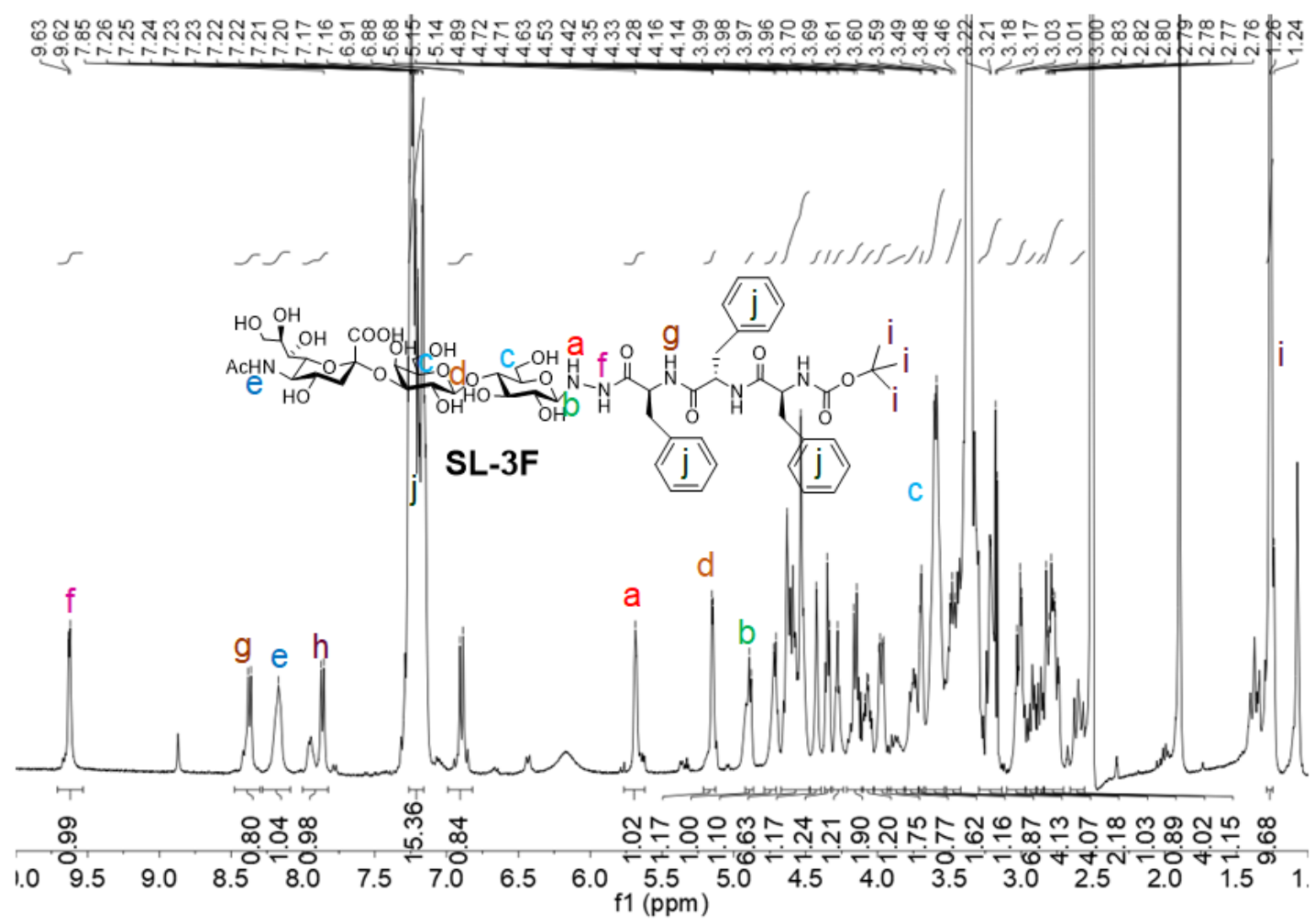

${ }^{1} \mathrm{H}$ NMR spectrum of SL-3F in DMSO- $d_{6}$ 

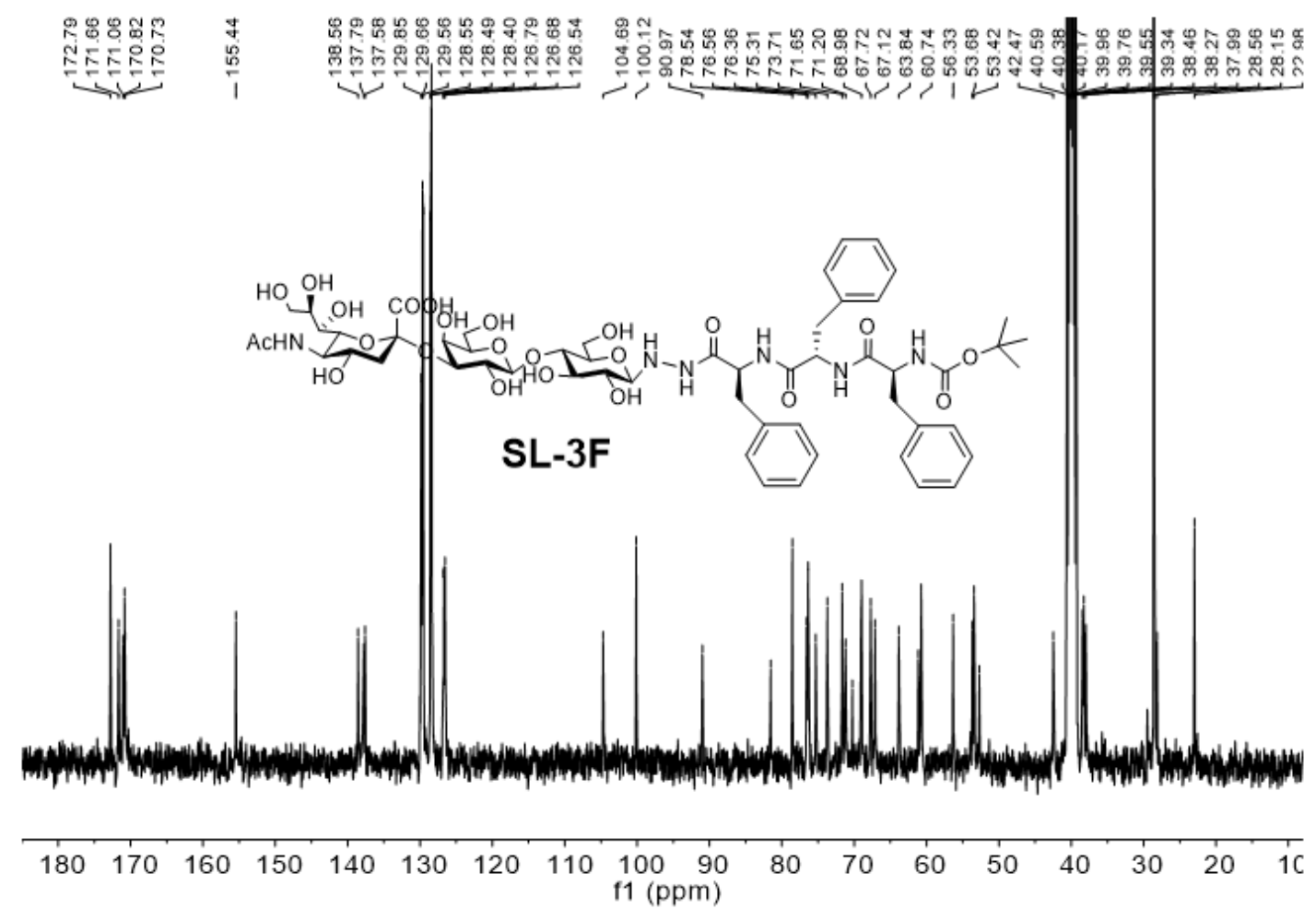

${ }^{13} \mathrm{C}$ NMR spectrum of SL-3F in DMSO- $d_{6}$

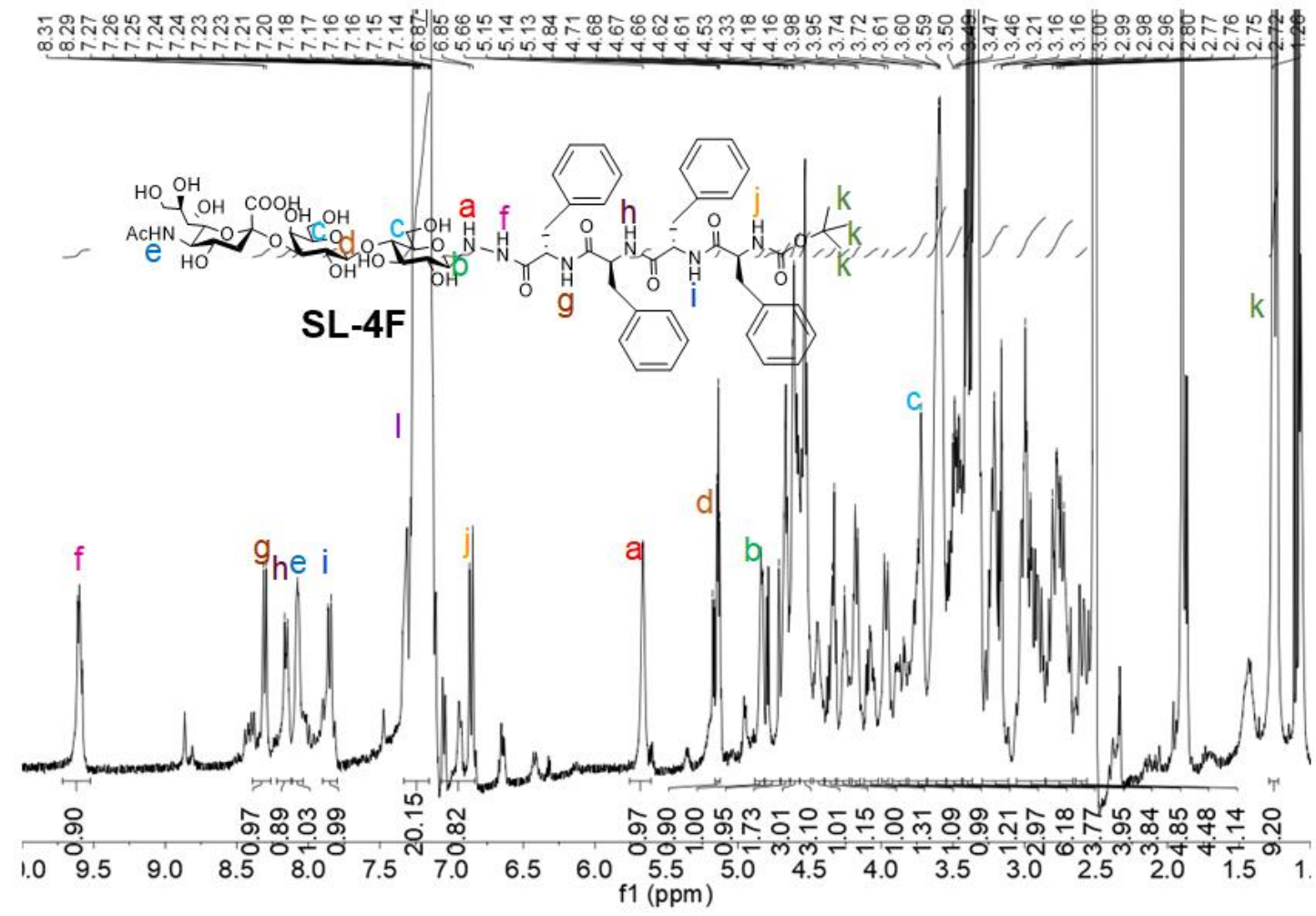

${ }^{1} \mathrm{H}$ NMR spectrum of SL-4F in DMSO- $d_{6}$ 


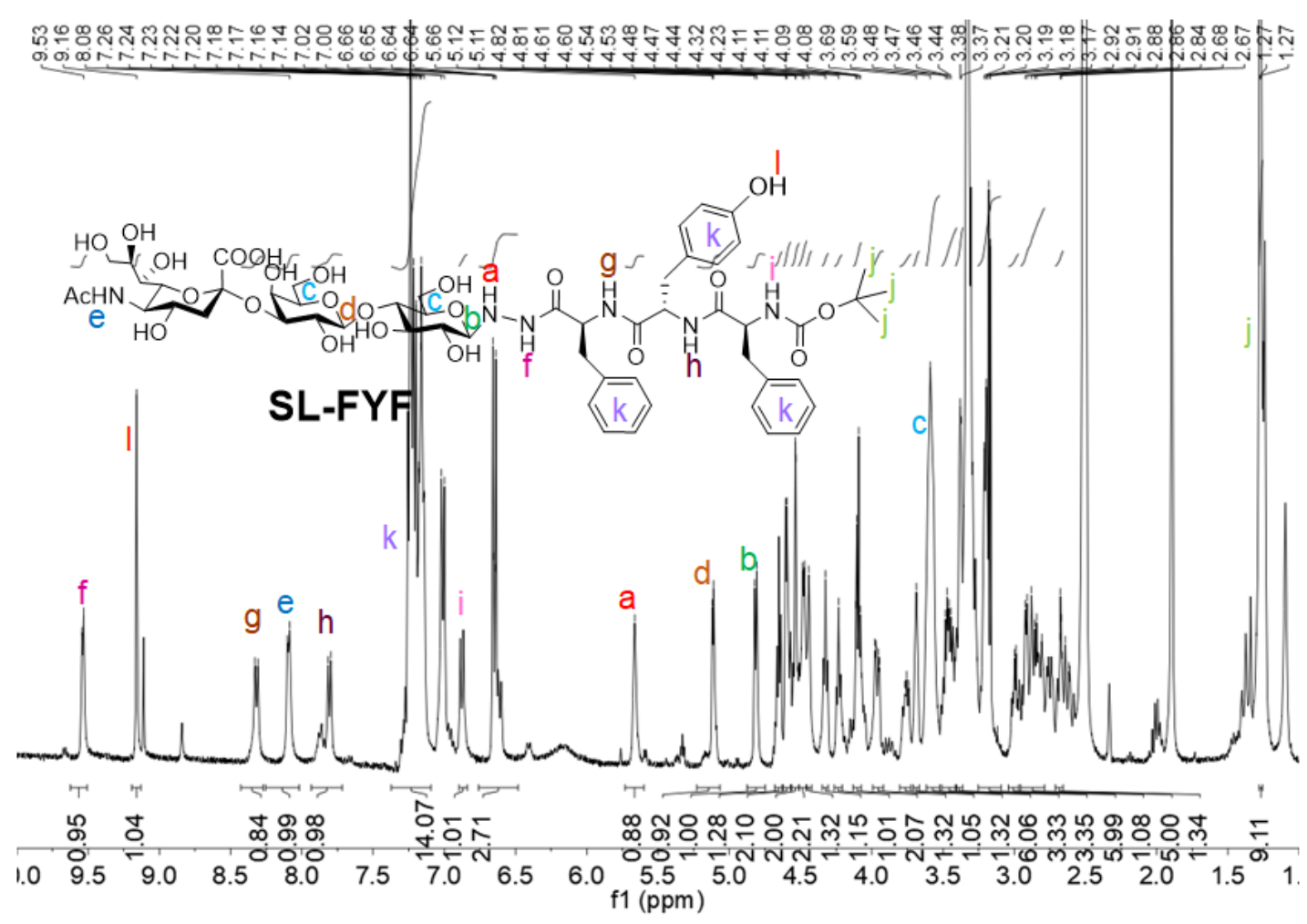

${ }^{1} \mathrm{H}$ NMR spectrum of SL-FYF in DMSO- $d_{6}$

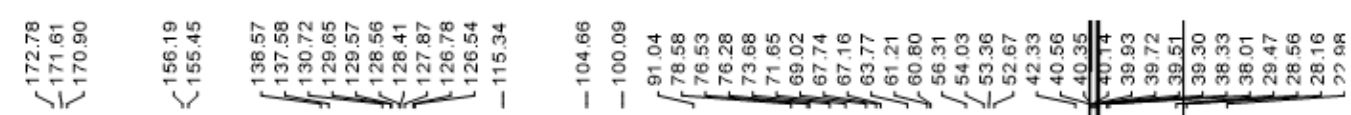

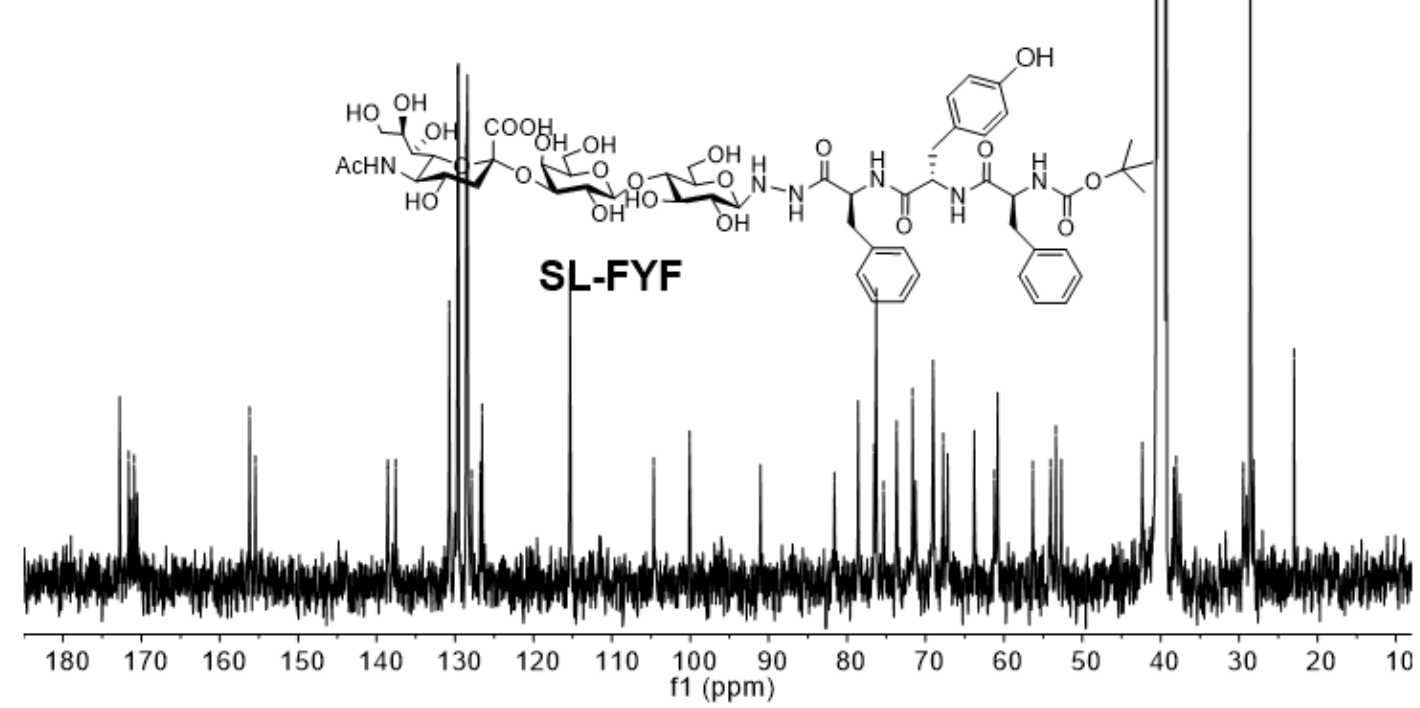

${ }^{13}$ C NMR spectrum of SL-FYF in DMSO- $d_{6}$ 


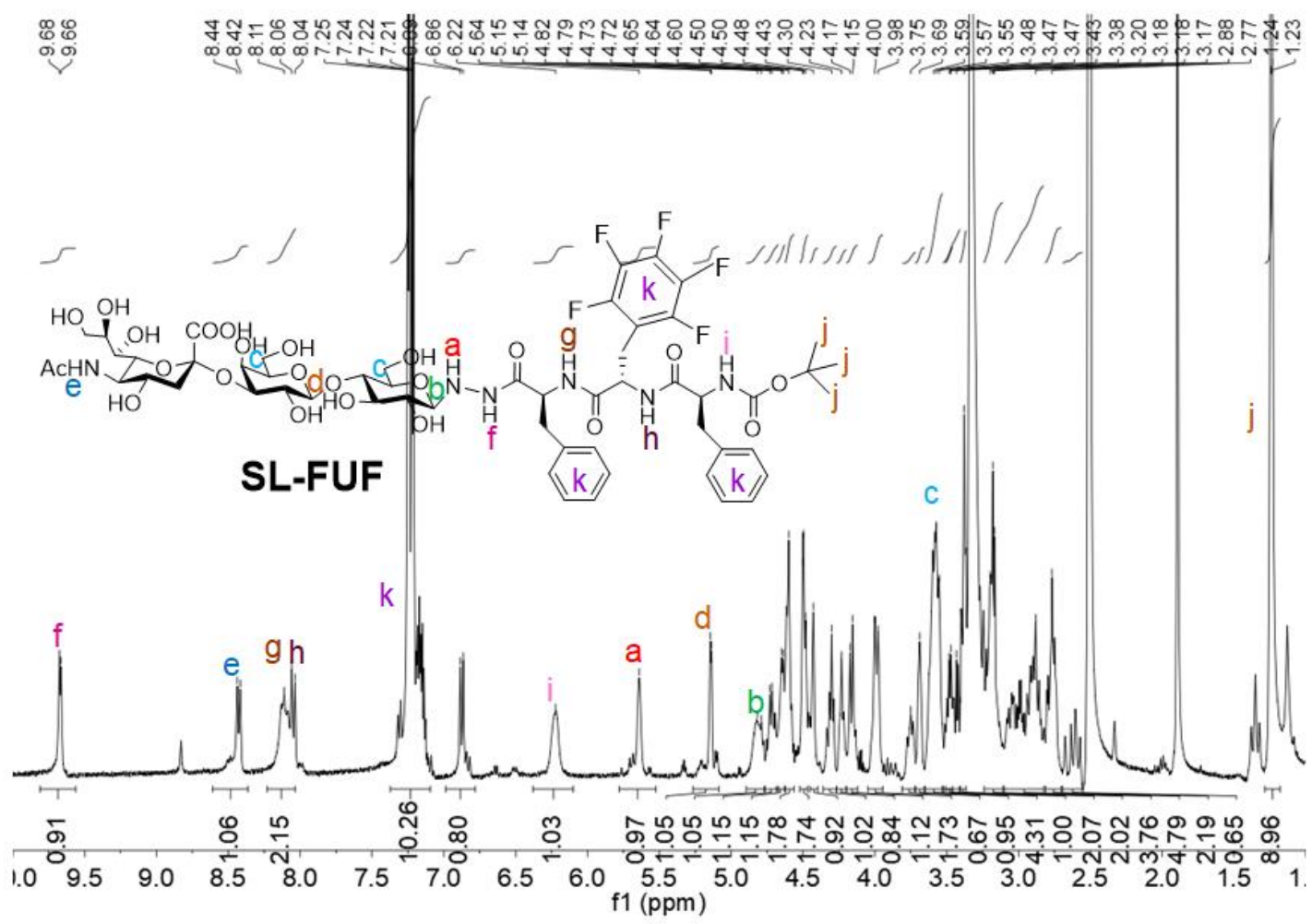

${ }^{1} \mathrm{H}$ NMR spectrum of SL-FUF in DMSO- $d_{6}$

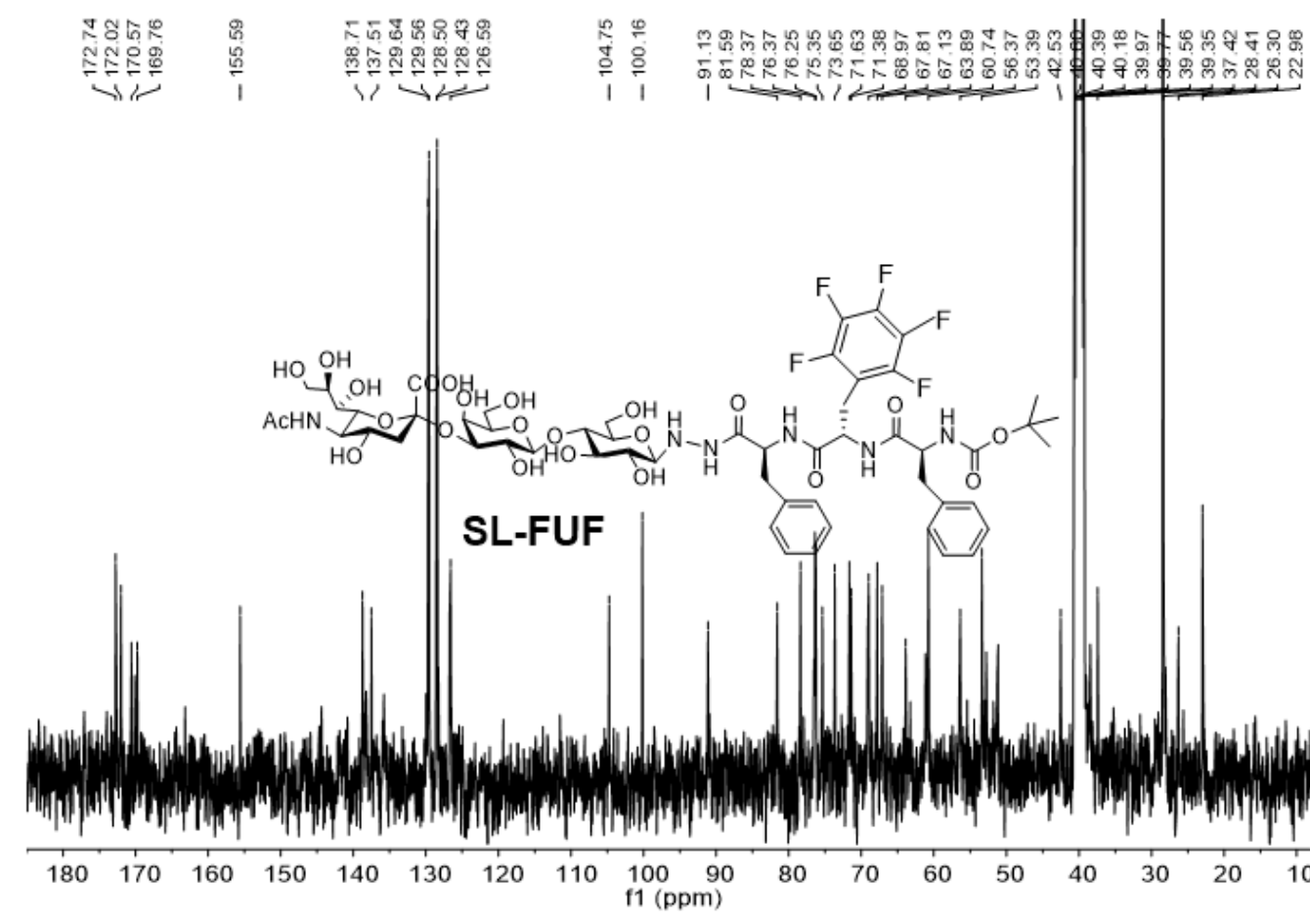

${ }^{13} \mathrm{C}$ NMR spectrum of SL-FUF in DMSO- $d_{6}$ 


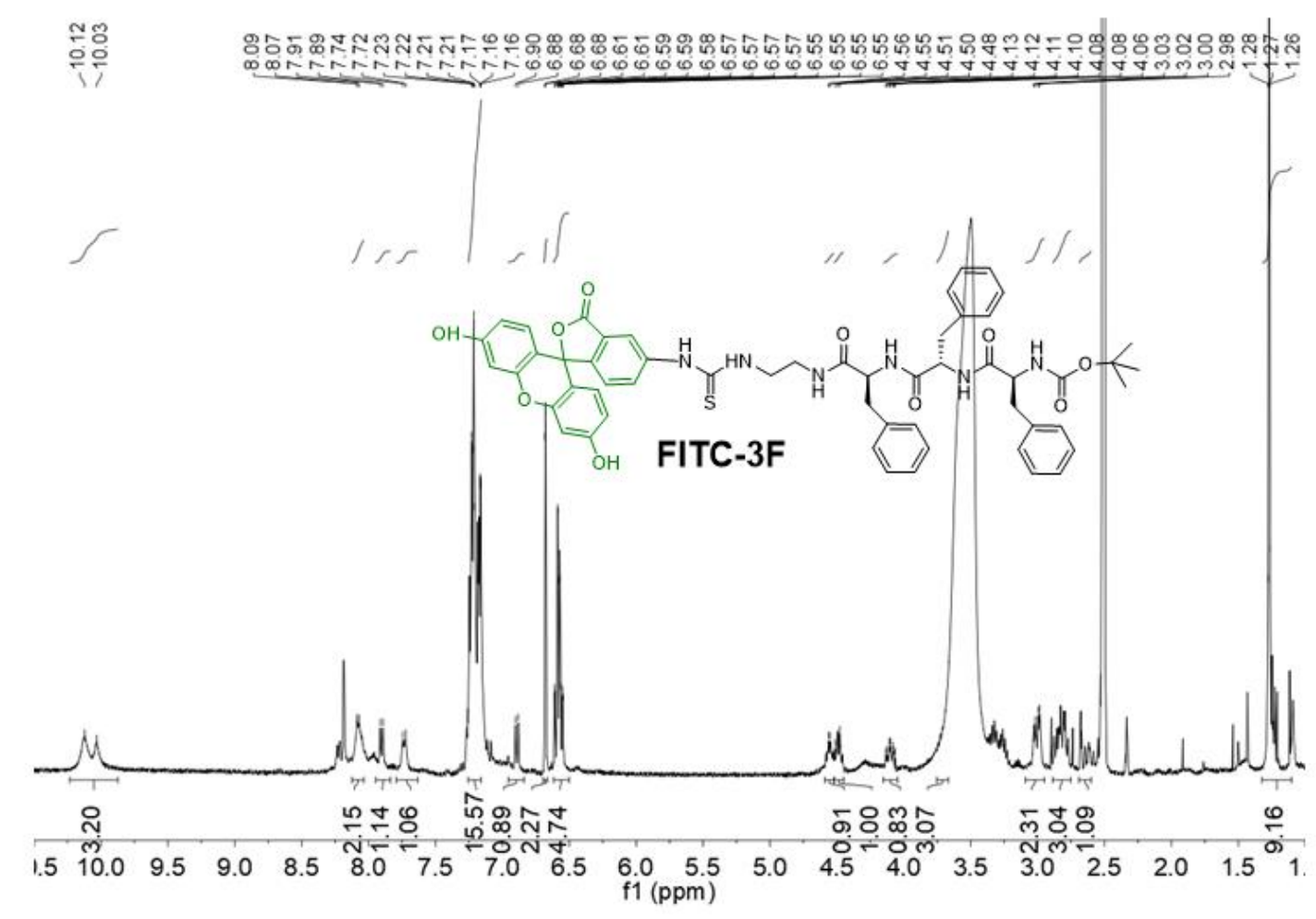

${ }^{1} \mathrm{H}$ NMR spectrum of FITC-3F in DMSO- $d_{6}$
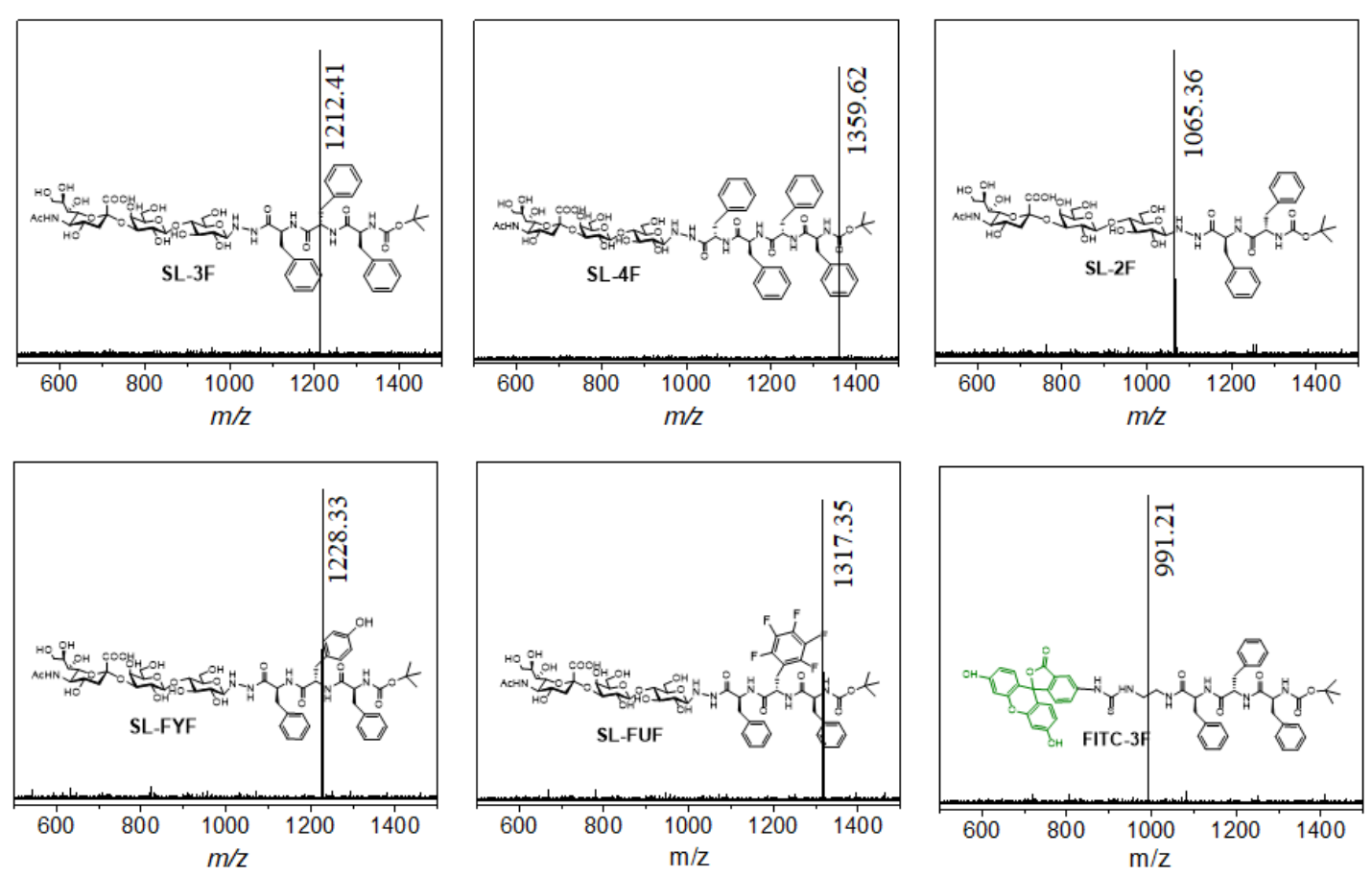


\section{References}

1. Van der Spoel, D., Lindahl, E., Hess, B., Groenhof, G., Mark, A. E., Berendsen, H. J. C. GROMACS: Fast, flexible, and free. J. Comput. Chem. 26, 1701-1718 (2005).

2. Guvench, O., Mallajosyula, S. S., Raman, E. P., Hatcher, E., Vanommeslaeghe, K., Foster, T. J., Jamison, F. W., MacKerell, A. D. CHARMM Additive All-Atom Force Field for Carbohydrate Derivatives and Its Utility in Polysaccharide and Carbohydrate- Protein Modeling. J. Chem. Theory Comput. 7, 3162-3180 (2011).

3. Huang, J., Rauscher, S., Nawrocki, G., Ran, T., Feig, M., de Groot, B. L., Grub- muller, H., MacKerell, A. D. CHARMM36: An Improved Force Field for Folded and Intrinsically Disordered Proteins. Biophys. J. 112, 175A-176A (2017).

4. Jorgensen, W. L., Tirado-Rives, J. Potential energy functions for atomic-level simula- tions of water and organic and biomolecular systems. PNAS 102, 6665-6670 (2005).

5. Darden, T., York, D., Pedersen, L. Particle Mesh Ewald - an N.Log(N) Method for Ewald Sums in Large Systems. J. Chem. Phys. 98, 10089-10092 (1993).

6. Reches, M., Gazit, E. Casting metal nanowires within discrete self-assembled peptide nanotubes. Science 300, 625-627 (2003).

7. Adler-Abramovich L. et al. Controlling the Physical Dimensions of Peptide Nanotubes by Supramolecular Polymer Coassembly. ACS Nano 10, 7436-7442 (2016).

8. Ortony, J. H., Newcomb, C. J., Matson, J. B., Palmer, L. C., Doan, P. E., Hoffman, B. M., Stupp, S. I. Internal dynamics of a supramolecular nanofibre. Nat. Mater. 13, 812-816 (2014).

9. Silva, R. M. P. D., et al. Super-resolution microscopy reveals structural diversity in molecular exchange among peptide amphiphile nanofibres. Nat. Commun. 7, 11561 (2016).

10. Sato, K., Ji, W., Palmer, L. C., Weber, B., Barz, M., Stupp, S. I. Programmable Assembly of Peptide Amphiphile via Noncovalent-to-covalent bond conversion. J. Am. Chem. Soc. 139, 8995-9000 (2017).

11. Tzokova, N. et al. Soft hydrogels from nanotubes of poly(ethyleneoxide) - tetraphenylalanine conjugates prepared by click chemistry. Langmuir 25, 2479 - 2485 (2009).

12. Hayden, M. R., Tyagi, S. C., Kerklo, M. M., Nicolls M. R. Type 2 diabetes mellitus as a conformational disease. JOP. J Pancreas 6, 287-302 (2005).

13. Kakinen, A. et al. Nanoscale inhibition of polymorphic and ambidextrous IAPP amyloid aggregation with small molecules. Nano Research 11, 3636-3647 (2018).

14. Makky, A., Bousset, L., Maris, J. P., Melki, R. Nanomechanical properties of distinct fibrillar polymorphs of the protein $\alpha$-synuclein. Sci. Rep. 6, 37970 (2016).

15. Adamcik, J. et al. Understanding amyloid aggregation by statistical analysis of atomic force microscopy images. Nat. Nanotech. 5, 423-428 (2010).

16. Takehara, S., Yanagishita, M., Podyma-Inoue, K. A., Kawaguchi, Y. Degradation of MUC7 and MUC5B in Human Saliva. Plos One 8, e69059 (2013). 
17. Hughes, G. W. et al. The MUC5B mucin polymer is dominated by repeating structural motifs and its topology is regulated by calcium and pH. Sci. Rep. 9, 17350 (2019).

18. Kas, J. et al. F-Actin, a model polymer for semiflexible chains in dilute, semidilute, and liquid crystalline solutions. Biophis. J. 70, 609-625 (1996).

19. Farhadi, L. et al. Active self-organization of actin-microtubule composite self-propelled rods. Front. In Phys. 6, 1-16 (2018).

20. Graham, J. S. et al. Multi-Platform compatible software for analysis of polymer bending mechanics. Plos One 9, e94766 (2014).

21. Yu, Q. et al. Rodlike block copolymer micelles of controlled length in water designed for biomedical applications. Macromolecules 52, 5231-5244 (2019).

22. Zhang, Q. W. et al. Low length dispersity fi ber-like micelles from an A - B - A triblock copolymer with terminal crystallizable poly(ferrocenyldimethylsilane) segments via living crystallization-driven self-assembly. Polym. Chem. 10, 3973-3982 (2019).

23. Usov, I., Adamcik, J., Mezzenga, R. Polymorphism in bovine serum albumin fibrils: morphology and statistical analysis. Faraday Discuss. 166, 151-162 (2013).

24. Bochicchio, B., Tamburro, A.M. Polyproline II structure in proteins: identification by chiroptical spectroscopies, stability, and functions. Chirality 14, 782-792 (2010).

25. Gutierrez-Cruz G., Heerden, A. H., Wang, K. Modular motif, structural folds and affinity profiles of the PEVK segment of human fetal skeletal muscle titin. J. Biol. Chem. 276, 7442-7449 (2001). 